\title{
A Facile Review on the Sorption of Heavy Metals and Dyes Using Bionanocomposites
}

\author{
Uyiosa Osagie Aigbe $\left(\mathbb{D},{ }^{1}\right.$ Kingsley Eghonghon Ukhurebor ${ }^{(D)},{ }^{2}$ Robert Birundu Onyancha $\left(\mathbb{D}{ }^{3}{ }^{3}\right.$ \\ Benedict Okundaye $\mathbb{C D}^{4}{ }^{4}$ Kaushik Pal, ${ }^{5}$ Otolorin Adelaja Osibote ${ }^{D},{ }^{1}$ Ese Lawrence Esiekpe, ${ }^{6}$ \\ Heri Septya Kusuma $\mathbb{D}^{7}{ }^{7}$ and Handoko Darmokoesoemo ${ }^{8}$ \\ ${ }^{1}$ Department of Mathematics and Physics, Faculty of Applied Sciences, Cape Peninsula University of Technology, P.O. Box 1906, \\ Cape Town, South Africa \\ ${ }^{2}$ Department of Physics, Faculty of Science, Edo State University Uzairue, P.M.B. 04, Auchi, 312101 Edo State, Nigeria \\ ${ }^{3}$ Department of Physics and Space Science, School of Physical Sciences and Technology, Technical University of Kenya, \\ P.O. Box 52428-, 00200 Nairobi, Kenya \\ ${ }^{4}$ School of Art, Design, And Architecture, University of Huddersfield, Queensgate Huddersfield, UK HD1 3DH \\ ${ }^{5}$ Laboratório de Biopolímeros e Sensores, Instituto de Macromoléculas, Universidade Federal do Rio de Janeiro (LABIOS/IMA/ \\ UFRJ)-Cidade Universitária, Rio de Janeiro 21941-90, Brazil \\ ${ }^{6}$ Department of Physics and Computer Education, Federal College of Education (Technical), P.M.B, 1044 Asaba, Delta State, Nigeria \\ ${ }^{7}$ Department of Chemical Engineering, Faculty of Industrial Technology, \\ Universitas Pembangunan Nasional "Veteran" Yogyakarta, Indonesia \\ ${ }^{8}$ Department of Chemistry, Faculty of Science and Technology, Airlangga University, Mulyorejo, Surabaya 60115, Indonesia
}

Correspondence should be addressed to Robert Birundu Onyancha; 08muma@gmail.com

Received 8 September 2021; Accepted 5 February 2022; Published 7 March 2022

Academic Editor: Amit Kumar

Copyright ( 2022 Uyiosa Osagie Aigbe et al. This is an open access article distributed under the Creative Commons Attribution License, which permits unrestricted use, distribution, and reproduction in any medium, provided the original work is properly cited.

\begin{abstract}
Presently, hazardous metal and dye removal from wastewater is one of the major areas of research focus. For the elimination of these contaminants, many approaches have been devised and applied. However, the accomplishment of various water treatment processes has largely depended on the medium utilized and the associated problem with the leaching of harmful compounds into the water process with most commercial and chemically manufactured materials for water treatment processes. Hence, this study is aimed at reviewing existing studies on the sorption of heavy metals (HMs) and dyes using bionanocomposites (BNCs). The key focus of this review is on the development of eco-friendly, effective, and appropriate nanoadsorbents that could accomplish superior and enhanced contaminant sequestration using BNCs owing to their biodegradability, biocompatible, environmentally friendly, and not posing as secondary waste to the environment. The sorption of most pollutants was observed to be $\mathrm{pH}$, sorbent dosage, and initial contaminant concentration-dependent, with most contaminants' elimination taking place in the $\mathrm{pH}$ range of 2-10. The sorption process of HMs and dyes to various BNCs was superlatively depicted utilizing the Langmuir (LNR) and Freundlich (FL) as well as the pseudo-second-order (PSO) models, suggestive of the sorption process of a monolayer and multilayer and the chemisorption process, the rate-limiting stage in surface sorption. The established sorption capacities for the reviewed sorption process for various contaminants ranged from 1.47 to $740.97 \mathrm{mg} / \mathrm{g}$. Future prospective for the treatment and remediation of contaminated water using BNCs was also discussed.
\end{abstract}

\section{Introduction}

An energetic base for living organisms and which is utilized in humans' everyday endeavours is water. Owing to the fast manufacturing expansion, physical water reserves are impacted by various contaminants [1]. Notably, the World Health Organization (WHO) reports that an estimated 748 million of the global population are impacted by the supply 
of safe drinking water and water for sanitation. Alarming is the reported case of about 2.5 billion individuals without proper access to sanitation and about 3,900 infants that die daily owing to deficient water quality and infectious diseases; accordingly, water contamination by various contaminants has become a frightening issue globally as revealed by these reported figures [2].

Globally, humans have had the right to use water as an abundant, free resource for many centuries. This condition has dramatically changed in modern times, and water shortage has now become one of the menaces to the human community's long-term growth [3]. This problem is expected to grow at an exponential rate, making it a wide-reaching systemic risk. The global blue water scarcity statistics at a high spatial resolution was calculated by Mekonen and Hoekstra on a month by month basis, and according to this assessment, about four billion people, or two-thirds of the world's inhabitants, suffer from severe water shortage at least one month in every year, with half of these numbers living in India and China. Furthermore, they reported that 0.5 billion people around the globe are affected by this issue annually (Figure 1) [4].

Most of the obliterations of the quality of air, water, and soil which are critical for life sustenance on earth are due to the fast-growing global population and industrialization [5]. An imperative constraint for economic growth is the accelerated urbanization and industrialization as well as the swift increase in water consumption and the issue of water scarcity [6]. Water quality has exceptionally declined owing to the untreated effluents discharged into streams, lakes, and oceans by refining metal plating, mining, paint and dyes, and textile productions [5]. Water use in these industries has increased by as much as 22\% (industry), 70\% (agriculture), and $8.0 \%$ (household) of available freshwater, resulting in a massive amount of wastewater containing several contaminants. Without a doubt, the discharge of effluent from commercial and industrial sectors, as well as untreated sewage from households and chemical contaminants such as HMs, pharmaceuticals, pesticides, and dyes, is among the several compounds, released into freshwater supplies, which are harmful not only to humans but also to animals, plants, and the ecosystem in general $[4,7,8]$.

Presently, one of the utmost global environmental problems is the pollution of water with HMs and other toxic chemicals, released from mining, refining, electroplating, chemical plants, metallurgy, agriculture, and household effluents [9]. A serious hazard is posed to an individual's health, environment, and other ecological receptors by HMs such as lead $(\mathrm{Pb})$, zinc $(\mathrm{Zn})$, copper $(\mathrm{Cu})$, and mercury (Hg). Biologically, owing to HMs accumulating in the food chain, they cannot be degraded by microorganisms when released into the ecosystem [6]. Grave health issues, as well as decreased growth and development, cancer, organ injury, impairment to the nervous system, rheumatoid arthritis, kidney injury, and death in extreme cases, are caused by HMs [10]. High doses of metals are mostly received through food by children than adults, due to a huge amount of food consumed for their body weight than adults. Table 1 gives some details of the impact of excessive intake of heavy metal ion (HMI) and their noxiousness in the ecological perspective as well as their maximum allowed level (MCL) as recognized by the United States Environmental Protection Agency (USEPA) [11].

Among these noxious and aromatic contaminants released into water bodies without prior and proper treatment, the textile industry is a primary user of synthetic or noxious dyes for product colouring [12]. Dye is a major source of serious contamination owing to the fast industrial development and extensive utilization [13, 14]. Dyes have been used for textiles, paint, pigments, and other purposes for thousands of years. In the clothing, paper, plastics, leather, food, and cosmetic industries, dyes and pigments are commonly used to dye goods. The majority of dyes are poisonous and must be discarded before being discharged into waterways [15]. The global textile production is projected to be valued at around a trillion United States Dollars (USD), and its overall global export contribution is about $7.0 \%$ and with the global engagement of 35 million individuals. The greatest major and vicious contamination form triggered by textile production is the contamination of water owing to dye industries. Wastewaters from textiles are both visually contaminated and have elevated salinity, ecotoxicity, and chemical oxygen demand. Also, owing to their enhanced omnipresence in surface water, it negatively affects the health of humans, wildlife, and marine ecology [16]. A major consideration has been drawn by pollution of water through the discharged dye from paper production, food processing, textile dyeing, paints, and cosmetic industries owing to community health and ecosystem hazards. At present, the worldwide colourant market is about 32 billion USD and is projected to grow to about 42 billion USD in 2021. Yearly, the total of synthetic dyes manufactured is estimated to be over 700,000 tons, and more than $15 \%$ of these are discharged into water annually. Water polluted by these dyes are noxious, xenobiotic, and carcinogenic, and they are grouped according to their chromophore structure into the solvent, reactive, basic, vat, and direct dyes. Exclusively, $47 \%$ of synthetic dyes are decomposable [17].

At present, about a hundred thousand different dyes are commercially manufactured, and in terms of volume, 1.6 million tons of dyes are consumed annually. As a result, $10-15 \%$ of the product is lost during usage. A dyeing process involves organic dyes and water usage in several industries, including textile, leather, paper, cosmetics, plastics, and food [15]. Dye-containing wastewaters such as water sources polluted with dye molecules are coloured organics with low biodegradability, resulting from these processes. Dyes, especially azo dyes, are tenacious, withstanding aerobic digestion and oxidizing agents. The multiple benzene rings in azo dyes cause this severe resistance. According to statistics, 1-20\% of global dye output is lost in textile effluents, negatively impacting human metabolism, ecosystems, and natural processes such as eutrophication. Coloured effluents released into the aquatic media block sunlight, preventing algal and aquatic plants from the photosynthesis process [4]. Furthermore, azo dyes and their metabolites have been shown to have negative effects on people and animals owing to their noxiousness, carcinogenicity, and mutagenicity. When they 


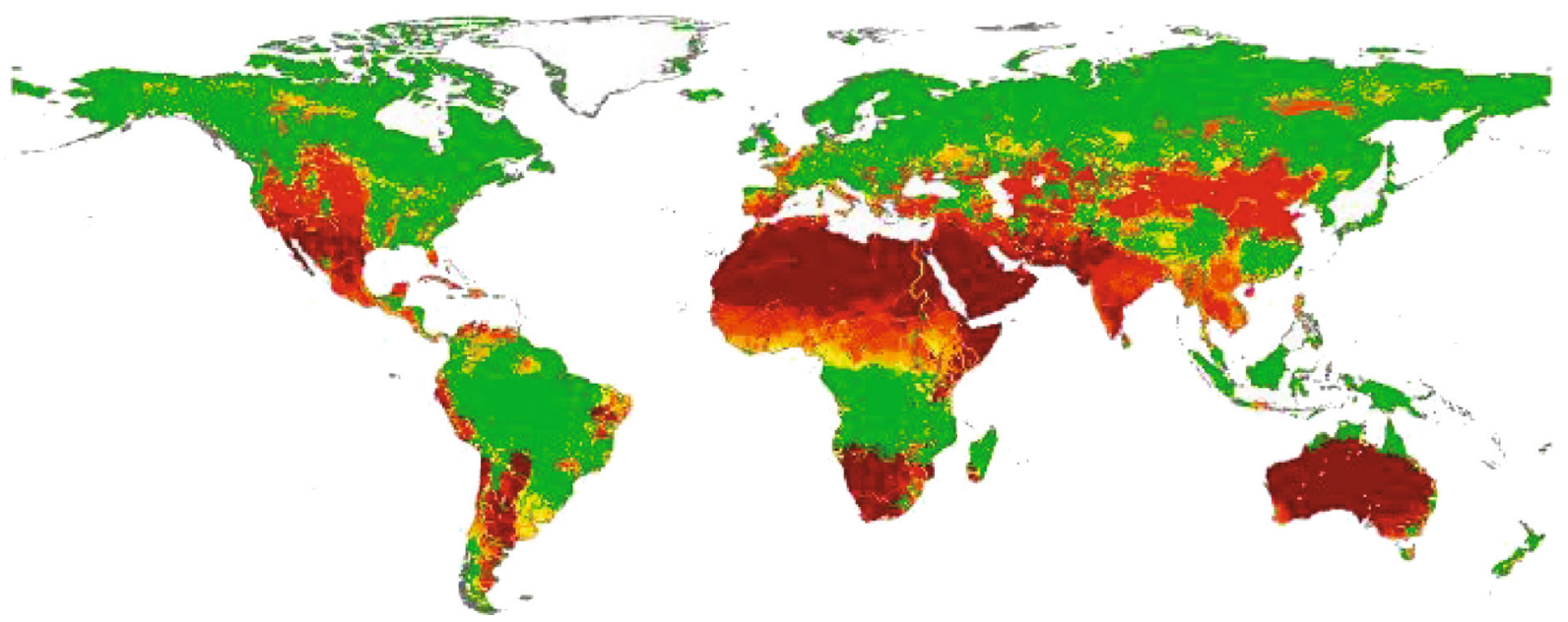

Number of months in which water scarcity is $>100 \%$

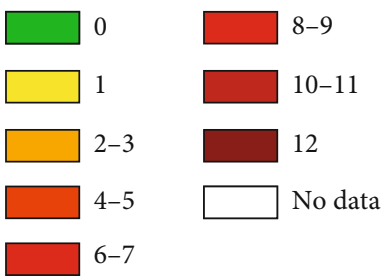

Figure 1: Recorded global water scarcity between 1996 and 2005 [4].

TABLE 1: Impact of excessive intake HMI, their noxiousness in the ecological perspective, and their MCL [11].

\begin{tabular}{lcc}
\hline $\mathrm{HMs}$ & Noxiousness & MCL $\left(\mathrm{mg} \cdot \mathrm{L}^{-1}\right)$ \\
\hline $\mathrm{As}$ & Visceral tumours, skin symptoms, and vascular disease. & 0.05 \\
$\mathrm{Cd}$ & Human carcinogen, kidney injury, and renal disease. & 0.01 \\
$\mathrm{Cr}$ & Carcinogenic, headache, diarrhoea, nausea, and vomiting. & 0.05 \\
$\mathrm{Cu}$ & Insomnia, liver impairment, and Wilson disease. & 0.25 \\
$\mathrm{Ni}$ & Human carcinogens, dermatitis, nausea, compulsive asthma, and coughing. & 0.20 \\
$\mathrm{Zn}$ & Heightened thirst, depression, fatigue, and nervous signs. & 0.80 \\
$\mathrm{~Pb}$ & Impairment to the developing brain, circulatory system, nervous system illnesses, and kidney disease. & 0.006 \\
$\mathrm{Hg}$ & Circulatory and nervous systems, rheumatoid arthritis, and kidney injury. & 0.00003 \\
\hline
\end{tabular}

are dissolved in water-soluble solutions, they are categorized based on their functional groups, colour, and ionic charges. The last form of classification, which is based on dye molecule ionization and has a significant impact on dye sorption performance, is more important. As a result, they can be divided into two categories: ionic and nonionic. Nonionic dyes are classified as cask and disperse dyes, while ionic dyes are classified as cationic (basic) and anionic (reactive, direct, and acidic) dyes [15].

The dyes mentioned in Table 2 are mainly carcinogenic and should be handled efficiently in dye processing plants to keep them from being released into the ecosystem. The properties, applications, and toxicity of individual dye forms are mentioned in Table 2 [18].

Therefore, capable technologies for water treatment have been recognized to raise water resource potential and reduce the water contamination challenges and fears [2]. Over the years, nanomaterials (NMs) have earned huge interest in various fields like electron devices, health care, energy, and environmental protection field. Under the nanoscale, unique features like surface effect, effect of small size, quantum effect, and effect of the macro quantum tunnel are exhibited by NMs. These features contribute to their remarkable sorption capacity and reactivity; together, they are advantageous for the sorption of HM ions and dyes. Extensive research has been conducted on NMs to study their uses in pollutants in water treatment, and they have shown significant promise as a viable alternative to removing contaminants from wastewater [6].

In the development and application of NMs (nanoparticles (NPs), nanotubes (NTs), nanofibers, and nanowires) in science and engineering, there has been improved attention on their research. NPs were chosen for contaminant removal from wastewater because of their low cost and qualities 
TABLE 2: Classification of dyes, their properties, applications, and noxiousness to the environment [4].

\begin{tabular}{|c|c|c|c|c|}
\hline $\begin{array}{l}\text { Types of } \\
\text { dye }\end{array}$ & Dye properties & Dye applications & Dye noxiousness & Examples \\
\hline Acidic & Anionic, water-soluble & $\begin{array}{l}\text { Wool, silk, ink-jet } \\
\text { printing, nylon, paper, } \\
\text { and leather }\end{array}$ & Carcinogenic & $\begin{array}{c}\text { Acid red } 183 \text { (AR-183), acid orange } \\
10(\mathrm{AO}-10) \text {, acid red } 18 \text { (AR-18), } \\
\text { sunset yellow (SY), acid green } 27 \\
\text { (AG-27), methyl orange (MO), amido } \\
\text { black 10B (AB-10B), and indigo } \\
\text { carmine (IC) }\end{array}$ \\
\hline Cationic & $\begin{array}{l}\text { Water-soluble and releases } \\
\text { colour cations }\end{array}$ & $\begin{array}{l}\text { Antiseptic for } \\
\text { biomedicine, paper, } \\
\text { PAN, treated polyesters, } \\
\text { and nylon }\end{array}$ & Carcinogenic & $\begin{array}{c}\text { Methyl blue (MB), basic violet } 10 \\
(\mathrm{BV}-10) \text {, Janus green (JG), basic green } \\
5 \text { (BG-5), and rhodamine } 6 \mathrm{G}(\mathrm{R}-6 \mathrm{G})\end{array}$ \\
\hline Disperse & $\begin{array}{l}\text { Nonionic, for aqueous/ } \\
\text { hydrophobic dispersions, } \\
\text { and water-insoluble }\end{array}$ & $\begin{array}{l}\text { Nylon, polyester, acrylic } \\
\text { fibers, cellulose (CLL), } \\
\text { and CLL acetate }\end{array}$ & $\begin{array}{l}\text { Skin allergenic } \\
\text { and carcinogenic }\end{array}$ & $\begin{array}{c}\text { Disperse orange } 3 \text { (DO-3), disperse } \\
\text { red (DR), disperse red } 1(\mathrm{DR}-1) \text {, and } \\
\text { disperse yellow } 1 \text { (DY-1) }\end{array}$ \\
\hline Direct & $\begin{array}{l}\text { Water-soluble, anionic, and } \\
\text { chelate with metal salts }\end{array}$ & $\begin{array}{l}\text { Cotton, paper, leather, } \\
\text { and regenerated CLL }\end{array}$ & Cancer of bladder & $\begin{array}{l}\text { Congo red (CR), direct red } 23 \text { (DR-23), } \\
\text { and direct blue } 86(\mathrm{DB}-86)\end{array}$ \\
\hline Reactive & $\begin{array}{l}\text { Generates brighter colours } \\
\text { and a high wash grip due to } \\
\text { the covalent bond to the fibers }\end{array}$ & $\begin{array}{l}\text { Wool, cotton, ink-jet } \\
\text { printing of textiles, } \\
\text { and nylon }\end{array}$ & $\begin{array}{l}\text { Dermatitis, conjunctivitis } \\
\text { allergic reaction, rhinitis, } \\
\text { and work-related asthma }\end{array}$ & $\begin{array}{l}\text { Reactive black } 5 \text { (RB-5), reactive } \\
\text { green } 19 \text { (RG-19), reactive blue } 4 \\
\text { (RB-4), reactive red } 195(\mathrm{RR}-195), \\
\text { reactive red } 198 \text { (RR-198), reactive } \\
\text { red } 120 \text { (RR-120), reactive blue, } \\
\text { and } 19 \text { (RB-19) }\end{array}$ \\
\hline Vat & $\begin{array}{l}\text { Water-insoluble and } \\
\text { reduction into weakly acidic } \\
\text { leucon form by } \mathrm{NaOH}\end{array}$ & CLL and fibers & & $\begin{array}{c}\text { Vat blue } 4,(\mathrm{VB}-4) \text {, vat green } 11(\mathrm{VG}-11) \text {, } \\
\text { vat orange } 15(\mathrm{VO}-15) \text {, vat orange } 28 \\
(\mathrm{VO}-28) \text {, and vat yellow } 20(\mathrm{VY}-20)\end{array}$ \\
\hline
\end{tabular}

(particle size, shape, even distribution of particle size, crystal structure, component distribution, purity, aggregation control, and stabilisation). Organic or inorganic NPs with high porosity, small size, and broad surface area make full use of their interface with dye or HM molecules via multiple contaminant binding sites, resulting in high sorption efficacy [19].

In respect of water purification technology as well as treatment of potable water, desalination, and treatment of water, nanocomposites (NCs) play a considerable part to provide substantial machinery for water purification at a reduced price employing a reduced amount of energy and further reducing the environmental effects. To prevent various environmental issues such as the treatment of water polluted with HMs, organic contaminants, inorganic anions, pathogen, dyes, and industrial effluents, they have been applied extensively using zero-valent metal NPs, metal oxide NPs, carbon nanotubes (CNTs), bionanocomposites (BNCs), biopolymers (BPs), etc. [2].

When their sizes approach the nanoscale, and as the atom segment at the material's surface gains momentum, NMs such as NPs, CNTs, nanosheets, and nanofibers have shown distinct chemical and physical properties due to their nanoscale dimensions. For example, they have massive surface-to-volume ratios or massive interfacial reactivity. NPs have a large surface-to-volume ratio and a high percentage of surface-associated atoms and molecules [19].

To meet the aforementioned requirements, a wide range of sorbents with dimensions below the nanoscale have been established over the last few decades as nanotechnology has progressed. These NMs have a large reactive surface area for a low density, and they can be synthesized at a lower cost and extract dyestuff in a much smaller quantity than activated carbon. Several nanoadsorbents in various shapes and dimensionalities (D) of NPs, (0D), nanofibers and nanotubes (1D), nanosheets (2D), and nanoflowers (3D) have been investigated in terms of dye removal. The 0D nanoadsorbents are those whose external dimensions are between 1 and 100 nanometres (nm) [4].

There has recently been a lot of interest in using the sorption technique to remove certain dyes from solutions on different adsorbent surfaces. Clays, fly ash, peat, activated carbon, polymers, and alumina are only a few examples of different adsorbents. The procedure is well-known for being simple and effective in treating concentrated dyes [20].

Although there are no stand-alone methods to fully decolourize or remove HMI from wastewater due to the overwhelming variety of azo dye chemophysical and structural properties, the growth of industries with dye byproduct contamination, combined with declining water supplies, necessitates the development of new methods and materials to recycle wastewater. Natural materials, BPs, and BNCs have all gained a lot of publicity as possible adsorbents in this regard. Natural materials are biodegradable and biocompatible, making them environmentally friendly. Protein-based sorbents have distinct advantages over traditional polysaccharide-based adsorbents like CLL, chitosan (CS), and lignin due to their structural and chemical diversity. Furthermore, certain proteins can self-assemble and transform into highly organized nanofibrils that can 
withstand high temperatures and salt concentrations and have strength and stiffness similar to steel and silk [21].

A variety of HMs and synthetic dye wastewater disposal methods have been developed to reduce their environmental effects [22]. HM and dye sequestration from water bodies has substantial importance to the ecosystem, and developing effective and cost-effective removal techniques is a going continuous effort. These methods comprise of the sorption of pollutants to mineral or carbon-based matrix [23], photocatalysis or oxidation processes [24], chemical precipitation [25], ion exchange [26], microbiological or enzymatic decomposition [27], coagulation [28], reverse-osmosis [29], membrane filtration, etc. [30].

Sorption of inorganic or organic matrices, photocatalysis and/or oxidation processes, microbiological or enzymatic decomposition, and so on are some of the technologies. Because of its convenience, ease of use, and simplicity of design, the sorption process is regarded as the most successful of the various available water treatment technologies $[22,23]$.

The process of sorption is a distinctive technique for the confiscation of contaminants from water-soluble solutions by putting them precisely on the surface of the adsorbent [28]. For the purification of effluent media, sorption is a popular industrial separation technique. It is a mass transfer operation in which a solid material attracts dissolved solutes to its surface and thereby selectively removes them from an aqueous solution [3]. As a result, it entails the interphase aggregation of material concentrations at a surface or in the interphase. The removal of dye from aqueous media is a popular application for this separation technique [31]. It is used in the clothing, leather, dyeing, cosmetics, plastics, fruit, and paper industries, among others, where water recovery is critical [20].

Consequently, this paper is aimed at reviewing existing studies on the sorption of HMs and dyes using BNCs. The paper examines some of the most recent developments for the removal of HMs and dyes from wastewater using BNCs. The major emphasis of this review is on the development of eco-friendly, effective, and appropriate nanoadsorbents that could accomplish superior and enhanced contaminant sequestration using BNCs owing to their biodegradability, biocompatible, environmentally friendly, and not posing as secondary waste to the environment. Consequently, the roles of NMs for the treatment and remediation of wastewater and contaminants in water are presented systematically and comprehensively drawn from existing publications. Future prospectives for the treatment and remediation of contaminated water vis-à-vis water purification technology in the form of suggestions and recommendations are also discussed.

\section{BNCs as a Sorbent for the Treatment of Wastewater Contaminated with HMs and Dyes}

BNCs have evolved over the last few decades into a standard word describing a naturally occurring polymer (BP) in combination with an inorganic component that appears at least a $\mathrm{nm}$ scale measurement $(<1000 \mathrm{~nm})$ because of their widespread availability. They have gained international attention, and their environmental friendliness contributes to green chemistry [32]. They are divided into groups based on their origin, the types of matrix used, and the size and shape of the reinforcements. BNCs are classified as layered structures, particulate, and elongated particles based on the morphology of the particles used for reinforcement $[33,34]$. Isodimensional particles are mostly used as supports for specific BNCs, and the strengthening force is moderate because of the low aspect ratio. This sort of support is used to increase flammability resistance, reduce permeability, and lower the cost of composites. BNCs (CNTs and CLL nanofibrils) are used as a support in elongated particles [35].

Natural species (mainly BPs) and mineral solids with a wide range of shapes and structures bonded at the nanoscale scale make up BNCs (biohybrid materials). In terms of preparation methodology, characteristics, functions, biocompatibility, biodegradability, and applications, they differ from NCs. BNCs are also known as biocomposites, NCs, nanoBNCs, green composites, biohybrids, or biobased plastics, even though the name is new to the public (bioplastics) [36]. BPs are polymers that occur naturally and have potential use in disciplines such as agricultural science, sanitary products, wastewater treatment, and medicine delivery [37].

BPs are often made up of nontoxic monomers and are carbon neutral. Because biomass morphology is often structured at the nanoscale, BPs make it easier to make NMs. BPs are chemically distinct and have a wide range of physiological features. BPs, in particular, form molecular capsules by intramolecular hydrogen bonding [38].

Natural biodegradable BPs include plant carbohydrates (starch, CLL, CS, alginate, agar, carrageenan, etc.) and plant and animal source proteins (soy protein, corn zein, wheat gluten, gelatine, collagen, whey protein, casein, etc.), synthetic biodegradable BPs like polylactic acid (poly(L-lactide) (PLA), poly(glycolic acid) (PGA), poly(-caprolactone) (PCL), poly(butylene succinate) (PBS), poly(vinyl alcohol) (PVA), and other synthetic biodegradable BPs, and BPs produced by microbial fermentation (poly(hydroxyalkanoates) (PHAs) such as poly(-hydroxybutyrate) (PHAs) comprising of poly $(\beta$-hydroxybutyrate) (PHB), poly(3-hydroxybutyrateco-3-hydroxyvalerate) (PHBV), etc., and microbial polysaccharides, like pullulan and curdlan) [39].

As for BPs, the polysaccharides like CS, CLL, starch, alginate, and polylactide are generally utilized for the preparation of BNCs. The major BPs employed are shown in Figure 2, and from an environmental perspective, polysaccharides are the ideal BPs owing to their characteristic biodegradability, creation from renewable supplies, accessibility, lack of noxiousness, and relative minimal cost [40].

Polysaccharides originating from plants and microbial biofilms, such as CS, starch, dextran, and CLL, are commonly used in NM fabrication. Starch, for example, can combine metals or metal oxides to generate polymeric NCs. Because of its broad compatibility, CS is also used in nanotechnology applications. CS has been utilized for colour removal and wastewater treatment in particular. Metals can be attached to BPs to create BP NMs (Figure 3) [38]. 


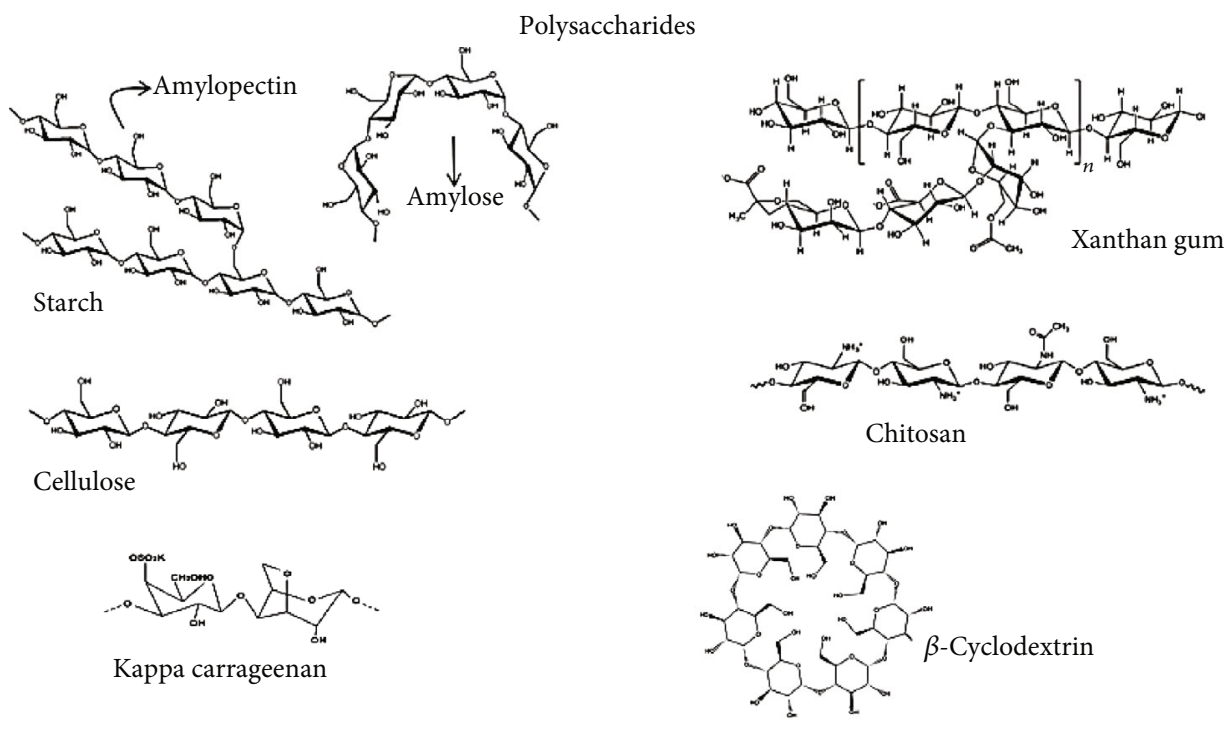

Proteins
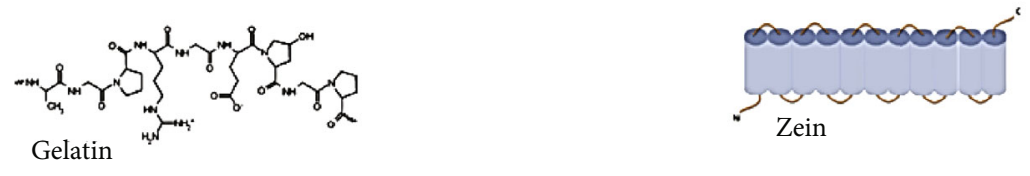

Polylactic acid

Figure 2: Chemical structures of BPs generally employed for the creation of BNCs [40].

In situ polymerization, solution blending, casting, and melt processing are commonly used to make BNCs. Other synthesis processes including electrospinning and processing have recently gained popularity under supercritical conditions. In situ polymerization, melt processing or blending, and solution casting or blending are commonly used in the creation of polymer NCs, with the purpose of optimal NP dispersion during processing $[37,41]$.

They have improved mechanical behaviour because of the large aspect ratio of this support. Based on particle dispersion in the matrix, layer-supported BNCs (layered polymer NCs) are divided into three secondary classes. When there is no barrier between layers due to particle-particle interactions, phase/flocculated separated NCs are formed, and because specific components are not separated, they are referred to as microcomposites. As a result, they act as dissolved microparticles in the polymeric matrix. When polymer chains are intercalated between sheets of layered NPs, intercalated NCs are formed, and exfoliated NCs are formed when individual layers are detached. Mechanical characteristics, biodegradability, and biocompatibility are all outstanding. They are increasingly being used in biomedical applications (drug delivery systems, vaccination, wound dressing, and tissue engineering), BNC films (low-cost, environmentally friendly, and renewable food packaging materials with enhanced antimicrobial activity), and as an emerging sorbent for dye and HM ion removal [36, 42].
In this study by Song et al. [43], CLL/clay composite was created for the sorption of Drimarine yellow HF-3GL direct dye. The prepared composite was characterized using SEM, which showed the morphology before and after the sorption of the dye onto the composite. It was noticed that the composite had a rough and porous surface and the surface becomes smooth after sorption of dye as shown in Figure 4. The sorption of this dye was also observed to be optimally removed at $\mathrm{pH} 2$, and this was ascribed to the interaction between the created positive active sites on the composite surface and the dye. The pseudo-second-order (PSO) and the Redlich-Peterson models best described the sorption process using the nonlinear kinetic (KNT) and equilibrium isotherm (IST), while the thermodynamic (TMD) factors showed that the sorption process was spontaneous, exothermic, and reasonable. $\mathrm{NaOH}$ showed a high desorption efficiency and the composites showed high efficiency of $90-96.07 \%$ and $97-98.23 \%$ for the dye removal using the respective dyes (composite I and II).

To obtain films that possess optimal functional properties such as biodegradability, nonnoxiousness, and bioadhesion, natural biodegradable CS-based thin-film nanogels (TNGs) were prepared for the sequestration of HMI. 2Hydroxyethyl methacrylate (HEMA) and acrylic acid (AA) were grafted to the CS through the redox initiator system of ammonium persulfate (APS), and complex catalyst $\mathrm{CuSO}_{4} /$ glycine in the presence of foaming agent sorbitol 


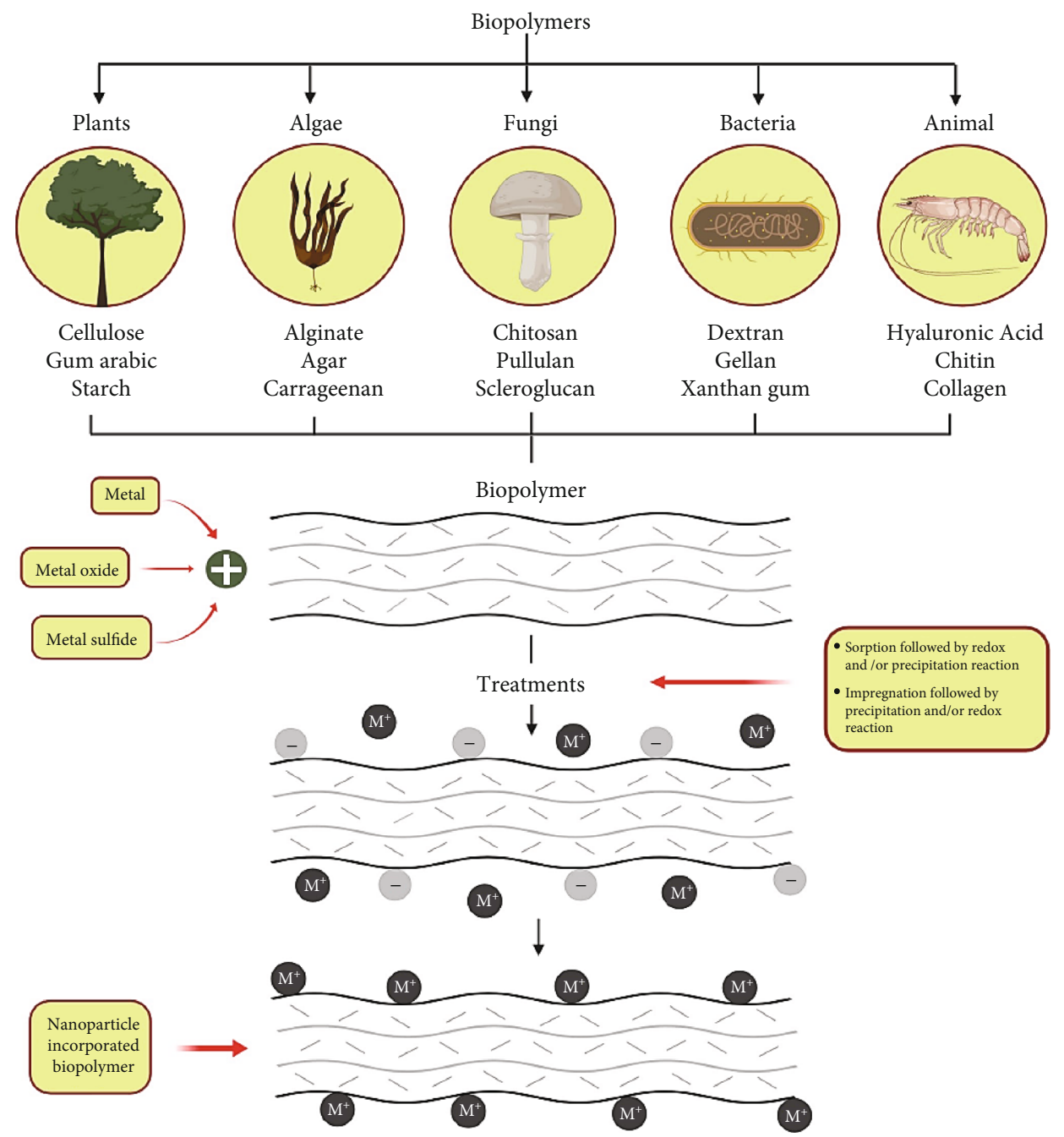

Figure 3: BP sources and their utilization in preparation of green polymeric NMs $\left(\mathrm{M}^{+}: \mathrm{MI}\right)[38]$.

was created. A new thin-film (CS-g-P(HEMA-co-AA)/nano$\mathrm{CaO}$ nanogel) created from the blend of CS-g-P (HEMA-coAA) copolymers altered with snail shell was employed to capture active noxious HMI. The sorption of $\mathrm{Cr}$ (VI) to TNG was best defined using the Langmuir (LNR) and the LNR-Freundlich (FL) as well as the PSO sorption models. The determined sorption capacity was calculated to be $149.7 \mathrm{mg} / \mathrm{g}$ at a temperature of $25^{\circ} \mathrm{C}$ [44].

While guar gum/bentonite BNCs prepared using the solution intercalation technique were employed for the removal of $\mathrm{Pb}(\mathrm{II})$ and crystal violet dye (CV), the SEM images in Figure 5 show the micrographs of the BNCs (a) indicating the existence of a solid bounded network structure with pores or voids present within the surface. With the BNC surface being irregular and permeable, it offered a good platform for $\mathrm{CV}$ and $\mathrm{Pb}$ (II) sorption. After sorption of $\mathrm{CV}$ and $\mathrm{Pb}$ (II), a smooth surface presence on the surface of the sorbent was noticed, indicating that the pores or voids are being filled by the contaminants. Their particle sizes ranged from 3 to $11 \mathrm{~nm}$ according to the TEM analysis.

The point of zero charge $\left(\mathrm{pH}_{\mathrm{PZC}}\right)$ of the BNCs was found to be 2.2 , with optimum sorption capacity noticed at $\mathrm{pH} 5.1$ and 7.6 for $\mathrm{Pb}$ (II) (97.94 mg/g) and CV (39.149 mg/g). From the KNT and IST studies, it was found that the sorption of both $\mathrm{Pb}$ (II) and $\mathrm{CV}$ was best defined using the PSO and LNR (CV) and FL (Pb (II)). While the sorption process was depicted physisorption, spontaneous and endothermic with enhanced uncertainty, an efficient regeneration efficiency was observed up to five cycles using $0.1 \mathrm{M} \mathrm{HCl}$. The synthesized BNCs were successfully applied for the sequestration of HMs from the electroplating battery industrial and medical effluents before and after spiking it with $\mathrm{CV}$ dye solution [45].

A new sorbent was created in this study by the alteration of CS applied for the confiscation of Cu (II) and Cr (VI). To develop a crosslinked gel, Schiff-based was created from the CS reaction with 3-methyl-1-phenyl-5-(piperidin-1-yl)- $1 \mathrm{H}$ pyrazole-4-carbaldehyde, which was crosslinked with epichlorohydrin (ECSBNC). To get a magnetic sorbent material, $\mathrm{Fe}_{3} \mathrm{O}_{4} \mathrm{NPs}$ were integrated into the altered CS gel. Figure 6 shows the SEM images of $\mathrm{Fe}_{3} \mathrm{O}_{4}, \mathrm{ECSBNC}$, and ECSBNC loaded with $\mathrm{Cu}$ (II) and Cr (VI). Aggregation of spherical-shaped NPs of various sizes was visible on the surface of $\mathrm{Fe}_{3} \mathrm{O}_{4}$ (Figure 6(a)). The Schiff base of CS containing 


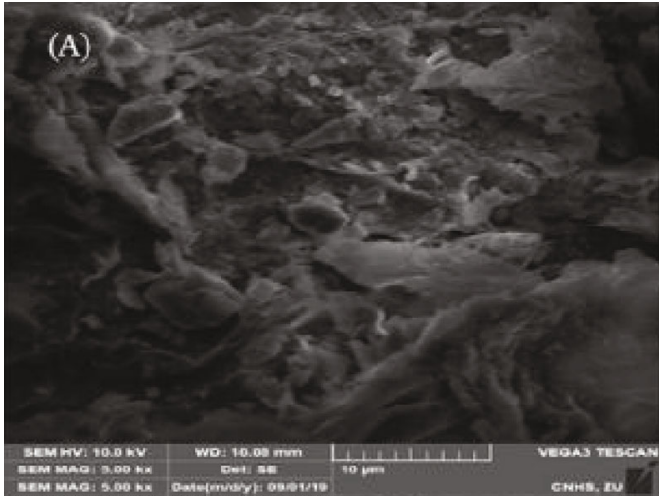

(a)

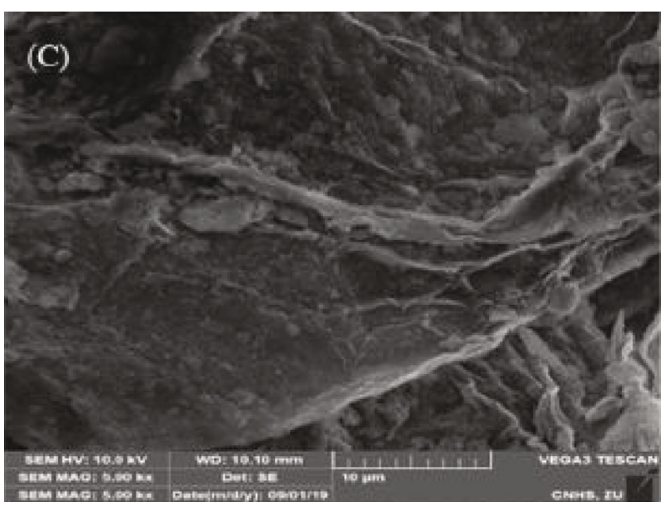

(c)

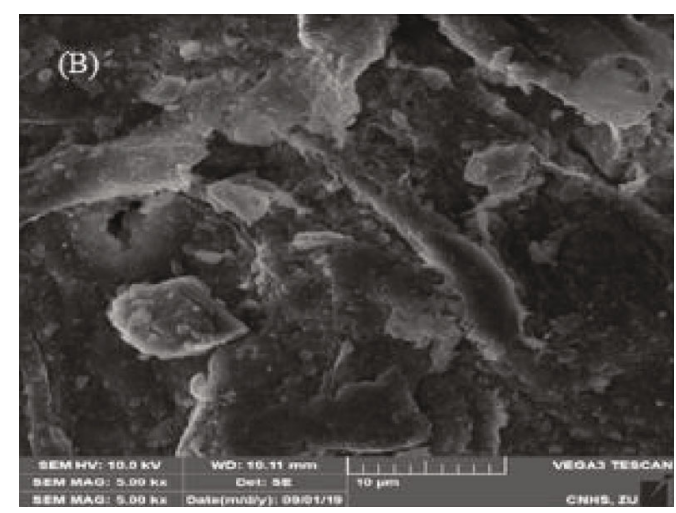

(b)

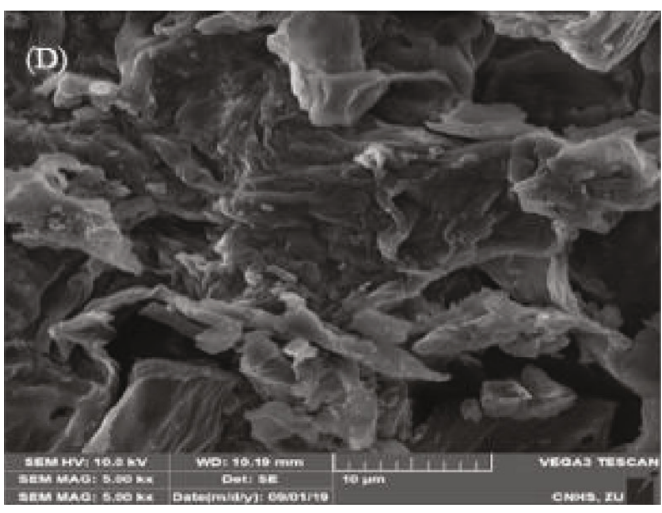

(d)

Figure 4: (a) CLL/clay composite SEM before and (b) after sorption of yellow HF-3GL direct dye [43].

$\mathrm{Fe}_{3} \mathrm{O}_{4}$ NPs had an uneven flake-like structure, as seen in Figure 6(b). Cu (II) and Cr (VI) sorption on the surface of the adsorbent is shown in Figures 6(c) and 6(d), respectively. The sorption looks to be consistent across the entire surface. The data of the sorption process were well fitted employing the LNR and PSO models, with a determined sorption capacity of 90.90 and $83.33 \mathrm{mg} / \mathrm{g}$ for Cu (II) and Cr (VI), respectively. While the parameters of TMDs show that the sorption process was endothermic and spontaneous, the desorption studies also show an effective recovery of the sorbate species and the possibility of sorbent material reuse [46].

A green technique was used to create a BNC-based protein concentrate; its nanofibrils and montmorillonite nanoclay (WPF/MMT) were employed for the removal of cationic dye (Chrysoidine-G (CG), Bismarck brown-R (BBR)), acid dyes (acid red-88 (AC88), acid red-114 (AR114)), direct dyes (direct violet-51 (DV51), congo red (CR)), and reactive dyes (reactive black-5 (RB5), reactive orange-16 (RO16)). It was observed that the BNCs sorbed the CG cationic dye much faster than the other dye type, and with a greater than $93 \%$ removal efficiency for a wide concentration range of CG dye, while the PSO and the linear Nerst models best depict the sorption of these dyes to the BNCs [21].

In this study, a BNC created from cyclodextrinpolycaprolactone titanium dioxide was employed as a biosorbent for confiscation of $\mathrm{Pb}$ (II). Titanium dioxide was prepared through the sol-gel method and was integrated into the polymer blend (CD-PCL) through the solution blending technique. The CD-PCL- $\mathrm{TiO}_{2}$ nanocomposite's size, shape, and aggregation were studied using TEM. As shown in Figure 7, CD-PCL- $\mathrm{TiO}_{2}$ exhibited a variety of morphological characteristics, including a rod-like structure with an average diameter of $395 \mathrm{~nm}$ and a few rectangular shapes. Aggregation of CD-PCL-TiO 2 was also noticed. The particles adhere to one another, resulting in an uneven crystal structure. However, there are no visible $\mathrm{TiO}_{2} \mathrm{NPs}$, which is due to $\mathrm{TiO}_{2}$ being evenly dispersed throughout the BNC matrix [47].

Optimum removal sorption of $\mathrm{Pb}$ (II) was $98 \%$ noticed at $\mathrm{pH}$ 9.7, using a $10 \mathrm{ppm}$ and a dosage of $0.005 \mathrm{~g}$. The surface charge of the BNCs was more negative at higher pHs when the $\mathrm{pH}$ of the solution is higher than the point of zero charge (pHpzc) of 8.80 . Hence, there is electrostatic attraction between the sorbent and the sorbate (Figure 8). The sorption of $\mathrm{Pb}$ (II) to the BNCs followed the LNR and PSO models [47].

A new circular method was employed to tackle issues relating to noxious secondary water using $\mathrm{TiO}_{2}$ nanorods (NRs), and functionalized gum ghatti (Gg) BP-based BNCs (TGB-hydrogel (TGB-H)) created via the free radical graft polymerization were used for brilliant green (BG) dye. The dye sorbed TGB-hydrogel was subsequently treated at $550^{\circ} \mathrm{C}$ for $3 \mathrm{~h}$ and reused for the degradation of antibiotic ciprofloxacin (CIP) photocatalytically. Thereafter, the sent 

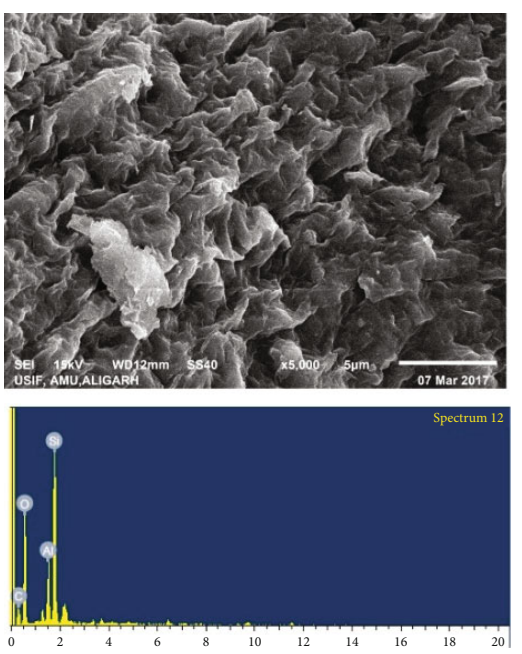

(a)
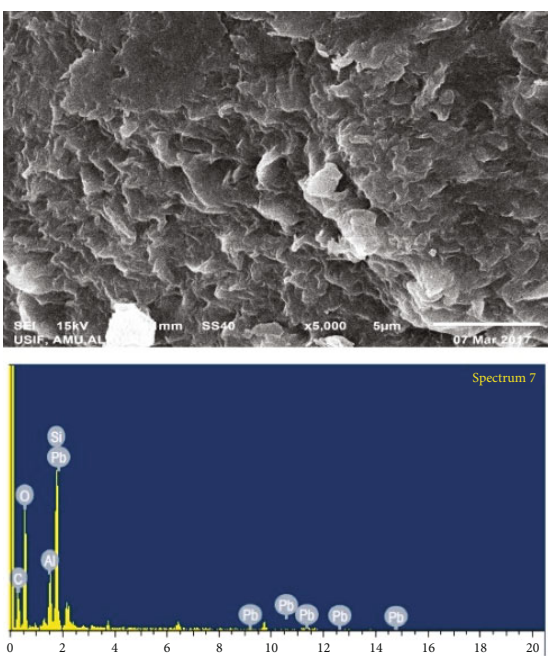

(b)
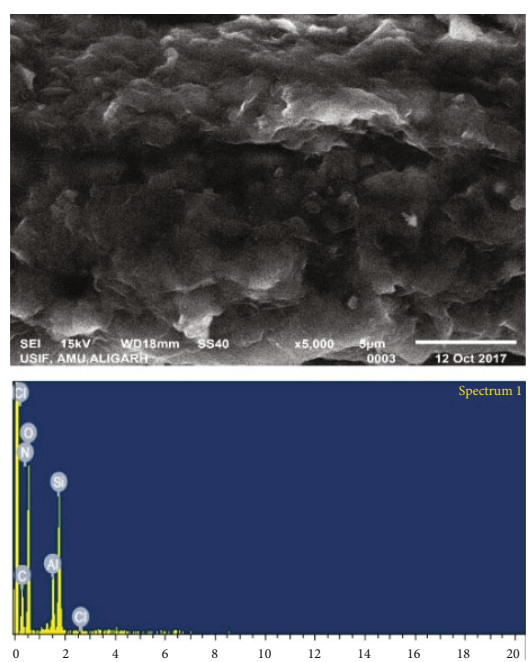

(c)

FIgURE 5: SEM images of (a) BNCs and (b, c) contaminants loaded BNCs with their respective EDX spectral [45]

photocatalyst was restored and employed for the sorption BG dye to finish the round. The sorption process was ideally defined using the LNR and PSO models. The determined sorption capacity was found to be $740.97 \mathrm{mg} / \mathrm{g}$, and the sorption process was found to be spontaneous and endothermic using the TMD studies, indicatives of physical sorption owing to the low calculated value of $\Delta \mathrm{H}^{\circ}$. The high photocatalytic efficiency of $88.7 \%$ was found for CIP using the acquired photocatalyst owing to the recombination delay of the charge carriers, high light sorption, and the elevated surface area. The high-resolution transmission scanning electron microscope (HR-TEM) was used to determine the morphologies and particle sizes of the synthesized materials $\left(\mathrm{TiO}_{2} \mathrm{NRs}\right.$ and TGB-H). The HR-TEM images shown in Figures 9(a) and 9(b) depict the created $\mathrm{TiO}_{2}$ with NR-like morphology with an average width and length of approximately 4 and $45 \mathrm{~nm}$. Bundles of NRs were created due to the surface polar functionalities, while Figure 9(c) shows a crystalline domain with a lattice fringe of $0.326 \mathrm{~nm}$ which relates to the 101 crystallographic planes of the rutile $\mathrm{TiO}_{2}$
NRs. The polycrystalline nature of $\mathrm{TiO}_{2} \mathrm{NRs}$ was confirmed using the selected area electron-diffraction (SAED) (Figure 9(d)), and the visible bright spots were attributed to the $110,101,111$, and 211 crystalline plane refection of the rutile $\mathrm{TiO}_{2}$ NRs, while the HR-TEM images in Figures 9(e) and 9(f) show the well-distributed $\mathrm{TiO}_{2} \mathrm{NRs}$ in the crosslinked polymer matrix of the hydrogel network [48].

The sorption of the cationic BG dye was attributed to the electrostatic interaction, van der Waals forces, ion exchange, $\pi-\pi$ interactions, hydrogen bonding, and Yoshida hydrogen bonding interactions, and based on the FTIR data, the possible interaction between the sites of the dye and the TGB-H sorbent (Figure 10), a loss of the carbonyl, and -C$\mathrm{O}$ peaks of the dye sorbed TGB-H was observed, which was indicative of the -COO- groups being involved BG dye sorption enabled by the interaction between the -COOgroups of the TGB-H and the positively charged nitrogen centre of the dye.

Magnetic chitosan (CS@ $\mathrm{Fe}_{3} \mathrm{O}_{4}$ ) NCs prepared using the solvothermal technique and which were altered using 


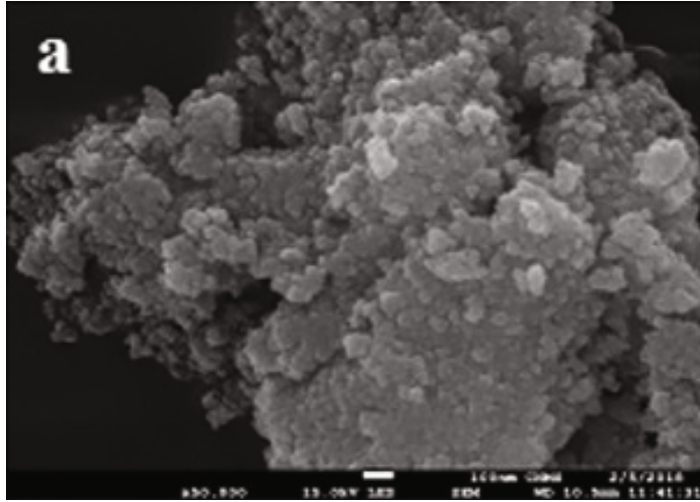

(a)

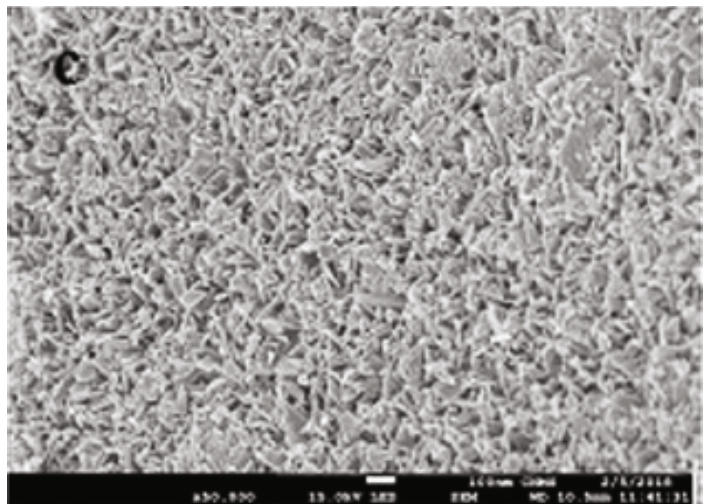

(c)

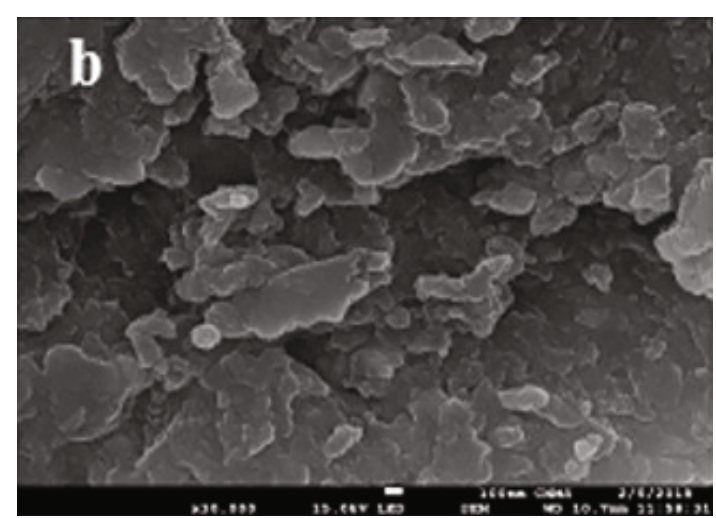

(b)

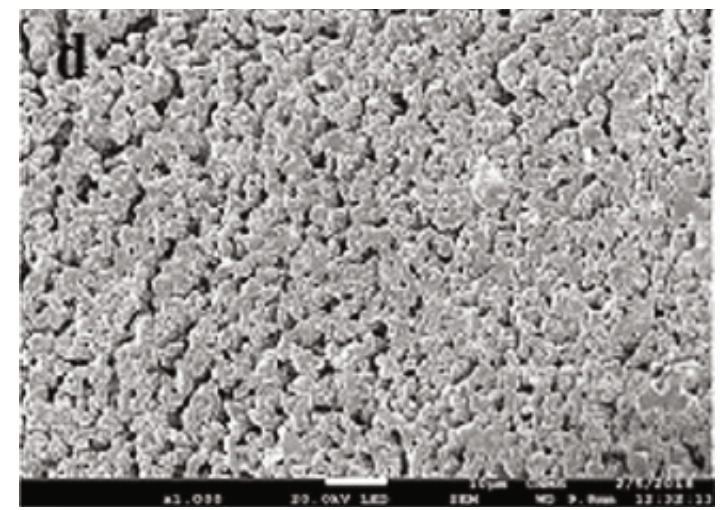

(d)

Figure 6: SEM images of (a) $\mathrm{Fe}_{3} \mathrm{O}_{4}$, (b) ECSBNC, and ECSBNC loaded with (c) $\mathrm{Cu}$ (II) and (d) $\mathrm{Cr}$ (VI) [46].

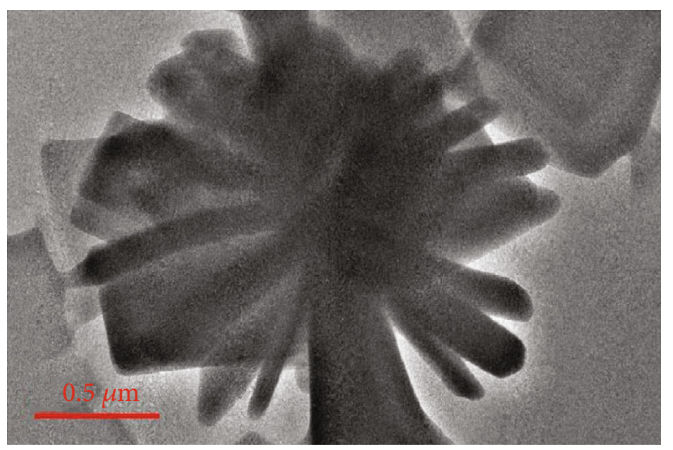

Figure 7: SEM image of CD-PCL- $\mathrm{TiO}_{2}$ BNCs [47].

graphene oxide (GO) to create $\mathrm{CS} @ \mathrm{Fe}_{3} \mathrm{O}_{4} \mathrm{GO} \mathrm{NCs}$ were employed as a sorbent for $\mathrm{Cr}(\mathrm{VI})$ confiscation from watersoluble solution. The XRD result of the sorbent in Figure 9 showed excellent agreement with the elemental study. $\mathrm{Fe}_{3} \mathrm{O}_{4}$ were allocated XRD peaks in the $2 \theta$ range of $35^{\circ}$, $43^{\circ}, 54^{\circ}, 57^{\circ}$, and $63^{\circ}$, the shoulder observed at $30^{\circ}$. Based on the result of XRD, no crystalline CS and carbon were present in the sorbent (Figure 11).

Optimum removal of $\mathrm{Cr}$ (VI) was noticed at $\mathrm{pH} 2$, with determined sorption capacities of $84.84,82$, and $10.28 \mathrm{mg} / \mathrm{g}$ applying $\mathrm{CS} @ \mathrm{Fe}_{3} \mathrm{O}_{4}, \mathrm{CS} @ \mathrm{Fe}_{3} \mathrm{O}_{4} \mathrm{GO}$, and $\mathrm{Fe}_{3} \mathrm{O}_{4}$. Improved sorption at the acidic $\mathrm{pH}$ was ascribed to the sorbent surface protonation owing to $\mathrm{H}^{+}$ions, which enhances the electro- static attraction between the negatively and positively charged sorbent surface and chromate ions. With the increase in the solution $\mathrm{pH}$, a drop in the sorption capacity is observed (Figure 12).

The KNT and IST reactions associated well with the PSO and FL models, with a determined sorption capacity of 142.32 and $100.1 \mathrm{mg} / \mathrm{g}$ for $\mathrm{CS} @ \mathrm{Fe}_{3} \mathrm{O}_{4}$ and $\mathrm{CS} @ \mathrm{Fe}_{3} \mathrm{O}_{4} \mathrm{GO}$. TMD parameter assessment shows that the interaction between the sorbate and the sorbent was spontaneous and endothermic. Also, the reusability studies indicated that the sorbent can be reused for four regeneration cycles. Results show that the created sorbent could be employed in the sequestration of $\mathrm{Cr}$ (VI) ions [49].

Biodegradable xanthan gum/montmorillonite (XG/ MMT) BNCs were employed for the sequestration of $\mathrm{Pb}$ (II) from industrial and synthetic effluents. The sorption process was perfectly illustrated using the PSO and the FL models, while the TMD study shows that the sorption process was spontaneous and endothermic. The sorbent was efficiently restored utilizing $0.05 \mathrm{M} \mathrm{HCl}$ for five runs, showing that this $\mathrm{BNC}$ was a promising and prospective sorbent for practical applications [50].

Mahdavinia and Mosallanezhad [51] report in this study the preparation of a magnetic BNC sorbent based on $\mathrm{k}$ carrageenan through the in situ technique which was crosslinked by CS polysaccharide via electrostatic attraction. The prepared magnetic BNC sorbent was used in the $\mathrm{MB}$ removal from water-soluble solution as shown in Figure 13. 


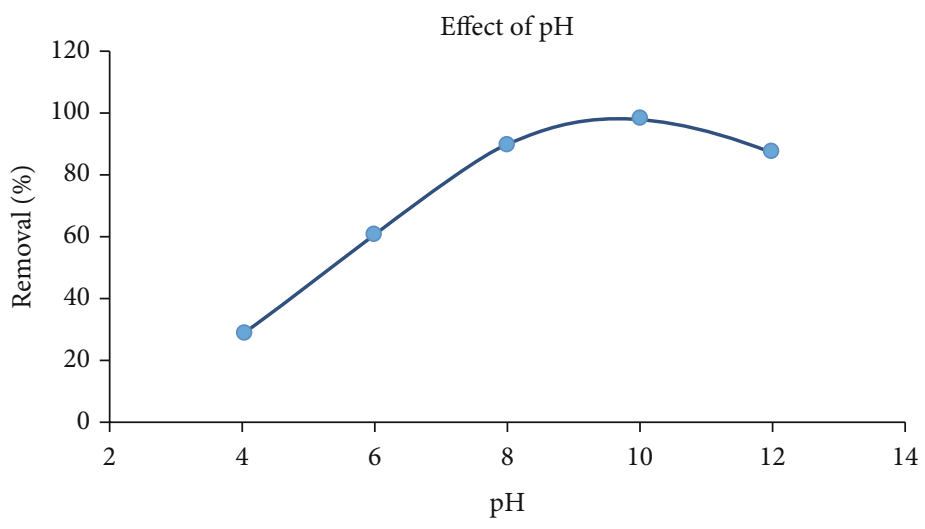

FIGURE 8: Impact of $\mathrm{pH}$ on the sorption of $\mathrm{Pb}$ (II) to the BNCs [47].
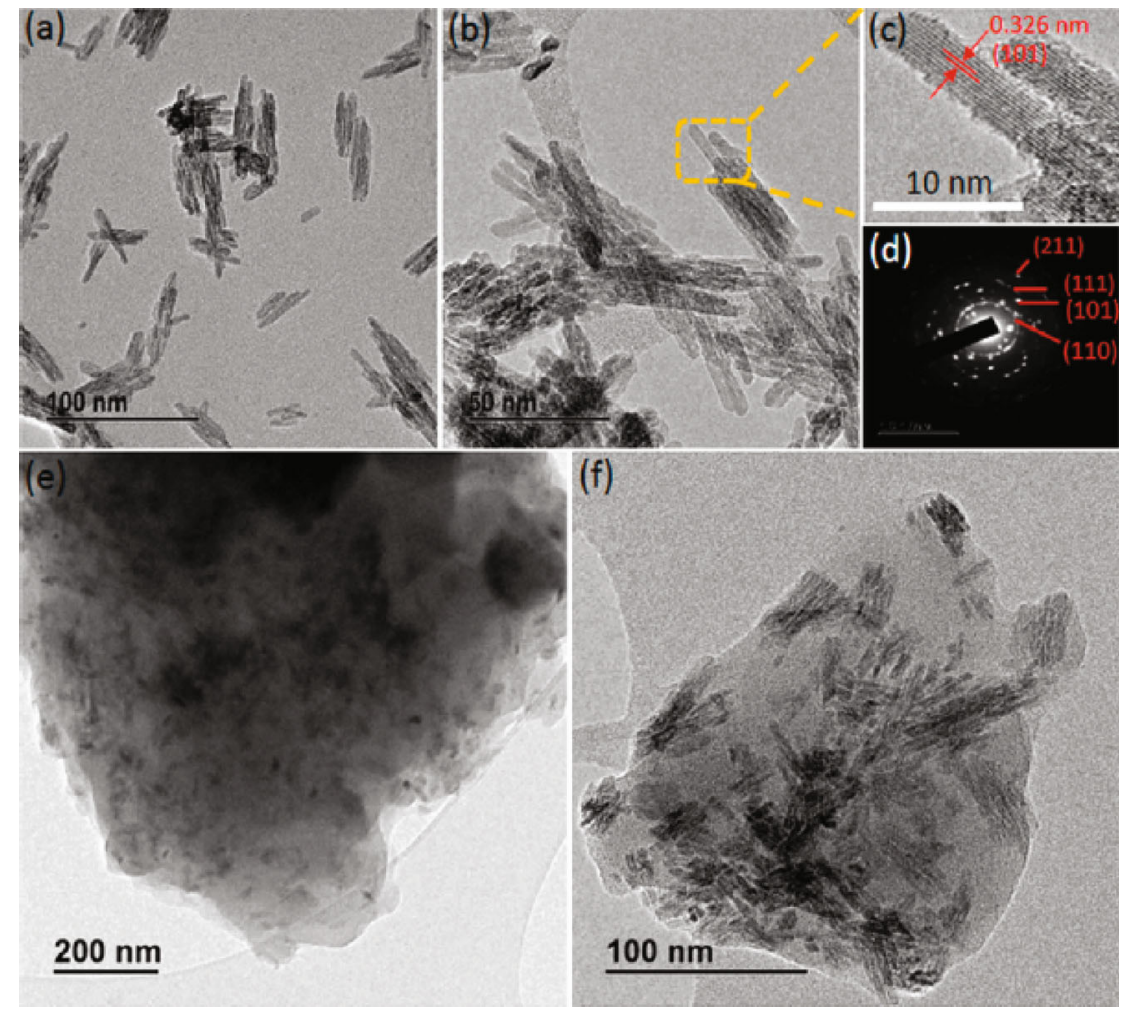

Figure 9: HR-TEM images of (a, b) of $\mathrm{TiO}_{2} \mathrm{NRs}$, (c) crystalline domain $\mathrm{TiO}_{2} \mathrm{NRs}$, (d) $\mathrm{SAED}$ patterns of TiO 2 NRs, and (e, f) TGB-H [48].

From the $\mathrm{pH}$ experimental result, the sorption of $\mathrm{MB}$ to the magnetic BNCs was via electrostatic attraction between positively charged $\mathrm{MB}$ dye and negatively sulfate pendants on the BNCs and optimum removal for $\mathrm{MB}$ was noticed at $\mathrm{pH}$ 12. The sorption of MB to the BNCs was ideally defined using the LNR and a determined sorption capacity of 130.4 and $123.1 \mathrm{mg} / \mathrm{g}$ using nonmagnetic and magnetic sorbents. The TMD result showed that the sorption process was spontaneous, endothermic, and improved randomness. With the rising temperature, the negative value of $\Delta G^{\circ}$ improved progressively which was indicative of sturdier sorptive forces between the MB and BNCs [51].

Synthesized starch/CLL nanowhisker hydrogel composite was effective sequestration of $\mathrm{MB}$. The sorption of $\mathrm{MB}$ to the hydrogel composite was best depicted using the LNR and PSO models. The determined sorption capacity of $2050 \mathrm{mg} / \mathrm{g}$ was obtained using this hydrogel composite for $\mathrm{MB}$ removal. The possible mechanism of sorption of $\mathrm{MB}$ to the hydrogel composite was ascribed to the combined hydrogen bonds, hydrophobic interaction, and electrostatic interactions between the negative charges' groups in the sorbent (-COO${ }^{-}$) and the positive charge MB (Figure 14) [52].

In this study, starch and sodium montmorillonite (starch/Na-MMT) NCs were created using an acetic acid solution using the intercalation method and employed in the sequestration of Co (II) and Ni (II) ions. Optimum confiscation of both HMI was detected at pH 4.5 and 6 for metal concentration of 100 and $140 \mathrm{mg} / \mathrm{L}$ of Co (II) and Ni (II) 


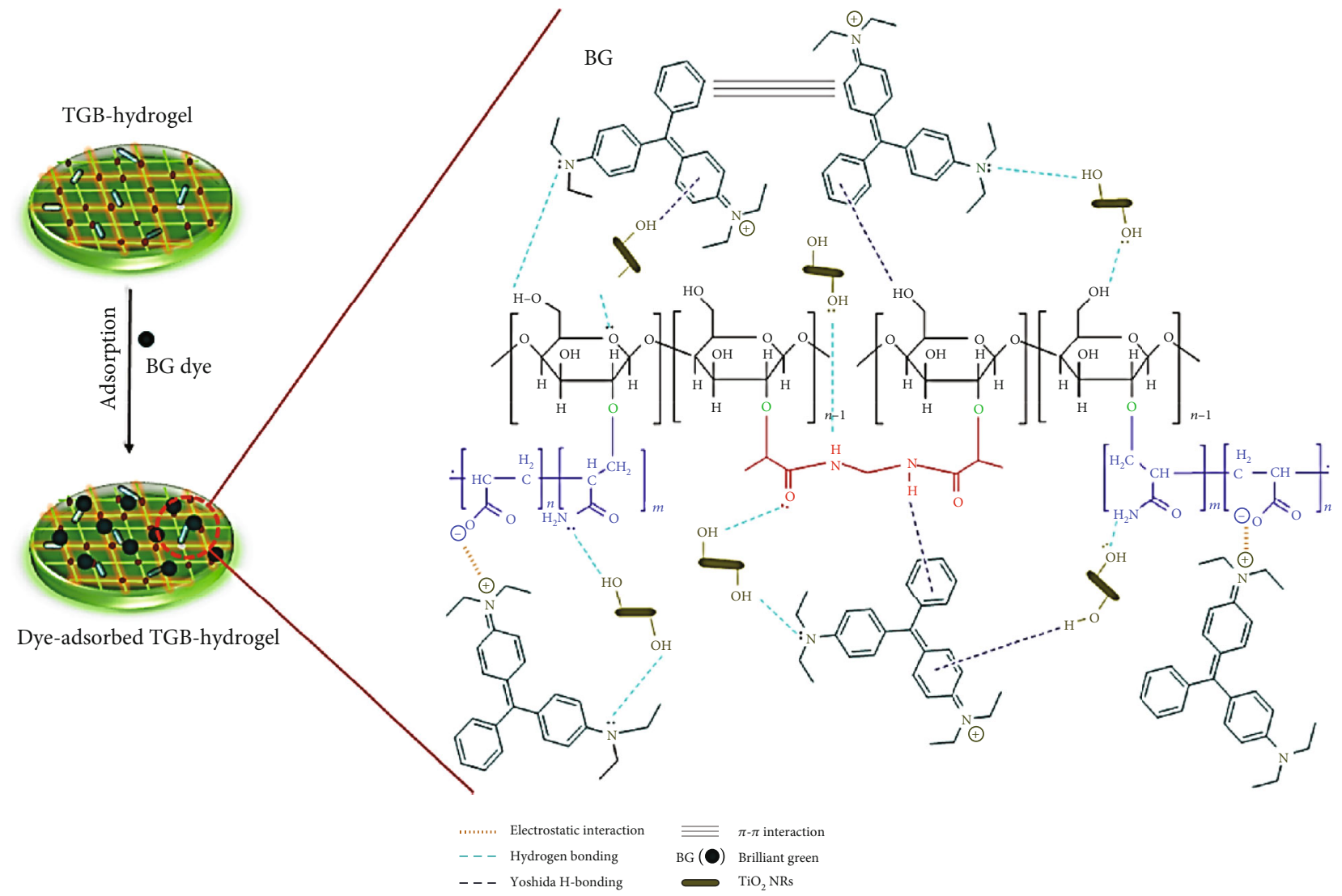

FIGURE 10: The mechanism of interaction between the BG dye and TGB-H sorbent [48].

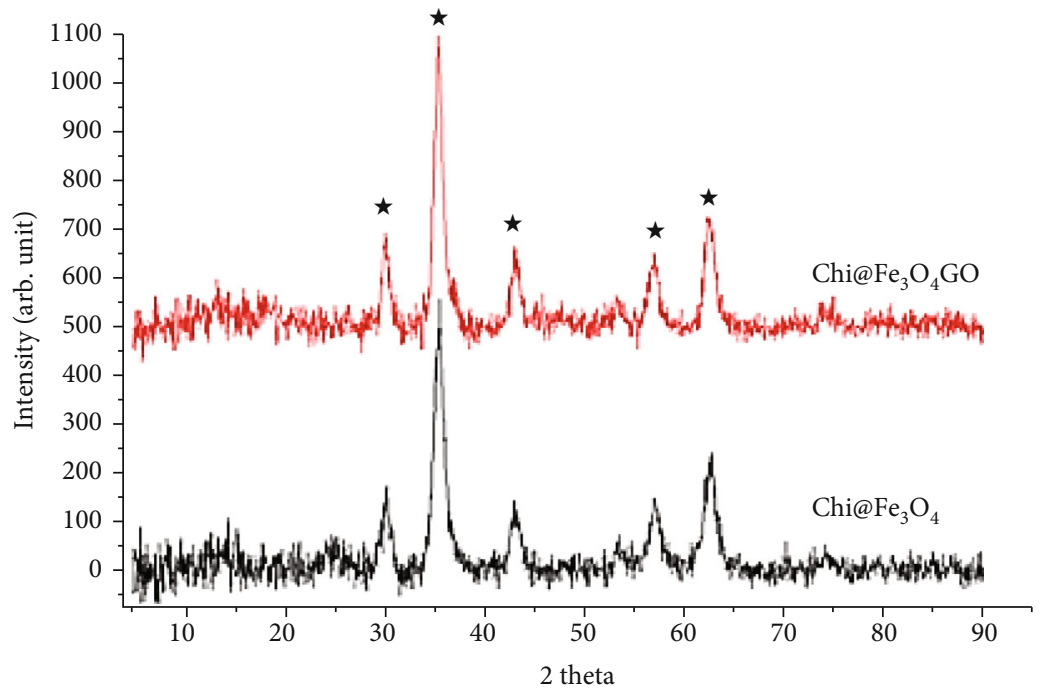

FIGURE 11: XRD pattern of prepared NCs for Cr (VI) removal [49].

with a determined removal yield of 78.07 and $97.1 \%$. The experimental data fitted well to the FL IST, which was indicative of a multilayer sorption process for both HMI [53].

Starch/poly (N,N-diethylaminoethyl methacrylate) copolymer was created through the grafting polymerization of N,N-diethylaminoethyl methacrylate monomers to heated starch utilizing as an initiator of a ceric ammonium nitrate/ nitric acid mixture. To convert the created copolymer to hydrogels, it was subjected to crosslinking treatment employing epichlorohydrin in an alkaline medium. The created hydrogel was employed for anionic dye DR-81 removal from water-soluble solution. The swelling ratio of the created 


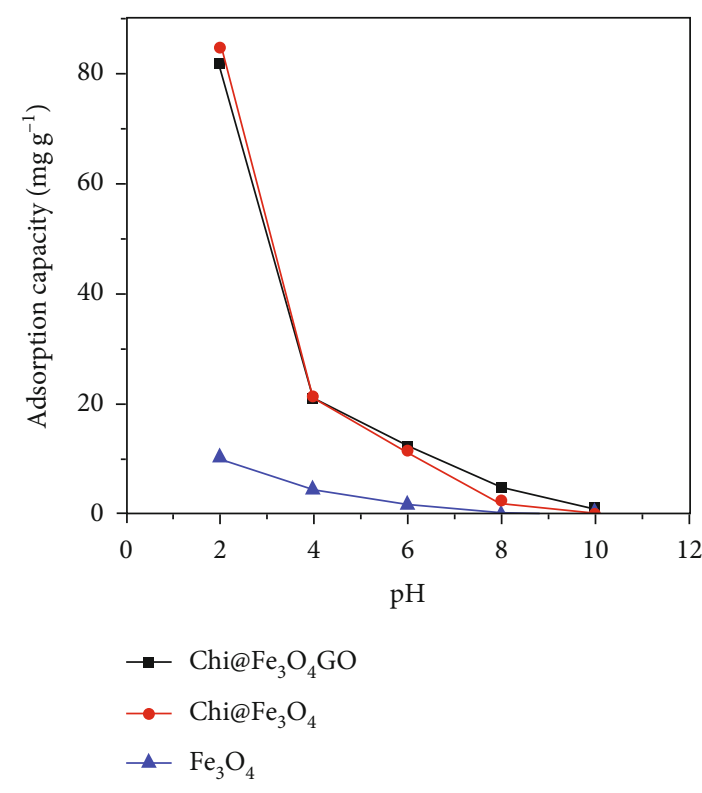

FIgURE 12: Impact of $\mathrm{pH}$ on the sorption of Cr (VI) [49].

hydrogel was found to be 100 . The sorption of DR-81 to the hydrogel was best described using the LNR model, and the determined sorption capacity was $112 \mathrm{mg} / \mathrm{g}$ [54].

In this study, CS/Ag-substituted hydroxyapatite NCs were prepared and applied as a sorbent for the confiscation of basic dye, HM, and microbes. The morphology of the CS utilized had a heterogeneous surface and was rough with intermittent pores. No change was noticed in the NCs with the introduction of Ag-substituted hydroxyapatite. The rough surface of the beads with intermittent pores provided improved surface area and sufficient sites for the sorption of pollutants to the surface of the beads (Figure 15). Optimum sorption capacities using this sorbent were observed at $\mathrm{pH} 7$ for both dye (rhodamine B-RhB) and HM (Cu II). The LNR and PSO model best depicted the interaction between the $\mathrm{Cu}$ (II) and $\mathrm{RhB}$, and the determined sorption capacity was found to be 40.11 and $127.61 \mathrm{mg} / \mathrm{g}$. The percentage of sequestration efficiency for $\mathrm{Cu}$ (II) and $\mathrm{RhB}$ from tap water and untreated river water ranged from 86.7 to $94.4 \%$, and microbial load decontamination was $99.99 \%$ [55].

While in the study by Eivazzadeh-Keihan et al. [56], a synthesized magnetic guanidinylated CS (MGCS) BNC was applied as an effective sorbent for the elimination of HMs such as $\mathrm{Cu}$ (II), $\mathrm{Pb}$ (II), and $\mathrm{Cr}$ (VI) and in vitro hyperthermia for cancer treatment. According to the $\mathrm{pH}$ result for $\mathrm{Pb}$ (II) sorption to the BNCs, it was reported that the maximum percentage removal occurred at $\mathrm{pH} 7$ (90.56\%). The sorption process of $\mathrm{Pb}$ (II) to the BNCs was best described using the LNR and the PSO models, with a maximum monolayer coverage capacity of $60.60 \mathrm{mg} \cdot \mathrm{g}^{-1}$. While for the in vitro treatment of cancer, it was discovered that specific sorption rate and saturation magnetization values obtained were $70.56 \mathrm{w} . \mathrm{g}^{-1}$ and $43.66 \mathrm{emu} / \mathrm{g}$ using an alternating magnetic field.

Also, in the study by Peralta et al. [57], a magnetic CS composite (MCSC) was synthesized by implanting a CS matrix into the magnetic materials using the one-step method. The synthesized MCSC was employed for the sequestration of noxious $\mathrm{Cu}$ (II), $\mathrm{Ni}$ (II), and $\mathrm{Pb}$ (II) ions from water. The isoelectric point $\left(\mathrm{pH}_{\mathrm{IEP}}\right)$ of the prepared MCSC was determined to be about 8.0. Since each HMs showed comparable sorption behaviour, the impact of $\mathrm{pH}$ on $\mathrm{Cu}$ (II) was evaluated as a model. A significant increase in the percentage of $\mathrm{Cu}$ (II) removed was noticed as the solution $\mathrm{pH}$ was increased from $\mathrm{pH} 2$, with a maximum percentage of $\mathrm{Cu}$ (II) removed noticed at $\mathrm{pH}$ 7. Low removal at $\mathrm{pH}$ lower than 3 was ascribed to the CS solubilization in an acidic medium. The sorption process of individual HMs was best depicted using the LNR and the PSO models, with maximum sorption capacities of 220.9 (Pb (II)), $216.8(\mathrm{Cu}$ (II)), and 108.9 (Ni (II)) mg. ${ }^{-1}$, respectively. Based on the experimental results from existing and reviewed studies, BNCs were found to be promising nanosorbents for the confiscation of HMs and dye ions. A listing of BNMs was utilized in the biosorption of various HMs and dyes with their optimum pH, IST, and KNT models, and TMD parameters best depicting the interaction between the sorbates and BNCs and values of determined sorption capacity are summarized in Table 3.

\section{Factors Affecting Sorption of HMs and Dyes Using BNCs}

To bind HM to diverse sorbents, ion exchange, complexation, coordination, microprecipitation, chelation, mechanism combination, and electrostatic interaction are all used. The sorption conditions like temperature, $\mathrm{pH}$, sorbent dosage, sorption system types, and volume treated, sorbent physicochemical features like chemical and textural functionality, and sorbate qualities are all taken into account when determining the mechanism of sorption [26]. The $\mathrm{pH}$, temperature, and coexisting are the most important parameters for the sorption of contaminants, and this has an impact on the efficacy of NMs for contaminants removal [58].

3.1. pH Impact on the Sorption of HM and Dyes to BNCs. The optimum $\mathrm{pH}$ selection is important in sorption studies [49]. In the process of sorption in a water-soluble medium, an important variable and a controlling factor are the medium $\mathrm{pH}$ [59]. An effective parameter for sorption, the solubility of contaminants in solution, sorbent functional group activity, and ionic competition are the $\mathrm{pH}$ [60].

During the sorption process, it changes the charges on the sorbent's surface, the degree of ionization, and the sorbate speciation, hence leading to the interaction between pollutants and $\mathrm{NMs}[54,61]$. The value of $\mathrm{pH}$ indicates the $\mathrm{H}^{+}$level of concentration in water, and electrostatic interaction and ion exchange are considerably affected by the concentration of $\mathrm{H}^{+}$[58]. The adjustment of the $\mathrm{pH}_{\mathrm{pzc}}$ of the sorbents by the surface modification improves the electrostatic interactions between the sorbent surface and contaminants. Remarkably, the sorbent has a positive and negative charge when the $\mathrm{pH}$ is less than $\mathrm{pH}_{\mathrm{pzc}}$ and more than $\mathrm{pH}_{\mathrm{pzc}}$ $[61,62]$. It was observed in this study that the sorption of $\mathrm{MB}$ to starch-g-PAAc/CNW nanocomposites (NCs) under 

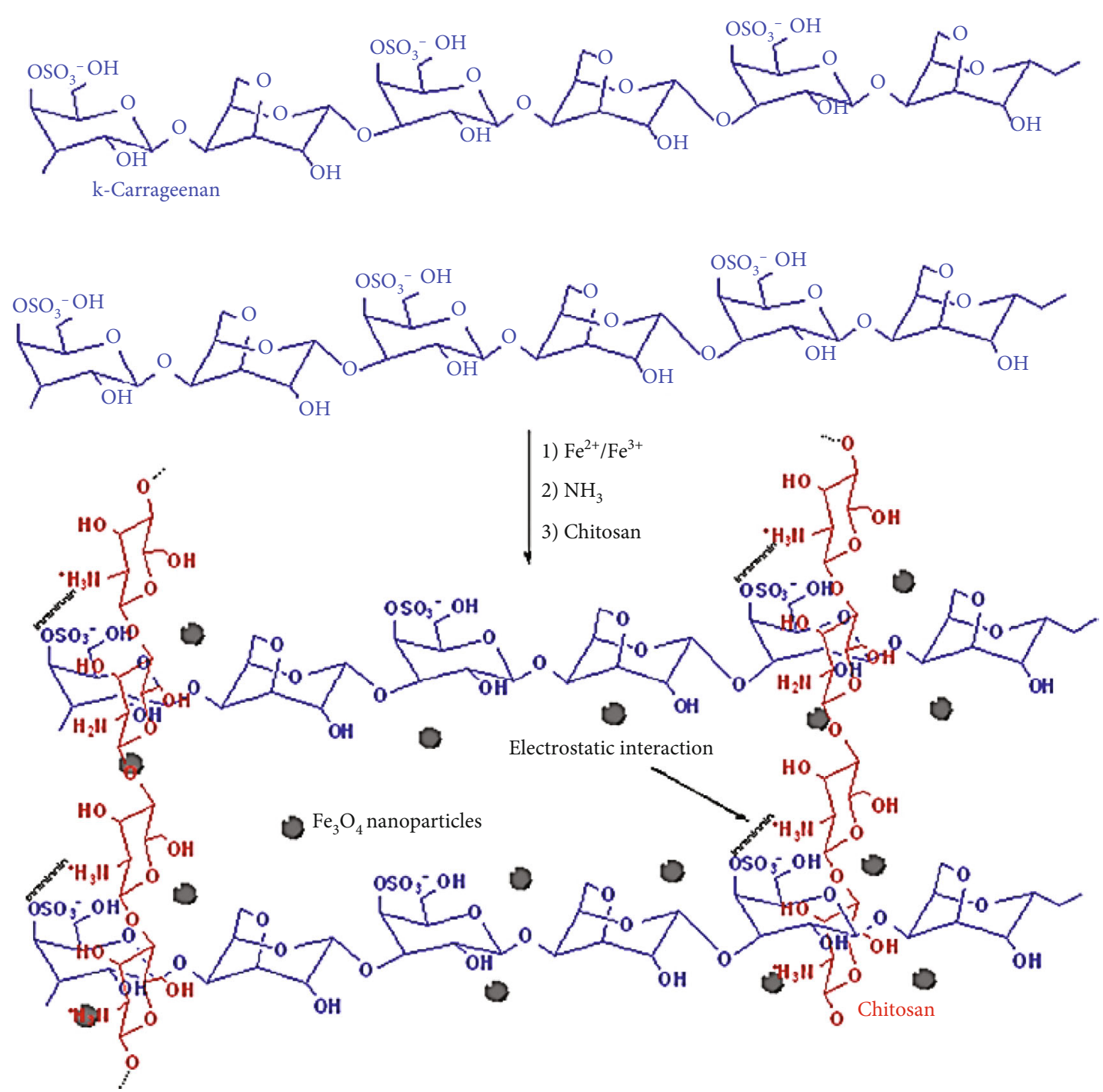

FIGURE 13: Schematics showing the steps of preparation of the magnetic BNC sorbent for MB removal [51].

varying solution $\mathrm{pH}$ was due to the variation in the electrostatic attraction and the dipolar interaction between the sorbent and sorbed molecules as depicted in Figure 16. At low $\mathrm{pH}$ values, there was competition for the sorption sites on the sorbent between the surplus protons $\left(\mathrm{H}^{+}\right)$and the $\mathrm{MB}$ cationic groups. Also, at these $\mathrm{pH}$ values, there was a suppression of the ionization of the carboxyl groups, which reduced the electrostatic interaction between the $\mathrm{MB}$ dye molecules and the sorbent. An increase in the sorption capacity was also observed as the $\mathrm{pH}$ value was increased from $\mathrm{pH} 2-5$. As noticed, as the $\mathrm{pH}$ preconditions close to the $\mathrm{pKa}$ of carboxyl groups, there was an increase in the negative charge density within the hydrogel/hydrogel NC matrixes leading to improved sorption capacity. The optimum sorption capacity of MB to the NCs was determined to be at $\mathrm{pH} 5$, as a subsequent increase in the solution $\mathrm{pH}$ ( $>\mathrm{pH} 5$ ) did not substantially enhance the sorption capacity [52].

For the removal of Cr (VI), a novel CS-g-PMMA/silica $\mathrm{BP}$-based hybrid NC manufactured using an emulsifier-free emulsion polymerization approach was used. As the solution $\mathrm{pH}$ was adjusted from $\mathrm{pH} 1$ to $4 / 5$, greater $\mathrm{Cr}$ (VI) removal was seen, with optimum $\mathrm{Cr}$ (VI) removal observed at $\mathrm{pH} 4$ using these NCs. The ionization of functional groups on the chelating surfaces of the sorbent, which involves the competitive reactions of protonation and complex binding, resulted in enhanced $\mathrm{Cr}(\mathrm{VI})$ removal at higher $\mathrm{pH}$. The reduced sorption of the sorbate to the sorbent at lower $\mathrm{pH}$ (acidic medium) was owing to a significant quantity of hydrogen ions competing with $\mathrm{Cr}$ (VI) ions for active sites on the sorbent surface [32].

In the study by Abdel-Halim [54], it was observed that the optimum percentage of dye removal (95.65\%) was obtained at $\mathrm{pH} 1$ as depicted in Figure 17. As the $\mathrm{pH}$ was increased to higher $\mathrm{pH}$, the percentage of dye removed decreased to $0 \%$ at $\mathrm{pH} 10$. The improvement and decrease in the percentage of dye sequestered in the sturdy acidic and alkaline mediums were ascribed to the sorbent surface charge owing to the amino group involved in its structure protonation. The ion exchange mechanism was suggestive 


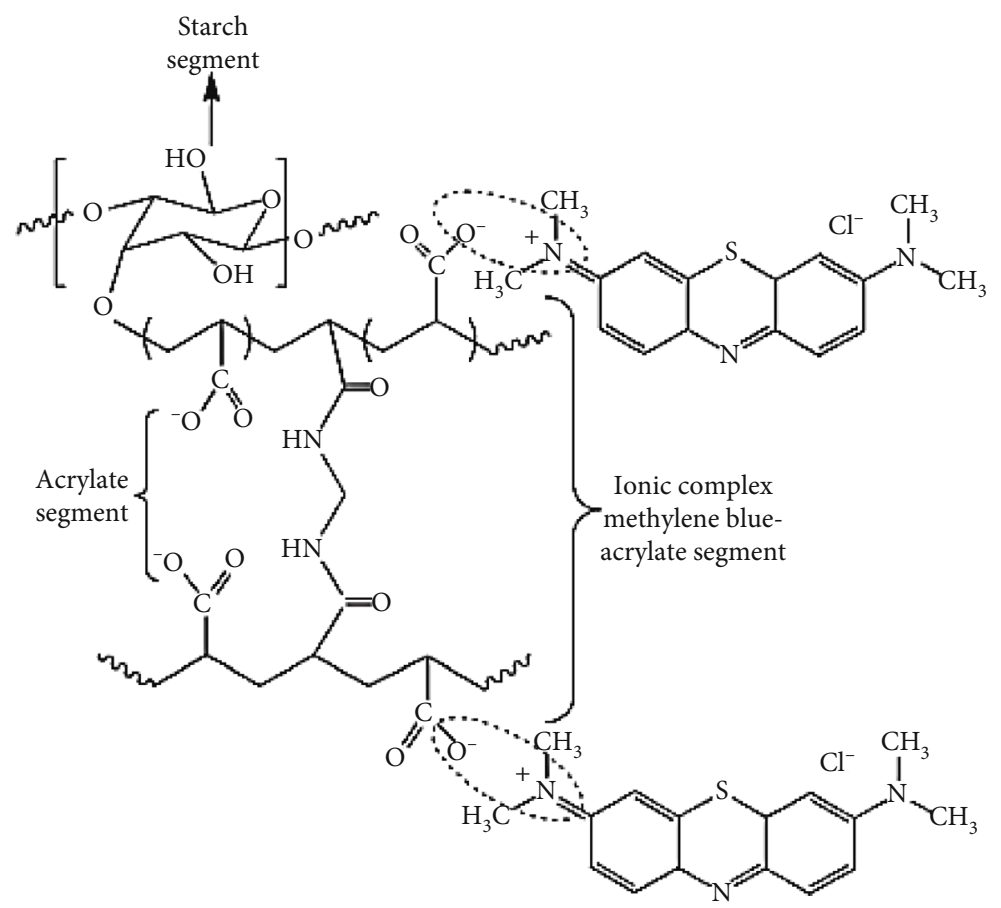

Figure 14: Possible mechanism of sorption of MB to hydrogel composite [52].

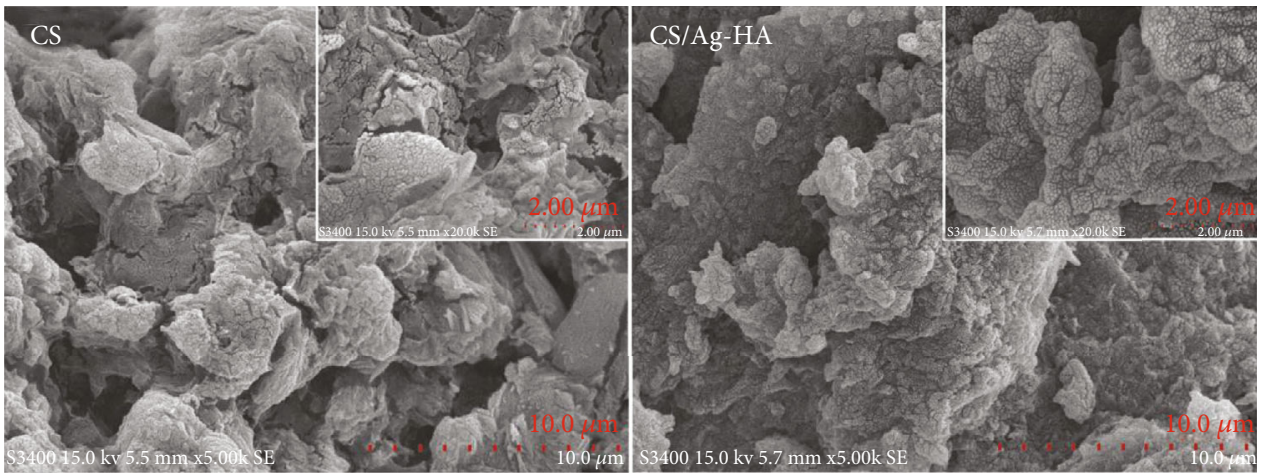

FIGURE 15: Morphology of CS/Ag-hydroxyapatite [55].

of the hydrogel amino protonation in the first phase, while in the second phase was due to the anionic dye molecules from the negative centre bonding to the protonated amino groups. The high concentration of $\mathrm{OH}$ groups at $\mathrm{pH} 10$ led to no protonation of the amino groups, hence leading to the nonavailability of ion exchange sites to attract the negatively charged dye anions.

The percentage removal of MI to grafted crosslinked chitosan beads was shown to be lower at lower $\mathrm{pH}$ levels, owing to the protonation of the CS amine group, which causes an electrical repulsion between the MI and the amine group on the chitosan. The surface of the beads becomes deprotonated and negatively charged as the $\mathrm{pH}$ rises. As a result, the elimination of these HMI was increased until an optimum value (pH 5-Pb (II) and $\mathrm{Cu}$ (II), pH 6- $\mathrm{Zn}$ (II) and $\mathrm{Cd}$ (II), and $\mathrm{pH} 7-\mathrm{Ni}$ (II)) is reached. The insoluble metal hydroxide begins to precipitate from the solution above the optimum value of removal, resulting in a reduction in $\mathrm{MI}$ removal (Figure 18) [63].

The $\mathrm{pH}$ was reported in this study to influence the sorption of several cationic dyes using a biodegradable magnetic composite microsphere (MCM). It was observed that the sorption capacities for the three dyes were enhanced with varying in the solution $\mathrm{pH}$ from 2 to 10 , with a rapid increase at $\mathrm{pH} 4.5$. With the subsequent increase in the solution $\mathrm{pH}$ above 5 , the uptake of dyes was slowly enhanced and until a maximum level is attained. Optimum confiscation efficiency for these dyes is attained at a $\mathrm{pH}$ range of 5-10. In strong acidic mediums, the protonation of the carboxyl and amino groups in MCM resulted in a positively charged surface on the magnetic MCM, hence resulting in a reduction in the sorption capacities of these cationic dyes at low $\mathrm{pH}$ conditions. At elevated $\mathrm{pH}$ conditions, the amino and carboxyl groups are deprotonated and the surface 


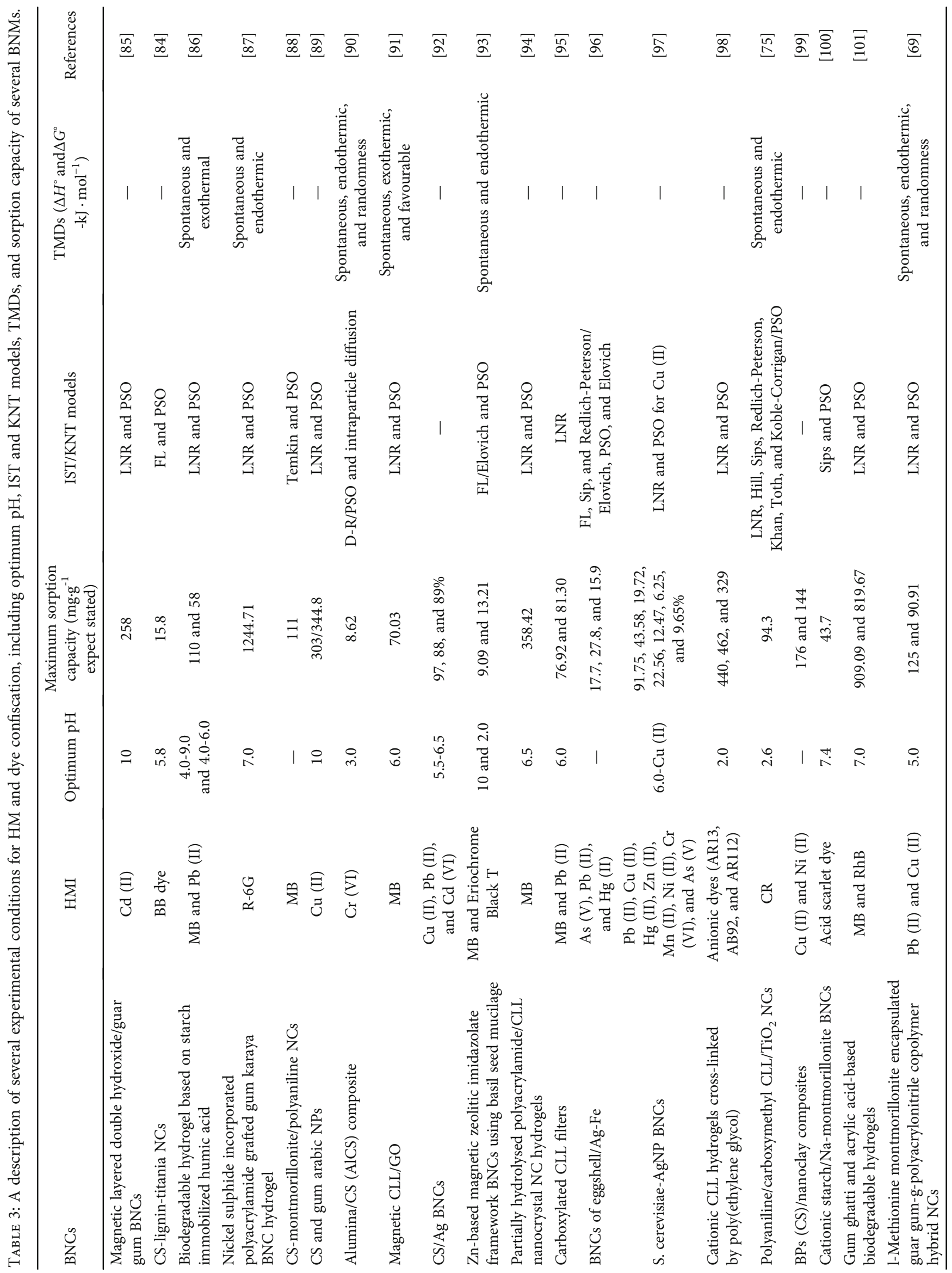




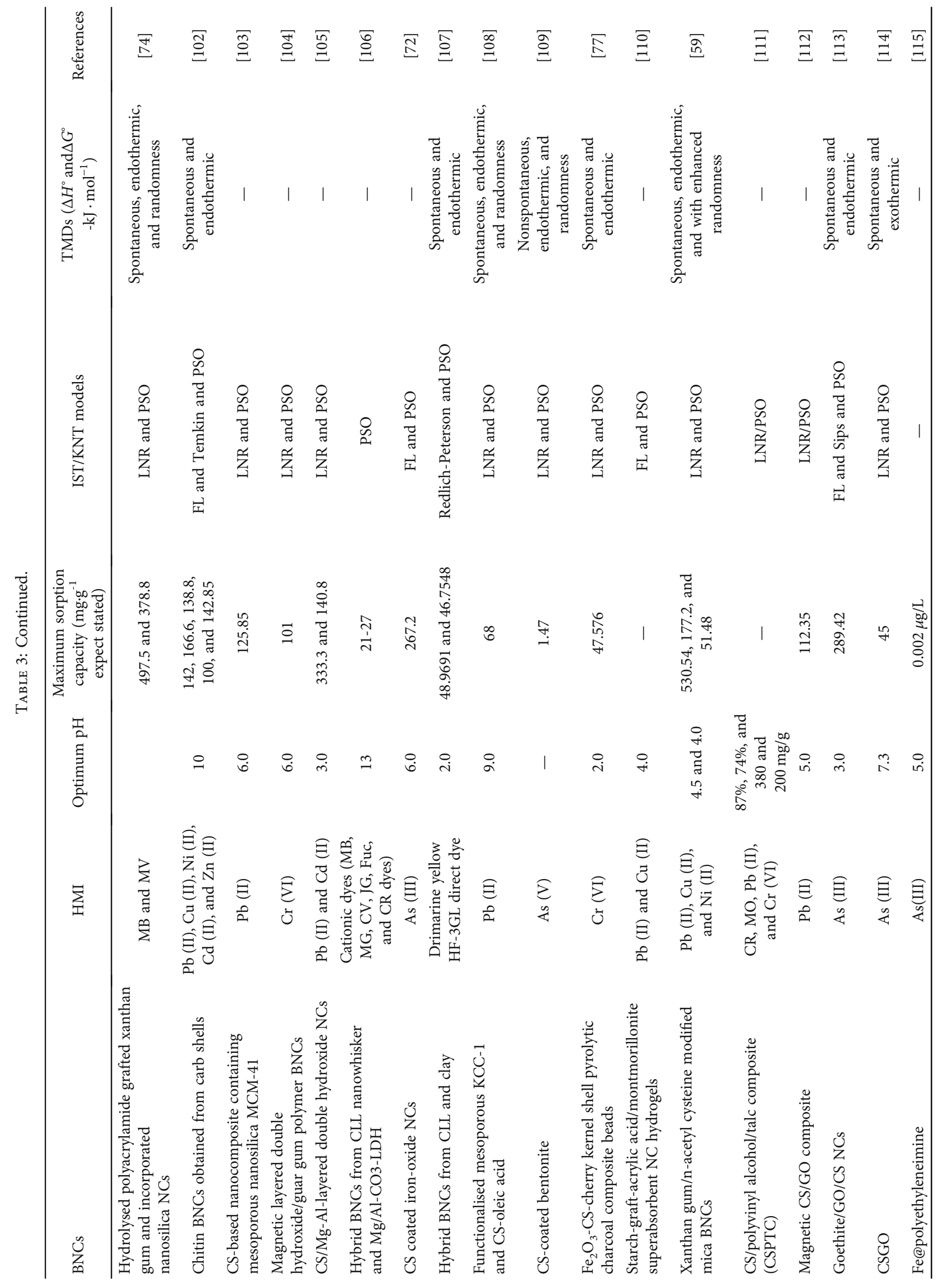




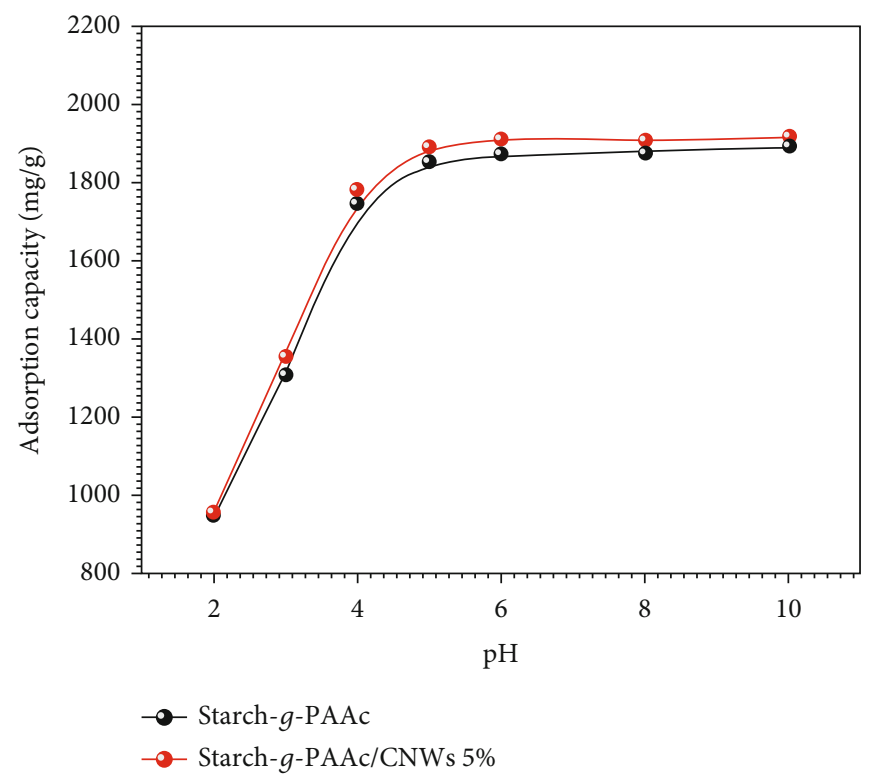

FIGURE 16: Sorption of MB to hydrogel NCs at various $\mathrm{pH}$ [52].

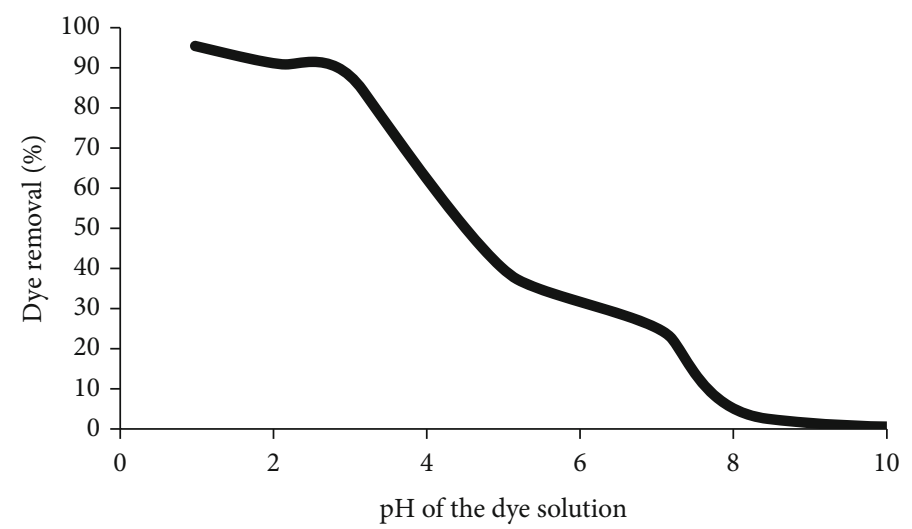

Figure 17: Impact of sorbate $\mathrm{pH}$ on the sorption of anionic dye [54].

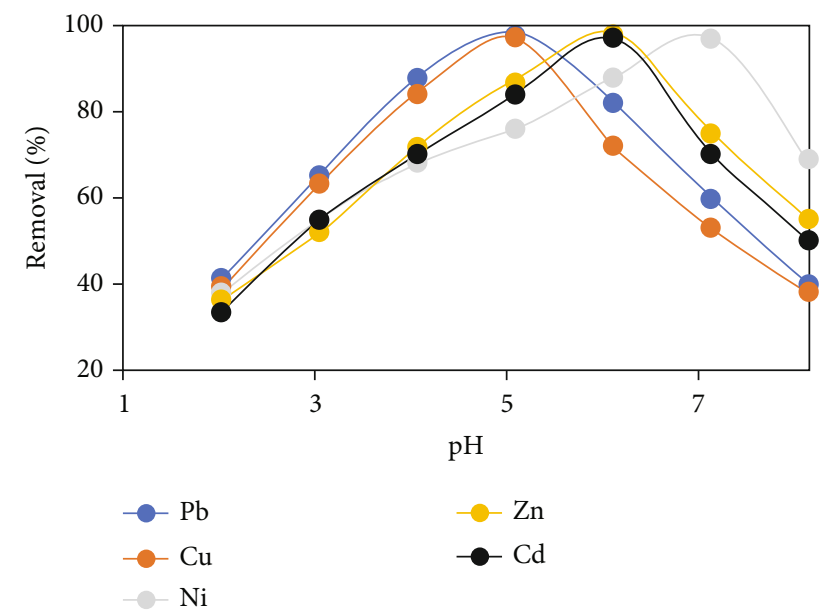

FIGURE 18: $\mathrm{pH}$ impact on the sequestration of HMI by BNCs [63]. charge on the sorbent surface becomes negative. This leads to improved removal of the cationic dyes owing to the interaction between the sorbate and the sorbent electrostatically (Figure 19) [64].

The effect of $\mathrm{pH}$ on anionic dye and HMI sorption was studied using BNCs. The $\mathrm{BNCs}^{\prime} \mathrm{pH}_{\mathrm{PZC}}$ was discovered to be 8.2. When the $\mathrm{pH}$ was more than $\mathrm{pH}_{\mathrm{PZC}}$, sorption favours positively charged sorbates, and when the $\mathrm{pH}$ is less than $\mathrm{pH}_{\mathrm{PZC}}$, sorption favours negatively charged sorbates. $\mathrm{Pb}$ (II), Ni (II), and CR had sorption capacities of 47.98, 42.91, and $40 \mathrm{mg} / \mathrm{g}$ observed at $\mathrm{pH} 5,4$, and 2.1. Reduced competition between $\mathrm{H}^{+}$and the positively charged MI was one of the reasons for the higher sorption capacity with an increase in $\mathrm{pH}$, while the electrostatic interaction between the positively charged CR solution and the negatively charged sites in the acidic $\mathrm{pH}$ resulted in the enhanced sorption capacity [65].

Using multiwalled CNTs/CS (MWCNTs/CS) NCs, the effect of solution $\mathrm{pH}(2-10)$ on the elimination of $\mathrm{Cu}$ (II), $\mathrm{Cd}$ (II), Zn (II), and Ni (II) was investigated. Owing to the 


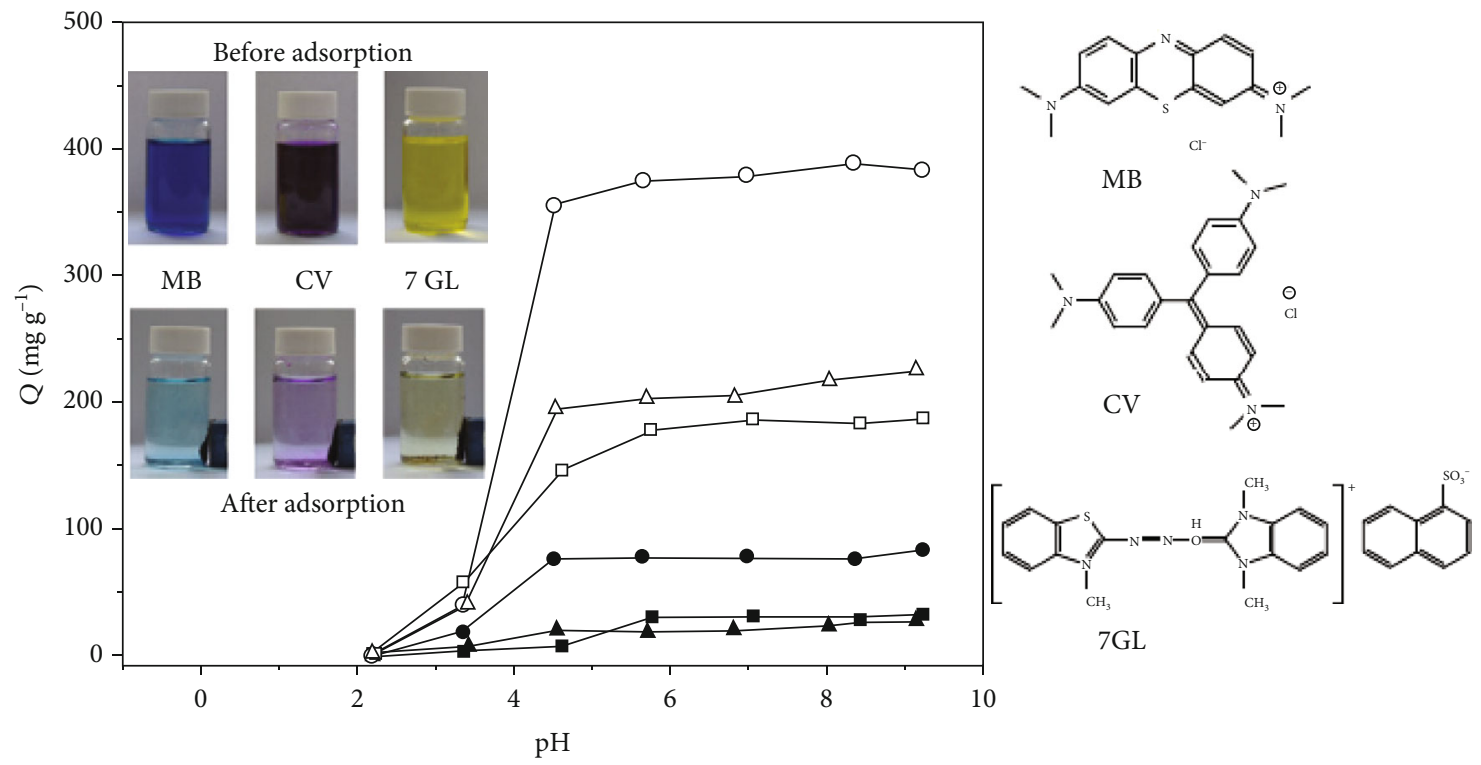

FIGURE 19: Impact of solution $\mathrm{pH}$ on the uptake of the different cationic dyes employing MCM [64].

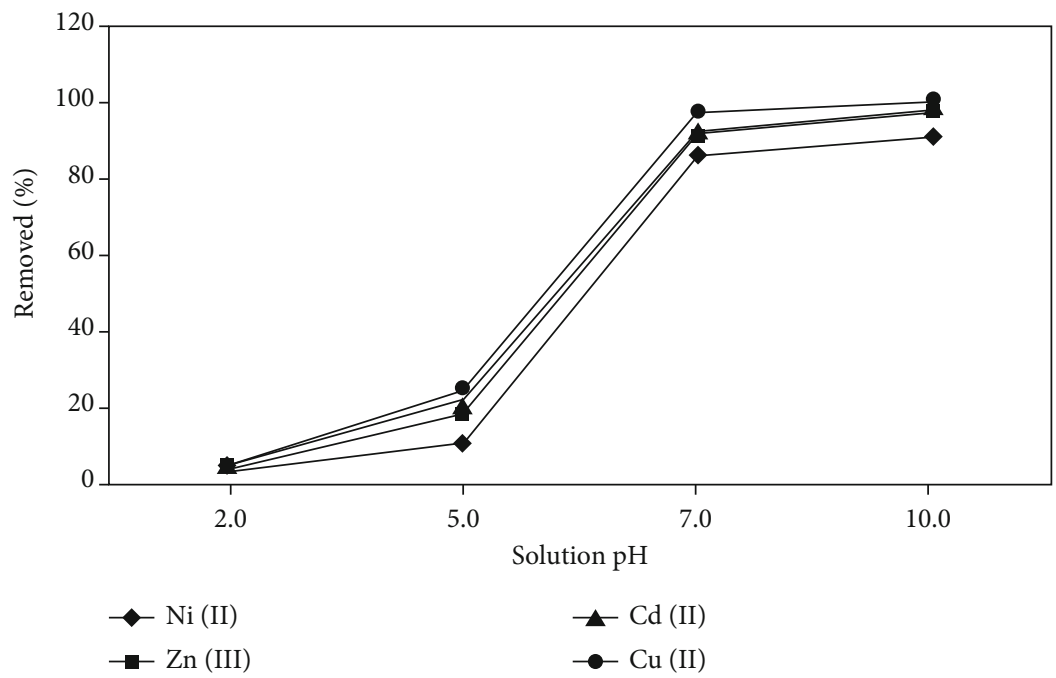

Figure 20: Impact of solution pH on the sorption of HMI to MWCNTs/CS NCs [66].

protons $\left(\mathrm{H}^{+}\right)$and the target $\mathrm{MI}$ competing for the active sites of the sorbent, confiscation of these MI was shown to be significantly low in the $\mathrm{pH}$ ranges of 2-5. Individual $\mathrm{MI}$ elimination was also enhanced at higher $\mathrm{pH}$ levels, which was attributable to MI hydrolysis (Figure 20) [66].

$\mathrm{pH}$ was observed in the study by Kazemi and Javanbakht [60] to influence the sorption of MB to the BNCs. As shown in Figure 21, it was noticed that enhanced solution $\mathrm{pH}$ led to improvement in the percentage of $\mathrm{MB}$ removed to the BNCs, with optimum removal noticed at $\mathrm{pH} 11$. At low $\mathrm{pH}$, reduced removal was due to competition between the hydronium ion and $\mathrm{MB}$ for the negative charged functional groups on the surface of the sorbent. With an increase in $\mathrm{pH}$, more ligands were freed and the negative charge generated caused the sorption of dye molecules to the surface of the sorbent. In detail, the general sorption of most HMI and dyes utilizing BNCs was observed to be in the $\mathrm{pH}$ range of 2-10 in the research publications examined, as presented in Table 3.

3.2. Impact of Time of Contact. The contact period between the NPs and various pollutants has a significant impact on the rate of removal throughout the sorption and redox processes. Various KNT models are used to investigate the effects of contact duration, and the rate of sorption of various pollutants to NMs rapidly reaches its highest point in the early stages before gradually slowing down till equilibrium is reached [67].

The sorption rate of $\mathrm{MB}$ onto various hydrogel composite was noticed to be swift during the first $15 \mathrm{~min}$ and a subsequent marginal increase in the sorption capacity with a reduced rate attaining equilibrium at about $60 \mathrm{~min}$ as 


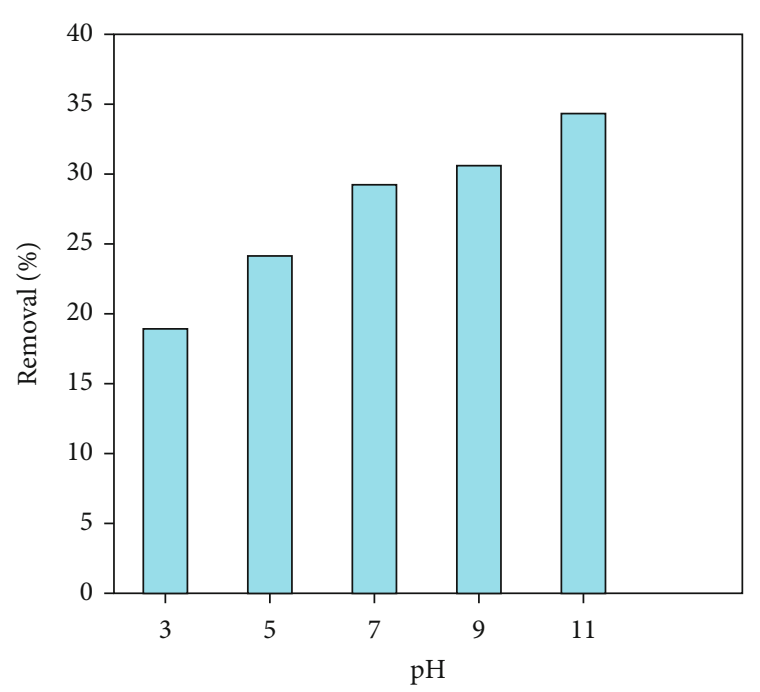

Figure 21: Impact of $\mathrm{pH}$ on the sorption of MB to BNCs [60].

depicted in Figure 22. The distinctive sorption rate at the start subsequently ascribed to the accessibility and availability of sorption sites in the hydrogels. At the start of the sorption experiments, most sorption sites were available for molecules of $\mathrm{MB}$ interaction and hence the rapid rate of sorption. With longer contact time, the sorption sites become filled and the sorption rate is slowly reduced reaching a continuous value (dynamic equilibrium). Hence, the sorptive capacities of the hydrogels were saturated after $60 \mathrm{~min}$ and the time was deemed as perfect [52].

The impact of time of contact on the sorption of $\mathrm{Pb}$ (II), $\mathrm{Ni}$ (II), and Co (II) to hydroxyapatite/CS composite was explored at an initial metal concentration of $10 \mathrm{mg} / \mathrm{L}$ at a time of contact of 5-60 min in this study. Optimum confiscation efficiency was noticed within 5 min of time of contact, and thereafter, the rate of confiscation became slow. No further change was noticed after $30 \mathrm{~min}$ for $\mathrm{Pb}$ (II) (93.5\%) and $40 \mathrm{~min}$ for $\mathrm{Ni}$ (II) (80\%) and Co (II) (88.72\%). Equilibrium was established at this point (Figure 23) [68].

The sorption of $\mathrm{Pb}$ (II) and $\mathrm{Cu}$ (II) to BNCs was rapid within the first 150 minutes due to the abundance of active sites on the sorbent surface. As a result of the reduced active sites on the sorbent surface, the sorption of these HMI became slow after $150 \mathrm{~min}$ and no further change was detected. At $150 \mathrm{~min}$, the determined sorption capacity for $\mathrm{Pb}$ (II) and $\mathrm{Cu}$ (II) was 32.65 and $25.74 \mathrm{mg} / \mathrm{g}$, respectively [69]. Swift sorption of various HMI onto BNCs was noticed within the first 30, 45, and $55 \mathrm{~min}$. An additional variation was not detected after the preliminary phase of the sorption process and with equilibrium attained subsequently. These phenomena were due to the abundant and well-supported available sites for binding of HMI and the binding sites been coated with HMI stemming in the repulsion of the HMI from the surface of the sorbent with time [63]. With an increase in the time of contact, the sorption capacities were noticed to increase. At $60 \mathrm{~min}$ of sorption process time of contact, the sorption capacities of $\mathrm{MB}$ were 87.9, 109.9, and $126.5 \mathrm{mg} / \mathrm{g}$ at $\mathrm{MB}$ initial concentrations of 100,120 , and $140 \mathrm{mg} / \mathrm{L}$. With a further increase in the time of contact above $60 \mathrm{~min}$, there was a slight change in the sorption capacity, and hence, 60 min time of contact was selected as the optimum time of contact (Figure 24) [70].

It was observed in this study that the rate of sorption for the interaction between $\mathrm{Cu}$ (II) and various BNCs at varying times of contact (0-90 min) was swift within the initial $45 \mathrm{~min}$ and with $96.4,132.3$, and $156.9 \mathrm{mg}$ of $\mathrm{Cu}$ (II) sorbed per gram of CS/clay, CS/AuNP-clay, and CS/Ag/clay. Sorption equilibrium was attained at $60 \mathrm{~min}$ with $134.5,174.1$, and $181.5 \mathrm{mg}$ of $\mathrm{Cu}$ (II) sorbed per gram of the Cs/clay, $\mathrm{CS} / \mathrm{AuNP}$-clay, and CS/Ag/clay. Owing to the quick diffusion of $\mathrm{Cu}$ (II) from the solution to the external surfaces of the various BNCs, there was a swift removal of $\mathrm{Cu}$ (II), while the slow rate of sorption was ascribed to the long diffusion range of $\mathrm{Cu}$ (II) into the CS/clay inner sphere or the exchange of ions in the CS/AuNP-clay and CS/Ag/clay inner surface (Figure 25) [71].

The removal of As (III) with varied contact times revealed rapid sorption within the first 15 minutes, with only minor increments for the remainder of the sorption period up to 60 minutes. The fast sorption that occurs during the first 30 minutes leads sorption sites to become saturated, resulting in an accumulation of As (III) on the surface of CS@iron oxide (CSIO) NCs that negates the benefit of changing contact duration further. The sorption curves were smooth and continuous, leading to saturation, demonstrating that As (III) could form a monolayer on the surface of BNCs [72].

3.3. Impact of Initial Concentration on the Sorption of HMI and Dyes to BNCs. The direct link between the initial sorbate concentration and the accessibility of the sorbing sites on the sorbent surface determines the effect of this factor on the sorption of contaminants. Aggregation of sorbent particles and poor sorption at high concentrations are two major processes that influence sorbate concentration [26].

Gupta et al. [68] reported in their study an increase in the sorption capacities of the biosorbent with an increase with the equilibrium concentration, and this increase in the equilibrium MI concentration for these various MI was in the order of $\mathrm{Pb}$ (II) $>\mathrm{Co}$ (II) $>\mathrm{Ni}$ (II) (Figure 26).

Initial metal concentrations had a significant impact on their confiscation from aqueous solutions. With an increase in the initial metal concentration from 10 to $150 \mathrm{mg} / \mathrm{L}, \mathrm{Pb}$ (II) and $\mathrm{Cu}$ (II) sorption capacities on the NCs rose from 26.62 and $27.12 \mathrm{mg} / \mathrm{g}$ to 209.49 and $195.57 \mathrm{mg} / \mathrm{g}$, respectively. When the initial As3+ concentration was increased from 5 to $100 \mathrm{mg} / \mathrm{L}$, the sorption capacity of As (III) to the NCs rose from 11.50 to $38.24 \mathrm{mg} / \mathrm{g}$. Higher initial metal ion concentrations resulted in higher mass gradient pressures between the aqueous solution and the NCs, which could act as a driving force to overcome mass transfer resistance [73]. It was observed in this study that the sorption of $\mathrm{MB}$ onto porous CLL-derived carbon/montmorillonite NCs improved with increasing initial $\mathrm{MB}$ concentration and equilibrium attained within $60 \mathrm{~min}$ after the gradual increase of the sorption capacity [70].

In the study by Kazemi and Javanbakht [60], it was reported that the sorption capacity of $\mathrm{MB}$ to the BNCs 


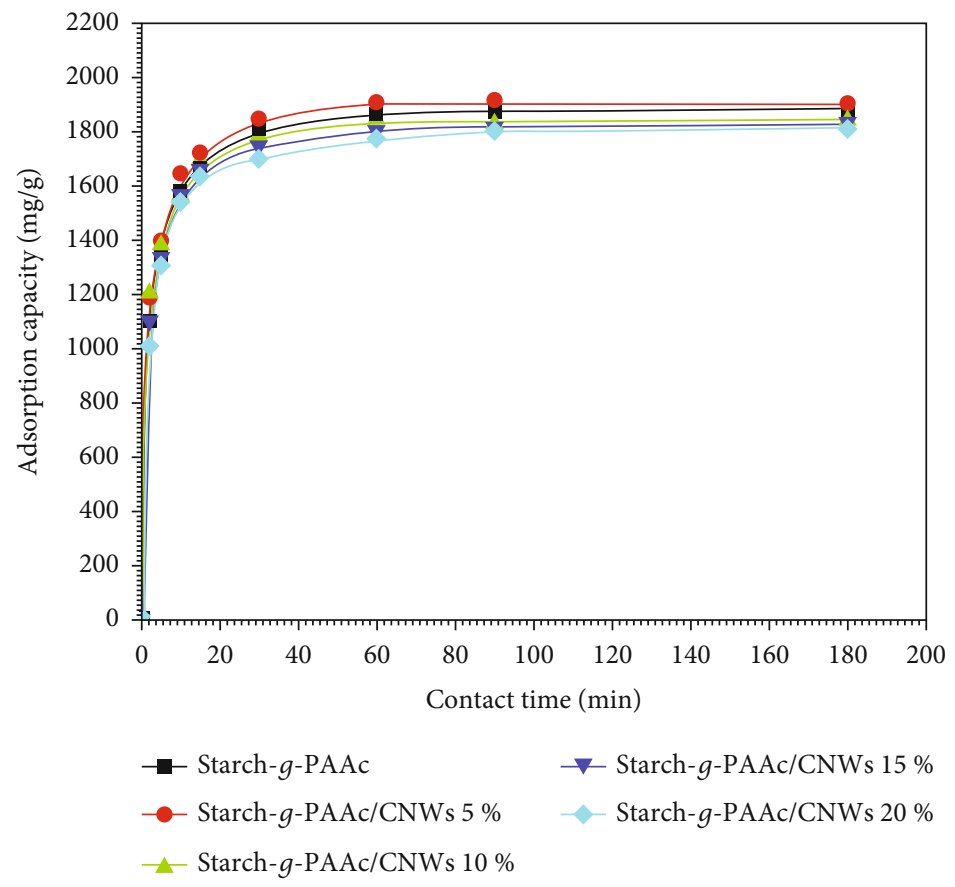

Figure 22: Impact of contact time on the sorption of MB onto various hydrogels [52].

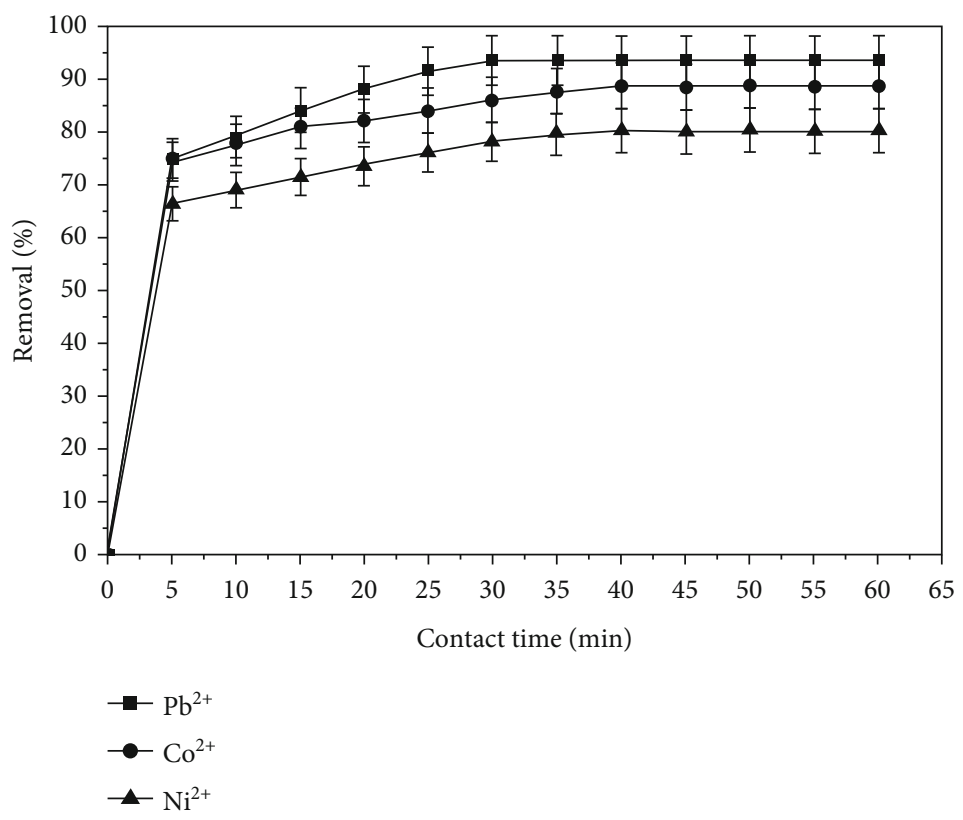

Figure 23: Impact of time of contact on $\mathrm{Ni}$ (II), $\mathrm{Pb}$ (II), and Co (II) to hydroxyapatite/CS composite [68].

increased with increasing dye concentration due to the mass transfer momentum force which is enhanced with an improved initial concentration of the solution as shown in Figure 27.

Ghorai et al. [74] report in their study a decrease in the number of dye molecules removed (99.4-81.5\%-MB and 99.1-87.7\%-MV) as the initial dye concentration was improved from 400 to 700 and 350 to $650 \mathrm{ppm}$. At low initial dye concentration, the optimum numbers of molecules of dyes were sorb on the surface of sorbent guaranteeing an elevated sorption percentage, while the high concentration of dye molecules results in a lesser option percentage due to the saturation of the active sorption sites. The determined sorption capacity at concentrations of 400 and $350 \mathrm{mg} / \mathrm{L}$ for $\mathrm{MB}$ and $\mathrm{MV}$ was 497.5 and $378.8 \mathrm{mg} / \mathrm{g}$ at $\mathrm{pH}$ values of 8 and 9 and time of contact of 20 and $15 \mathrm{~min}$. It was observed in this study that the level As (III) uptake with an increase in the initial MI concentration was influenced by 


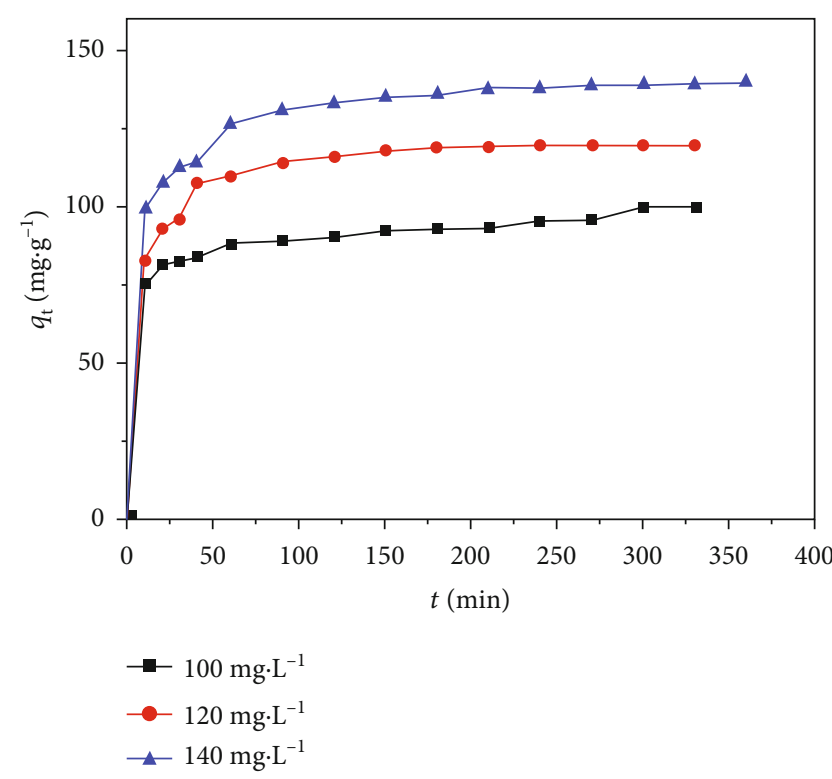

FIgURE 24: Impact of time of contact on the sorption of MB to porous CLL-derived carbon/montmorillonite NCs [70].

the driving force of the concentration gradient of the solvated MI, while the reduction in the rate of As (III) uptake with improving sorbate concentration was attributed to the sorption site saturation, as a static number of sites on the sorbent sorb of a specific number of the sorbate. Also, an increase in the net active sites is relatively more at lower levels of As (III) concentration leading to enhanced As (III) sorption, and at higher As (III) concentrations, restricted accessibility of the sorption sites contributes to the decreased sorption of As (III) (Figure 28) [72].

3.4. Impact of Sorbent Dosage. One of the key factors influencing the sorption process operational cost is the sorbent dosage [75]. The dosage of NMs has a significant impact on the pollutants' ability to be confiscated. In most publications, the appropriate dosage of the sorbent is chosen to achieve expected removal efficiency, which is important for the cost-effective deployment of NMs [67]. Because it governs the equilibrium between the sorbent and the sorbate, as well as the sorption cost for a single unit of a water-soluble solution, the amount of sorbent used in the sequestration of pollutants is extremely important. The number of contaminants sorbed tends to increase with improved sorbent dosage until equilibrium is achieved and it becomes constant. This rise in the number of contaminants sorbed with increasing sorbent dosage was owing to the enhanced quantity of active sites and also the superior surface area of the sorbent [76].

Utilizing a hydrogel sorbent dosage of $0.5-5 \mathrm{~g} / \mathrm{L}$ to treat the anion dye, it was noticed that the percentage of dye molecules removed increased from $31.2 \%$ using $0.5 \mathrm{~g} / \mathrm{L}$ of sorbent to $100 \%$ using $2.5 \mathrm{~g} / \mathrm{L}$. Increasing the sorbent dosage above $2.5 \mathrm{~g} / \mathrm{L}$, the percentage of dye removed remained constant. The improvement in the percentage of dye removed with an increase in sorbent dosage was ascribed to the superior available sorbent exchangeable sites, and the levelling of the sorption dosage was also ascribed to the complete enervation of the dye upon employing $2.5 \mathrm{~g} / \mathrm{L}$ dosage of the sorbent [54].

In this study, the impact of sorbent dosage on the confiscation of Cr (VI) to the NCs was explored at various NC dosages ranging from 0.25 to $1.5 \mathrm{~g} / \mathrm{L}$ and it was noticed the confiscation efficiency was enhanced with dosage increase and this remained unaffected when an optimum level of dosage was attained (Figure 29). This was ascribed to the fact that an increase in the mass of sorbent enhanced the sorption site availability, hence improving the $\mathrm{Cr}$ (VI) removal. The sorption capacity was also observed to be impacted negatively by the intensification of the sorbent dosage, as the sorption capacity of the sorbent is inversely proportional to the sorbent mass (Figure 29). Hence, at enhanced dosage, lesser active sorption sites are used which result in a reduced ratio of sorbed ions to the mass of sorbent and thereby lowering the sorption capacity of the sorbent [49].

In this investigation, there was a significant rise in the percentage of HMI eliminated using bionanosorbent when the sorbent dose was increased from 2 to $6 \mathrm{~g} / \mathrm{L}$, with a further shift in the removal percentage when the sorbent dose was increased above $6 \mathrm{~g} / \mathrm{L}$. This was attributed to the development of equilibrium between the HMI sorbed into the sorbent and the residue unadsorbed in the mixture due to adequate binding sites for metal complexation and increasing the sorbent dose over $6 \mathrm{~g} / \mathrm{L}[63]$.

An increase in the sorption of MI was improved from 78 to $93.5 \%$ for $\mathrm{Pb}$ (II), 71 to $86 \%$ for Co (II), and 64 to $77 \%$ for $\mathrm{Ni}$ (II) as the sorbent dosage was improved from 1 to $3 \mathrm{~g} / \mathrm{L}$ in this study. This was ascribed to enhanced surface area and accessible sorption sites at elevated sorbent dosage causing higher sequestration of various MI. A further improvement in the sorbent dosage, no significant improvement in the sequestration of these MI was noticed due to the MI concentration approaching equilibrium status between the solution phase and the solid (Figure 30) [68].

Altun and Ecevit reported an enhancement in the removal percentage of $\mathrm{Cr}(\mathrm{VI})$ ions as the nanosorbent dosage was increased, and the quantity of the substance held per unit sorbent dosage $\left(q_{e}\right)$ diminished. The increase in the percentage removal of $\mathrm{Cr}(\mathrm{VI})$ was due to the improvement in the number of active sites on the surface of the sorbent. With a further increase in the sorbent dosage, a decrease in the number of substances retained per unit sorbent mass was observed owing to the number of sorbates per sorbent particle [77].

As observed in the study by Tanzifi et al. [75], where the impact of sorbent dosage range of 0.02-0.2 $\mathrm{g}$ was tested on the confiscation of dye molecules, it was noticed that the sorption efficiency of the biosorbent improved for the dye molecule removal with an increase in the sorbent dosage (0.02-0.08 g) used and with optimum sorption efficiency of $96 \%$ attained. A subsequent increase in the sorbent dosage to $0.14 \mathrm{~g}$, a maximum sorption efficiency of $97.03 \%$ was reached as shown in Figure 31.

In the study by Wang et al., it was reported that an increase in the dosage of the BNCs resulted in a $78.3 \%$ increase in the removal of $\mathrm{Pb}$ (II) and a 63\% increase in 


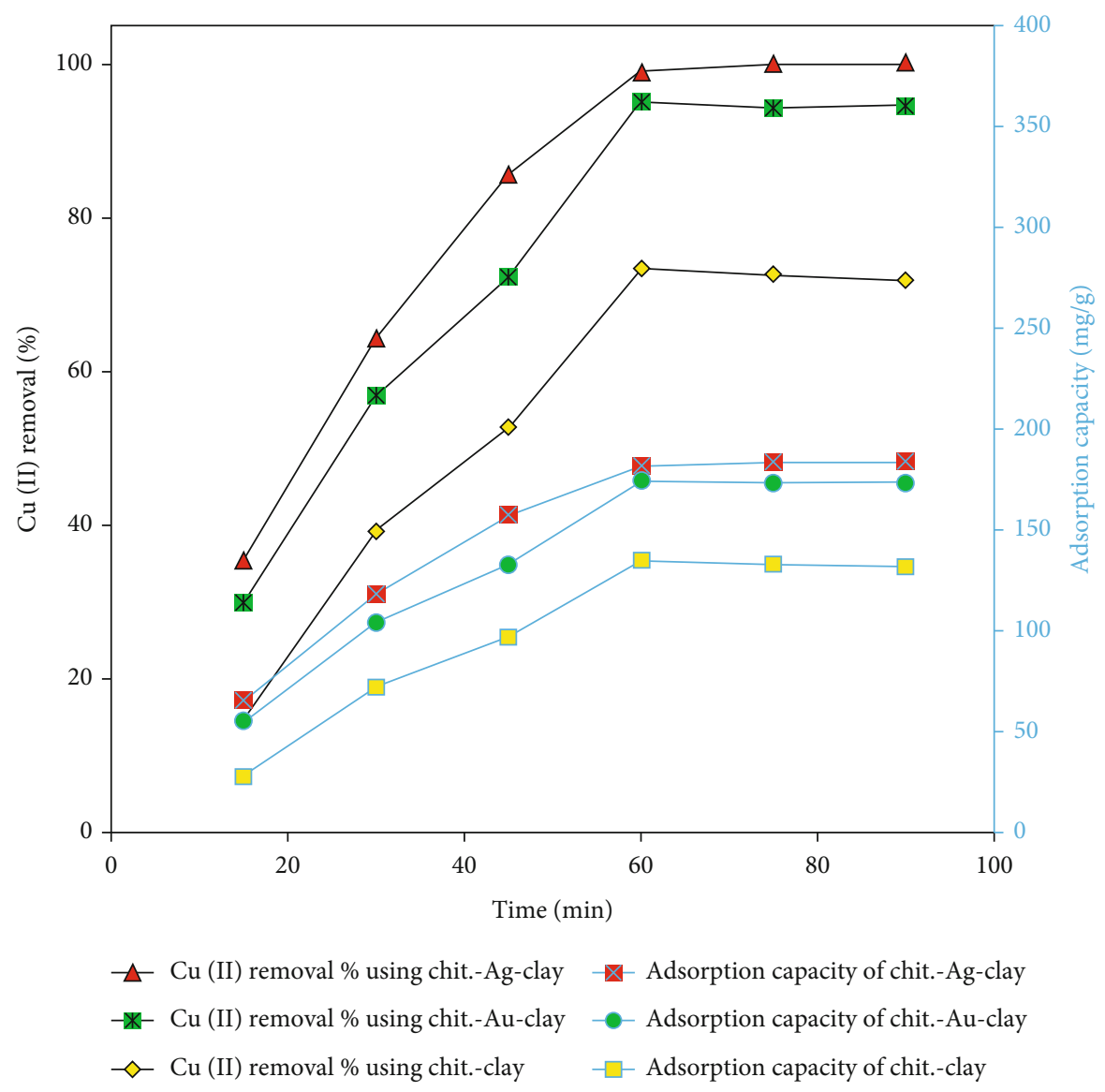

FIGURE 25: Impact of time of contact on the sorption of $\mathrm{Cu}$ (II) to various sorbents [71].

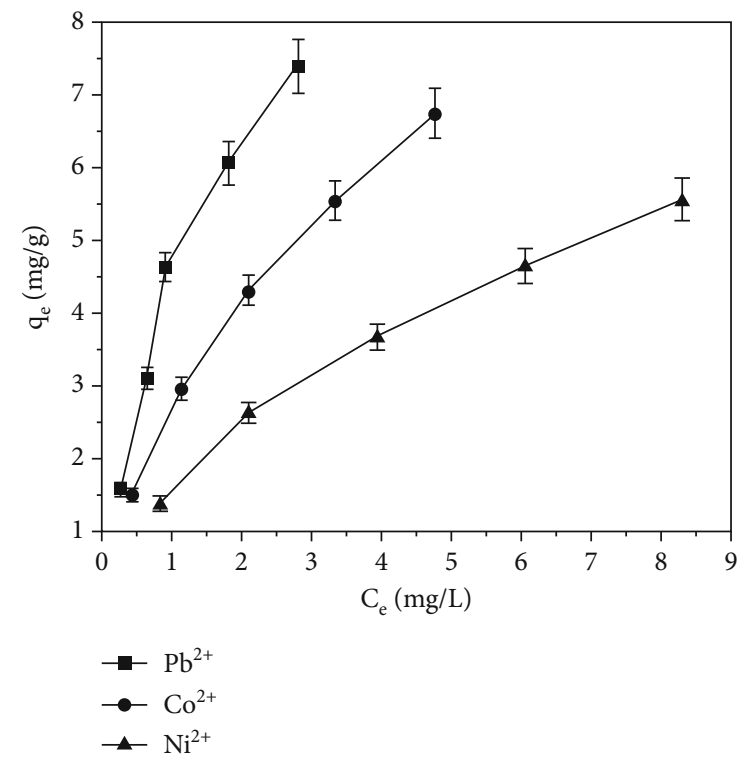

FIGURE 26: Impact of equilibrium metal ion concentration on the sorption of MI to biosorbent [68]. the removal of $\mathrm{Cu}$ (II). The availability of additional sorption sites and increased surface area with increasing BNC dosage resulted in better elimination of these MI [78].

\section{Isotherm Models, Kinetic Studies, Temperature, and Thermodynamic Studies}

4.1. Isotherm Models. In equilibrium studies of IST and understanding the KNT of the sorption process, investigations including changing contact time and initial metal concentration are important criteria [72]. The IST is the relationship between the solute equilibrium concentration in the solution and the solute equilibrium concentration in the sorbent at a constant temperature [79].

Selecting the ideal IST model for the process of sorption, the following conditions must be satisfied: (i) the IST model and the determined equilibrium data must be a good fit, (ii) the function of the IST must be thermodynamically realistic, and (iii) in ideal situations, analytical calculation of concentration from capacity and the other way around [16]. The sorption equilibrium data in most studies are assessed using the LNR, FL, Temkin, and Dubinin-Radushkevich (D-R) IST models [79].

The LNR model, which was created to describe gas-solid phase sorption processes, is frequently employed to calculate the sorption capacity of different sorbents in solutions. The 


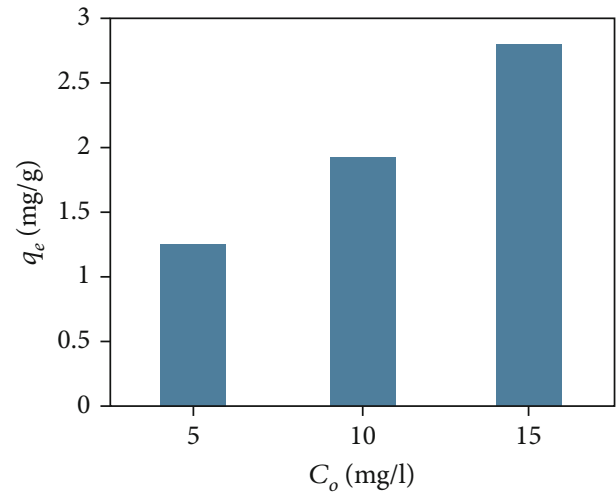

FIGURE 27: Impact of initial concentration on the sequestration of $\mathrm{MB}$ to BNCs [60].

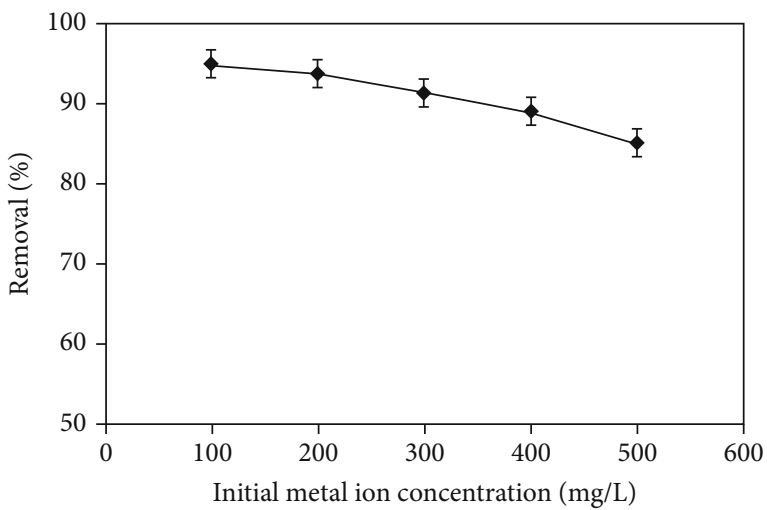

Figure 28: The impact of initial MI concentration on the sorption process [72].

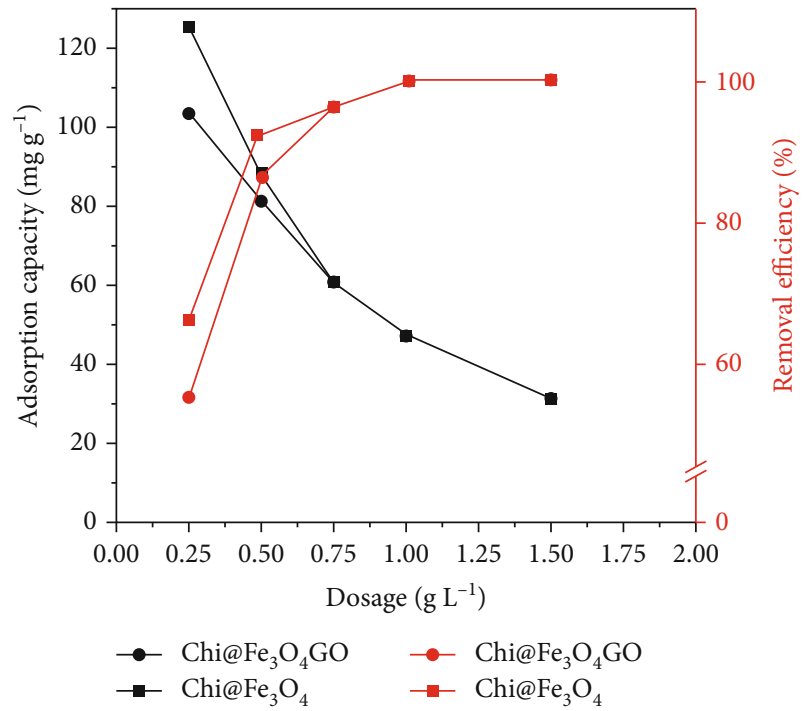

FIGURE 29: Sorbent mass impact on the sorption of Cr (VI) [49].

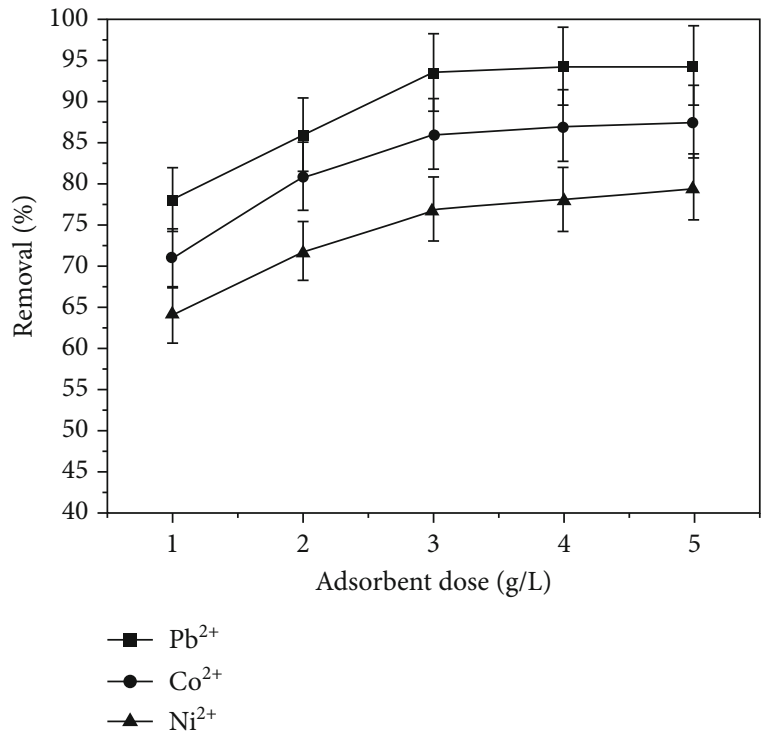

FIgURE 30: Impact of sorbent dosage on the sequestration of HMI to biosorbent [68].

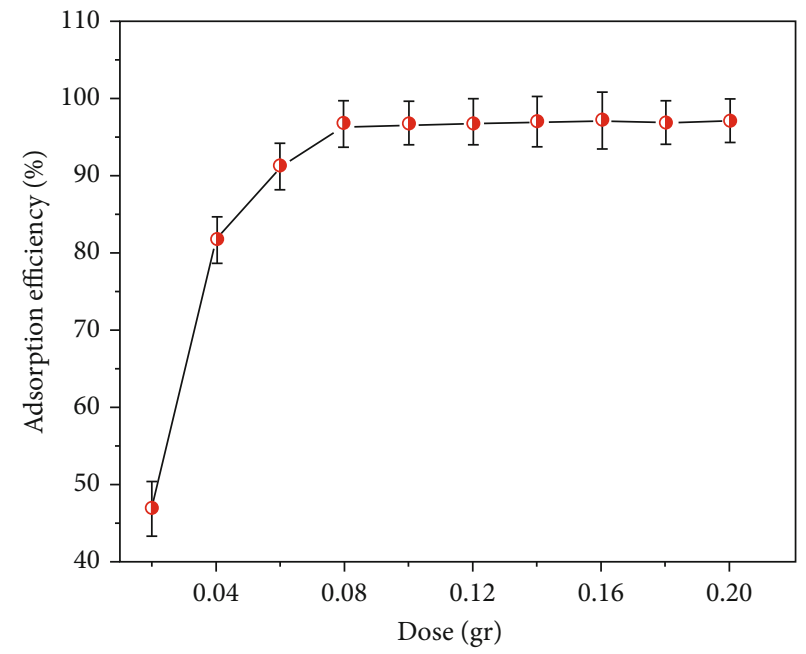

FIgURE 31: Impact of sorbent dosage on the sorption of dye molecules [75].

LNR IST is mostly written in the nonlinear and linearized form shown in the following:

$$
\begin{aligned}
q_{e} & =\frac{q_{m} K_{L} C_{e}}{K_{L} C_{e}+1}, \\
\frac{C_{e}}{q_{e}} & =\frac{1}{q_{e}} C_{e}+\frac{1}{q_{m} K_{L}},
\end{aligned}
$$

where $K_{L}(\mathrm{~L} / \mathrm{mg})$ and $q_{m}(\mathrm{mg} / \mathrm{g})$ represent the LNR IST constant and the corresponding saturation sorption capacity [80].

The earliest far-famed equation which described the sorption technique was the FL model. It is linked with an empirical equation and employed for a nonideal natural 
process that comprises of heterogeneous surface sorption [81]. On heterogeneous surfaces, the FL model has been employed to exemplify sorption processes. This IST provides useful information on surface heterogeneity, active site exponential distribution, and energetics. The FL IST is generally written in the nonlinear and linearized form shown in the following:

$$
\begin{gathered}
q_{e}=K_{F} C_{e}^{1 / n}, \\
\ln q_{m}=\frac{1}{n} \ln C_{e}+\ln K_{F},
\end{gathered}
$$

where $K_{F}(\mathrm{mg} / \mathrm{g})$ and $1 / n$ represent the constant of FL IST that is an indicator of sorption capacity and the sorption capacity measurement [82].

Sorbate-sorbate interactions are taken into account in the Temkin model. It is assumed that as the surface coverage increases, the heat of sorption of all molecules in the layer reduces linearly rather than logarithmically. The Temkin IST is generally written in the nonlinear and linearized form shown in the following:

$$
\begin{aligned}
q_{m} & =\frac{R T}{b_{T}} \ln \left(K_{T} C_{e}\right), \\
q_{m} & =\left(\frac{R T}{b_{T}}\right) \ln C_{e}+\left(\frac{R T}{b_{T}}\right) \ln K_{F},
\end{aligned}
$$

where $R\left(8.314 \mathrm{~J} \cdot \mathrm{mol}^{-1} \cdot \mathrm{K}^{-1}\right), T(\mathrm{~K}), K_{T}\left(\mathrm{~L} \cdot \mathrm{g}^{-1}\right)$, and $b_{T}$ represent the gas constant, the absolute temperature, the equilibrium binding constant of the Temkin IST, and the heat of sorption $\left(\mathrm{J} \cdot \mathrm{mol}^{-1}\right)$ relating to the Temkin IST constant. The $\mathrm{D}-\mathrm{R}$ model is a semiempirical equation in which sorption occurs on heterogeneous surfaces via a pore-filling mechanism with Gaussian energy distribution. It has been used to quantitatively describe the sorption of gases on microporous sorbents. The nonlinear and linearized forms of the D-R IST are as follows:

$$
\begin{aligned}
q_{e} & =q_{s} e^{\left(-K_{D R} \varepsilon^{2}\right)}, \\
\ln q_{e} & =\ln q_{s}-\left(K_{D R} \varepsilon^{2}\right), \\
\varepsilon & =R T \ln \left(1+\frac{1}{C_{e}}\right),
\end{aligned}
$$

where $K_{D R}\left(\mathrm{~mol}^{2} \cdot \mathrm{kJ}^{-2}\right)$ and $q_{s}(\mathrm{mg} / \mathrm{g})$ are the D-R constant and the theoretical D-R saturation capacity [80].

The least-squares approach is the most extensively used method by many studies to best fit the sorption IST. The models are tested for their ability to fit the experimental data with coefficients of determination that are near to unity in magnitude. However, it has the weakness of producing a large number of different outcomes, which radically changes the structure of error, contradicts error variance, and leads to sorption bias according to classic least-squares normalcy theories. In the case of optimum IST selection, nonlinear regression is the optimal method. In comparison to the linear methodology, the nonlinear methodology has the advantage of not changing the error distribution because all of the IST's parameters are set on the same axis. The linear regression method was utilized to get the best appropriate IST [26]. Table 3 summarizes the best IST models for the confiscation of metal and dye using several BNCs, indicating that the LNR and FL models described the sorption process of various contaminants to BNCs and that these models appear to be the most precise representation of the sorption process.

4.2. Kinetic Studies. Various sorption processes occur via a multistep mechanism which includes the dispersion across the liquid film bordering the particle of solid (external mass transfer coefficient controls this process), the dispersion within the individual particles assuming a pore diffusion mechanism (intraparticle diffusion), and the physical and chemical sorption at a sorption site. The transient behaviour of a batch sorption process at various temperatures and initial concentrations of the adsorbate is studied using the Lagergren first-order and the PSO models [83].

KNT research was generally employed by several scientists to study the mechanism by which the sorption process takes place. Preexisting models are applied in most sorption KNT research, and this acts as a guide in demonstrating the mechanism of sorption. Among the widely employed models to describe the sorption process are the pseudofirst-order (PFO), PSO, and particle diffusion models. An extensive range of standard models is existing to rationalize the sorption at various conditions, and the most appropriate is chosen for the given experimental conditions [16].

Some models of sorption IST and KNT are briefly introduced in this review to better demonstrate the sorption behaviours of the following biomaterials. The determination of KNT is critical for the design of sorption systems as well as the reaction rate control step during the chemical reaction. The number of sorbates adsorbed on the sorbents $\left(q_{t}\right)$ and the contact time is described by sorption KNT $(t)$. The PFO and PSO KNT models are extensively applied in sorption KNT. The sorption of liquid-solid phase systems based on the sorption capacity is defined by the PFO model, whereas the PSO model is based on the sorption capacity of the solid phases [6]. The nonlinearized and linearized forms of the PFO and PSO models are generally expressed as follows:

$$
\begin{aligned}
\frac{d q_{t}}{d t} & =K\left(q_{e}-q_{t}\right), \\
\log \left(q_{e}-q_{t}\right) & =\log q_{e}-\frac{K_{1}}{2.303} t \\
\frac{d q_{t}}{d t} & =K_{2}\left(q_{e}-q_{t}\right)^{2} \\
\frac{t}{q_{t}} & =\frac{1}{K_{2} q_{e}^{2}}+\frac{1}{q_{e}} t
\end{aligned}
$$

where $q_{e}(\mathrm{mg} / \mathrm{g}), q_{t}(\mathrm{mg} / \mathrm{g}), K$ and $K_{1}$, and $K_{2}$ indicate the equilibrium sorption capacity, the sorption capacity at a contact time $t, \mathrm{PFO}$ rate constants, and PSO rate constant [6]. 
The sorption mechanism enhanced by NPs is quick in terms of KNT. As a result, using NPs in the wastewater treatment process opens up a new avenue for NPs use [19]. Table 3 shows the summary of some of the best reported suited KNT models for metal and dye removal using various BNCs, which indicated that the sorption process of BNCs was characteristically followed by the PSO model and this model appears to be the most accurate approximation of the sorption process attributable to chemisorption processes, which are indicative of a rate-limiting phase in the sorption step.

4.3. Temperature and Thermodynamic Studies. The basic idea of TMDs was established based on the premise that entropy change is the driving force in a system that is kept isolated, where energy cannot be obtained or lost to the surroundings. Both energy and entropy considerations must be considered in environmental engineering practice to determine which processes will occur spontaneously. The change in entropy $\left(\Delta s^{\circ}\right)$ and change in enthalpy $\left(\Delta E^{\circ}\right)$ is linked with the process using

$$
\ln K=\frac{-\Delta H^{\circ}}{R T}+\frac{\Delta S^{\circ}}{R}
$$

The key measure of spontaneity is the change in Gibbs free energy $\left(\Delta G^{\circ}\right)$, and at aiven temperature, reactions happen spontaneously if $\Delta G^{\circ}$ is a negative quantity. Considering the sorption equilibrium constant $K$, the $\Delta G^{\circ}$ of the sorption reaction is given by

$$
\Delta G^{\circ}=-R T \ln K,
$$

where $K$ is defined by equation (8). $\Delta H^{\circ}$ and $\Delta S^{\circ}$ are determined from the slope and intercept of the plot of $\ln$ $K$ against $1 / T$ [63].

$$
K=\frac{q_{e}}{C_{e}}
$$

In this study, experiments were carried out at 298, 303, and $313 \mathrm{~K}$ to assess the influence of temperature on HMI sorption by the EDTA-MCS/GO NCs while maintaining all other parameter constant, such as sorbate and sorbent concentrations, $\mathrm{pH}$, and agitation speed. With an initial metal concentration of $50 \mathrm{ppm}$, the $\mathrm{Pb}$ (II) and $\mathrm{Cu}$ (II) sorption capacities declined dramatically from 134.82 and $95.91 \mathrm{mg} / \mathrm{g}$ to 119.91 and $60.6 \mathrm{mg} / \mathrm{g}$, respectively, as the temperature rose from 298 to $313 \mathrm{~K}$. In contrast, As (III) sorption capacity improved slightly from 11.50 to $11.96 \mathrm{mg} / \mathrm{g}$ as the temperature rose from 298 to $313 \mathrm{~K}$. $\mathrm{Pb}$ (II) and $\mathrm{Cu}$ (II) sorption on the EDTA-MCS/GO NCs were shown to be exothermic processes, while As (III) sorption was shown to be mildly endothermic. As a result, the temperature had a substantial impact on metal ion sorption by the EDTAMCS/GO NCs [73].

The effect of solution temperature on MWCNT/CS NC elimination of $\mathrm{Cu}$ (II), Cd (II), Zn (II), and $\mathrm{Ni}$ (II) from the aqueous medium was investigated, and the findings are

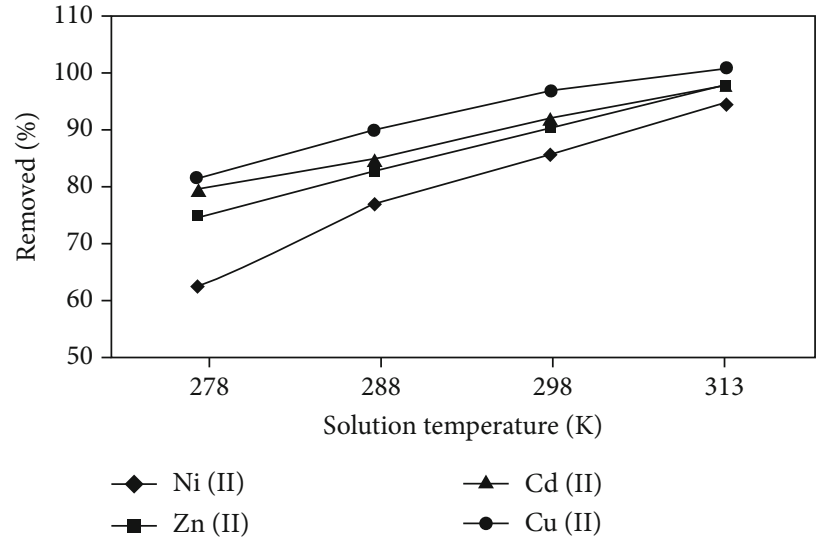

FIGURE 32: Impact of temperature on the sorption of MI to MWCNTs/CS [66].

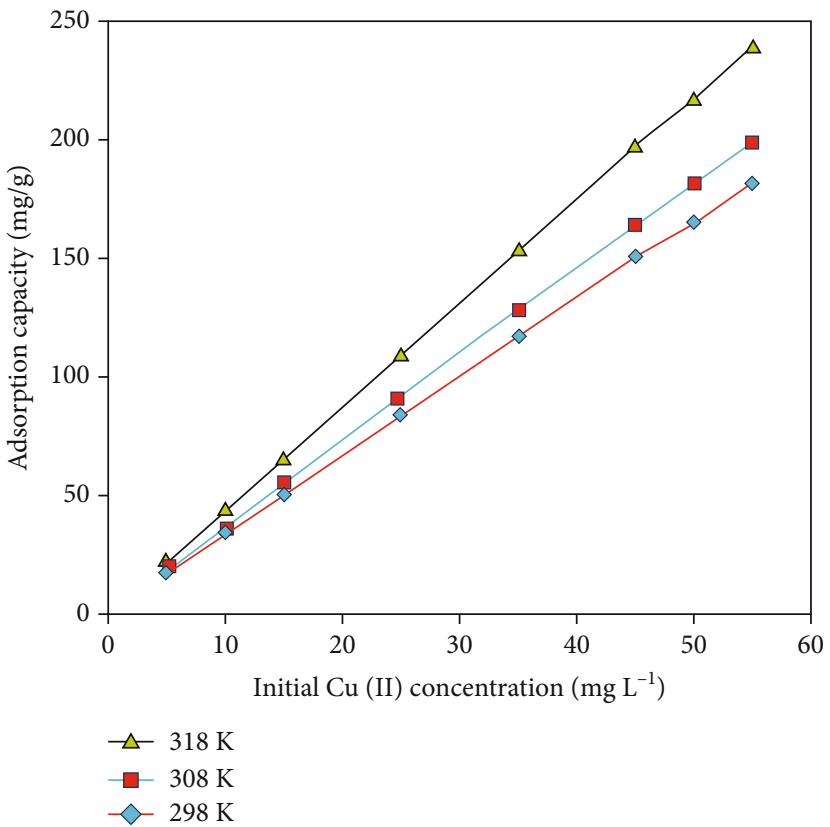

FIGURE 33: Impact of varying temperature on the varying initial $\mathrm{Cu}$ (II) concentration to CS/Ag/clay composite [71].

given in Figure 32. The four distinct solution temperatures chosen to represent aqueous environment temperatures were $5.0^{\circ} \mathrm{C}(278 \mathrm{~K}), 15.0^{\circ} \mathrm{C}(288 \mathrm{~K}), 25.0^{\circ} \mathrm{C}(298 \mathrm{~K})$, and $40.0^{\circ} \mathrm{C}(313 \mathrm{~K})$. It was observed that increasing the temperature of the solution increased the percentage removal of MI from the aqueous medium, showing that the sorption process was endothermic [66].

The impact of varying temperatures on $\mathrm{Cu}$ (II) using CS/ $\mathrm{Ag} /$ clay BNCs was reported in this study. It was noticed the efficiency of $\mathrm{Cu}$ (II) removed (sorption capacity) to the BNCs was enhanced with improvement in the temperature applied until equilibrium attained (Figure 33). The determined sorption capacity was $239 \mathrm{mg} / \mathrm{g}$ at $318 \mathrm{~K}$ at a $\mathrm{pH}$ of 7 for $60 \mathrm{~min}$ employing a dosage of sorbent of $0.3 \mathrm{~g} / \mathrm{L}$ and a stirring speed of $160 \mathrm{rpm}$ [71]. 


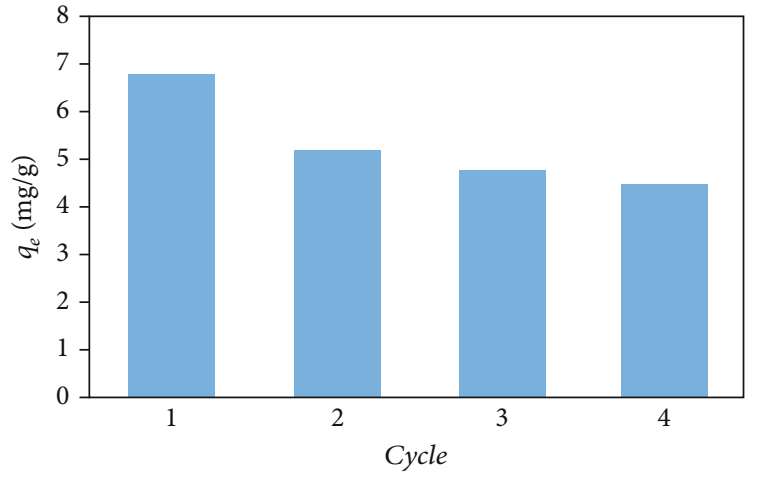

FiguRE 34: Regeneration of BNCs for MB removal [60].

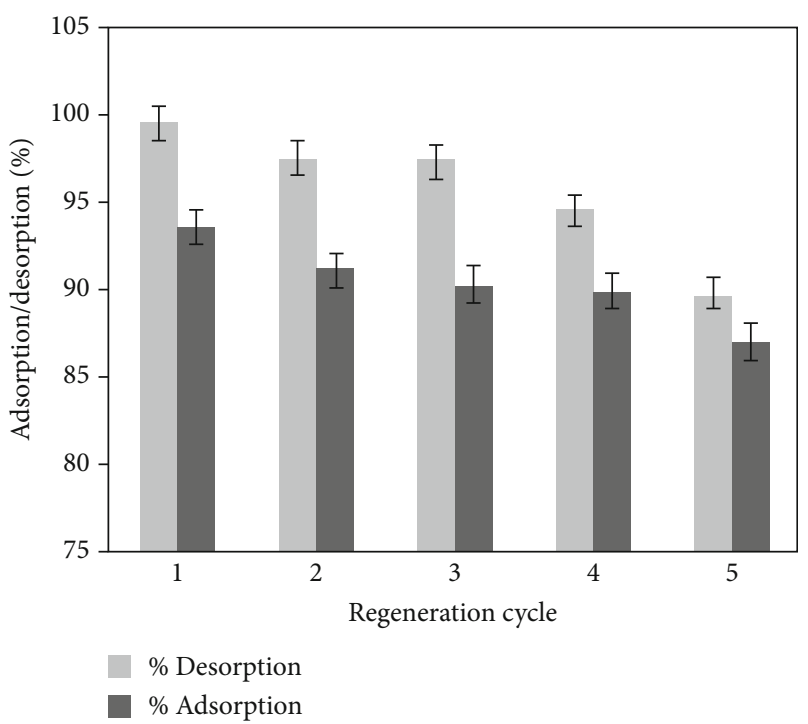

Figure 35: The cycle of sorbent regeneration for MI removal [72].

It was noticed that the efficiency of removal of brilliant black (BB) dye using CS-lignin-titania NCs was enhanced with increasing initial dye concentration and attaining equilibrium of $88 \%$ using $50 \mathrm{mg} / \mathrm{L}$ of the dye solution. An increase in the efficiency of removal of $\mathrm{BB}$ with intensifying concentration was attributed to the electrostatic interaction between the free dye molecules, and the sorbent and increase in the mass of $\mathrm{BB}$ dyes transfer to the sorbent active sites [84]. It was noticed in this study that the sorption process between the sorbate and the sorbent was endothermic and spontaneous. Intensification in the interaction temperature led to a reduction in $\Delta G^{\circ}$ indicative of suitable sorption of permanganate at elevated temperatures, while a positive value of $\Delta S^{\circ}$ indicated the enhanced possibility of the collision between the sites on the sorbent surface and the sorbate ions [82].

\section{Reusability of BNCs for HMI and Dye Confiscation}

Any sorbent material used in experimental applications should maintain its stability after many sorption remedia-

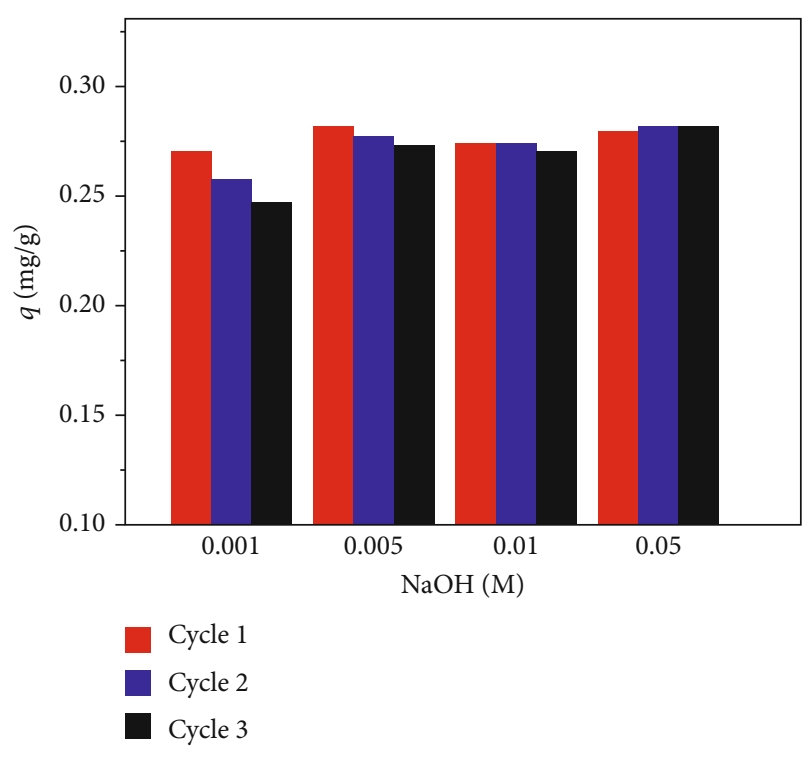

FIGURE 36: Sorption-desorption of Fe@CS for As (III) removal [116].

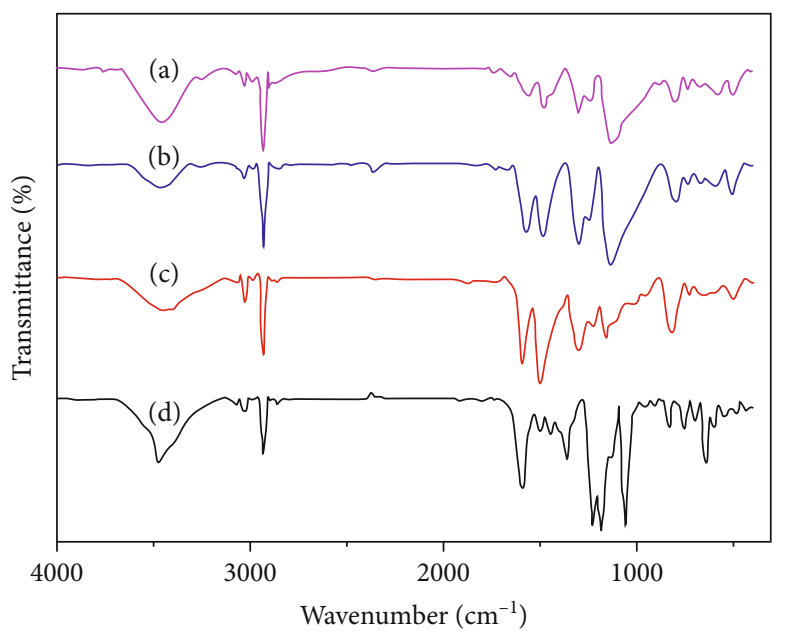

Figure 37: Spectra of PAN/CMC/TiO2 NCs (a) before sorption, (b) after sorption, (c) after desorption, and (d) CR dye [75].

tions [111]. A sorbent's sorption and desorption properties are critical for its possible application. To be economically viable and efficient, a sorbent should have high sorption capacity as well as outstanding desorption characteristics [74].

In this study, the BNCs employed for the MB dye were regenerated and reutilized for four cycles. The result in Figure 34 shows that the BNC sorbent was not reusable and showed the ability to sorb dye molecules after successive sorption cycles [60].

To explain the sorption mechanism, desorption experiments were carried out at various $\mathrm{pH}$ values of 2,7 , and 10 and the highest percentage of dyes desorb was obtained at $\mathrm{pH} 2$, with a percentage of 95.7 and 49.5 desorb for $\mathrm{MB}$ and MV. At the fourth cycle of desorption at $\mathrm{pH} 2,85.6$ and $83.5 \%$ of $\mathrm{MB}$ and MV were desorbed; hence, the BNCs depicted an efficient recycling ability for dye treatment [74]. 


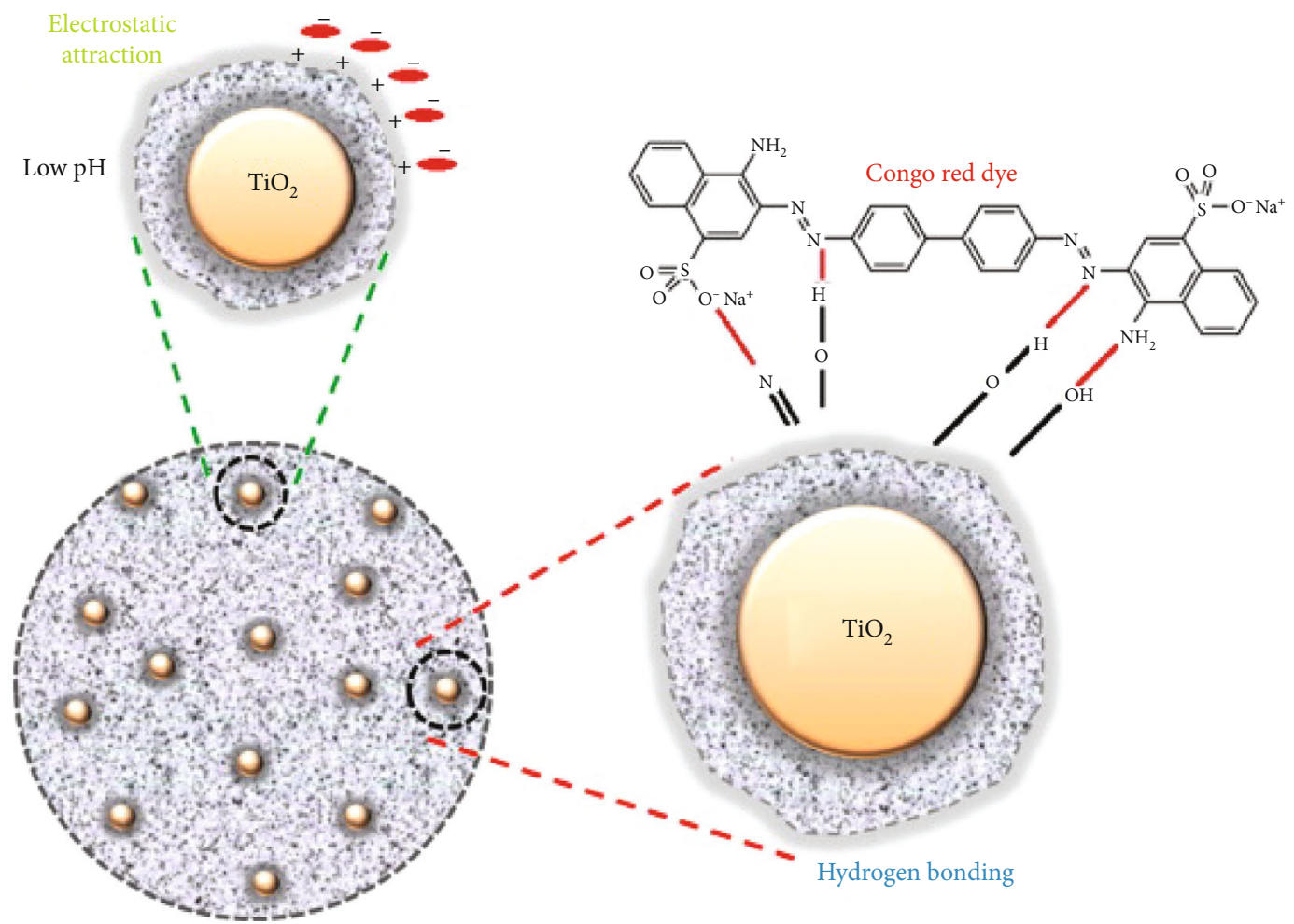

FIgURE 38: Mechanism of CR sorption to NCs [75].

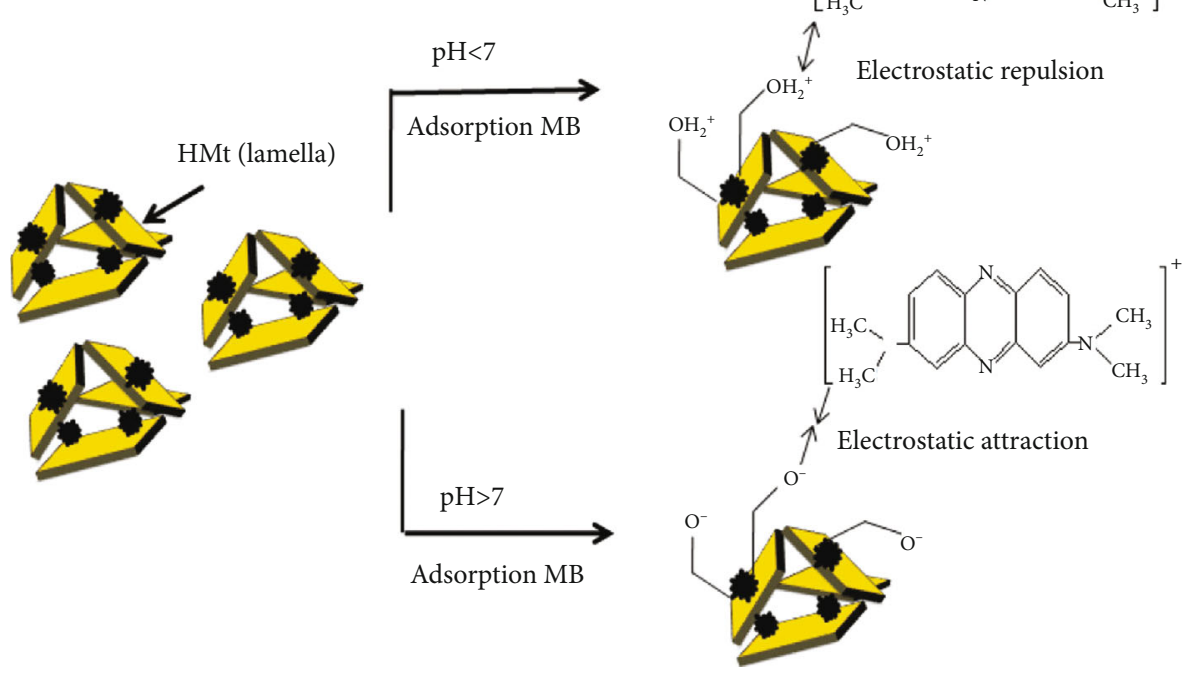<smiles>Cc1ccc2nc3ccc(N(C)C)cc3nc2c1</smiles>

FIGURE 39: Illustration of MB sorption mechanism to the BNCs [70].

High removal capacity was observed in this study notwithstanding five cycles of continual sorption and desorption (Figure 35). 87.00\% sorption capacity was shown by the CSIO at the fifth cycle, which was relative to their original capacity, and a marginal loss of $13.00 \%$ sorptive potential was noticed due to acid-base treatment of the NCs during the process of regeneration [72].

In this work, $0.05 \mathrm{M} \mathrm{NaOH}$ was employed to regenerate iron-doped electrospun CS nanofiber mat (Fe@Cs) for As (III) sorption and desorption cycles. More than $90.00 \%$ of 


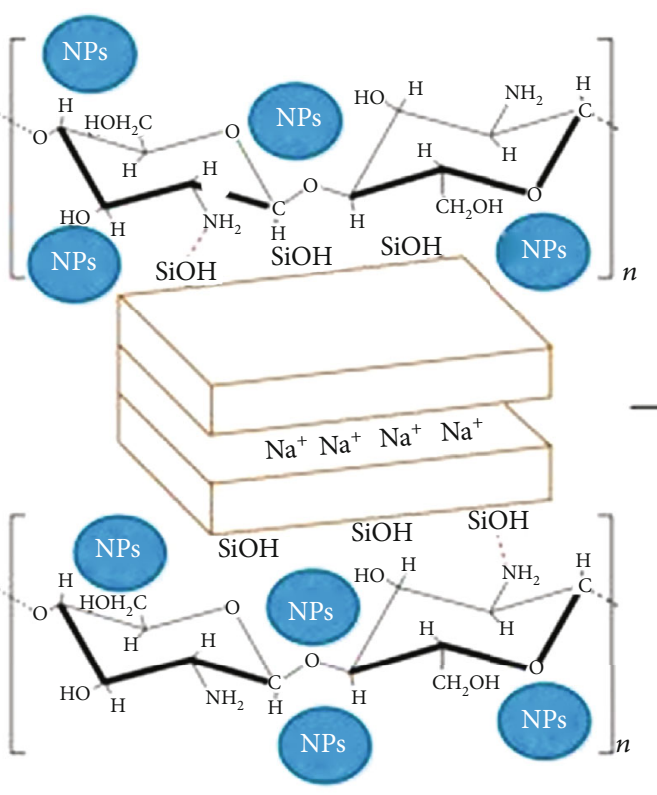

NPs : Ag NPs or Au NPs

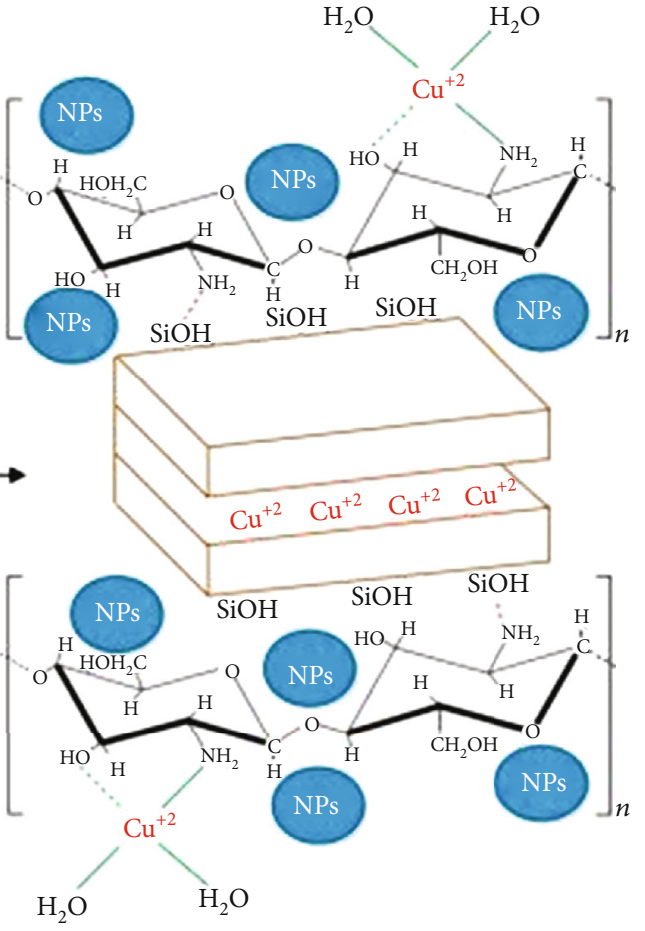

FIgure 40: Mechanism of Cu (II) sorption to CS/clay NCs [71].

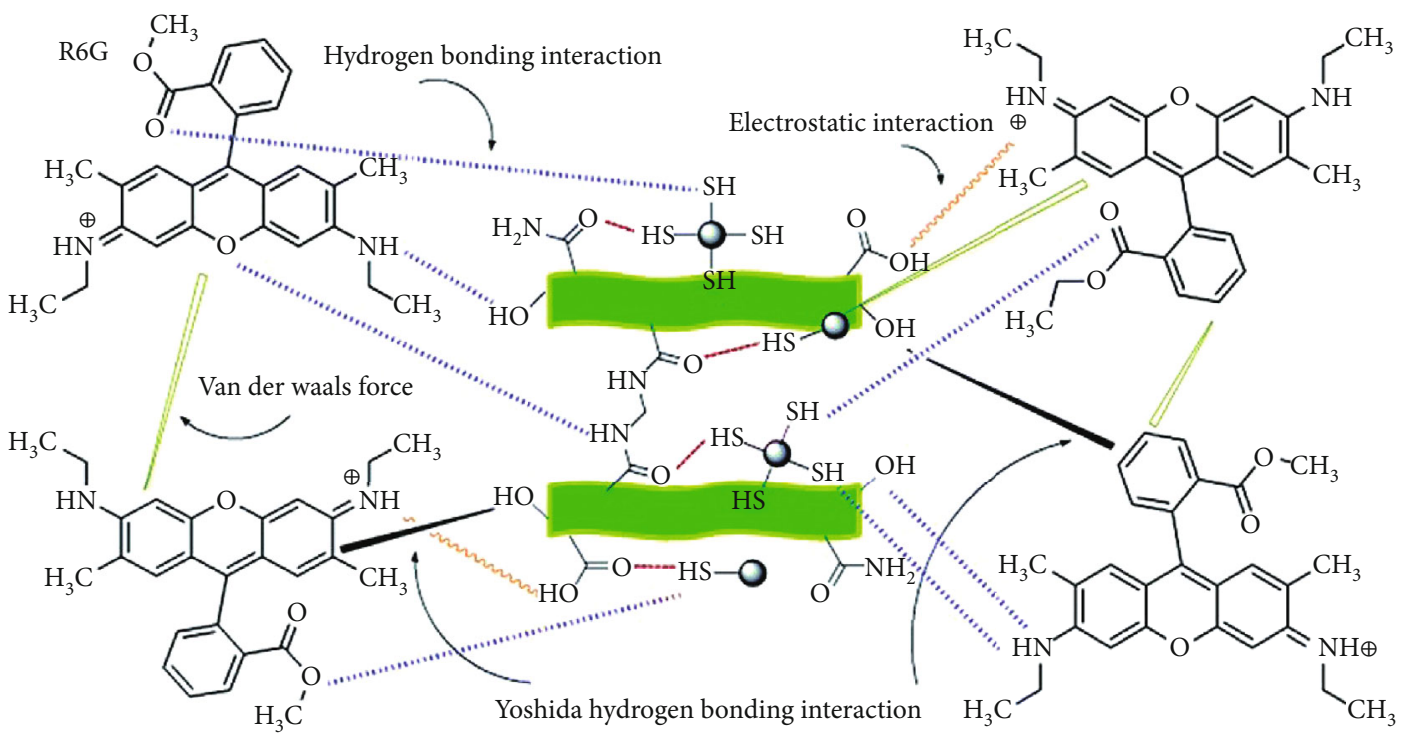

FIGURE 41: Mechanism of sorption of R-6G to BNC hydrogel [87].

the MI was desorbed from the sorbent surface for individual three cycles (Figure 36) [116].

\section{Mechanism of HM and Dye Sorption to BNCs}

The sorption IST are crucial for the sorption mechanism route optimization, the surface properties and sorbent capacity expression, and the constructive design of the sorption as they describe the sorbent material interrelation with the contaminants. Knowledge of the sorption mechanism, surface features, and the degree of sorbent affinity is provided by the physicochemical factors complemented by the basic TMD theories [117]. The sorbent sorption efficiency can be evaluated employing different parameters such as the number of active sites on the surface of the sorbent, sorbate functional and structural behaviour, sorbent surface characteristics, the process of mass transport, process of pollutant diffusion, and sorbate and sorbent interactions [87]. 


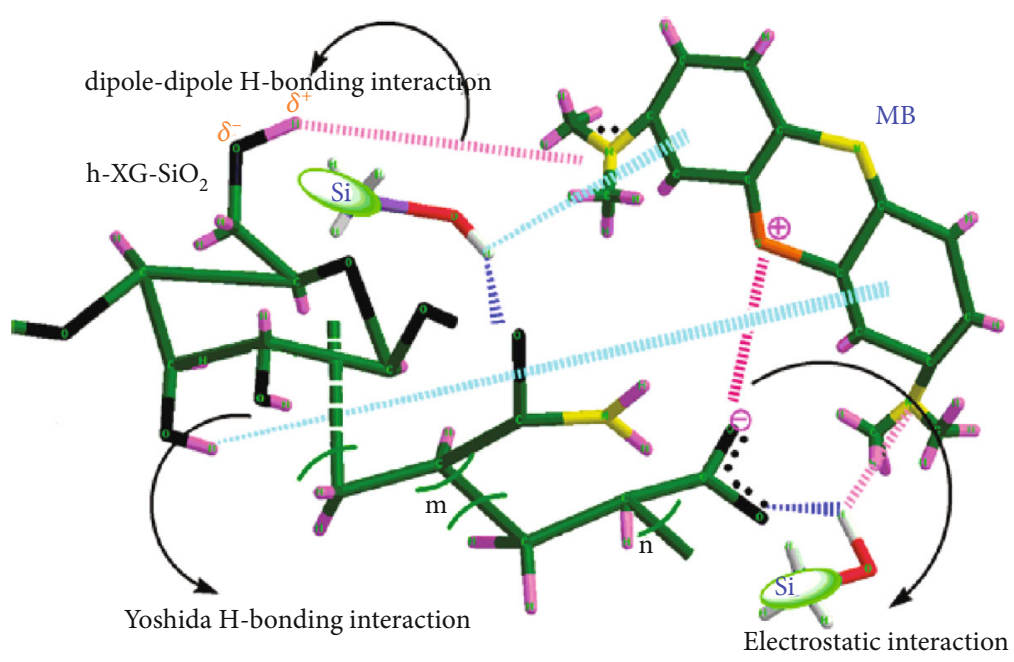

(a)

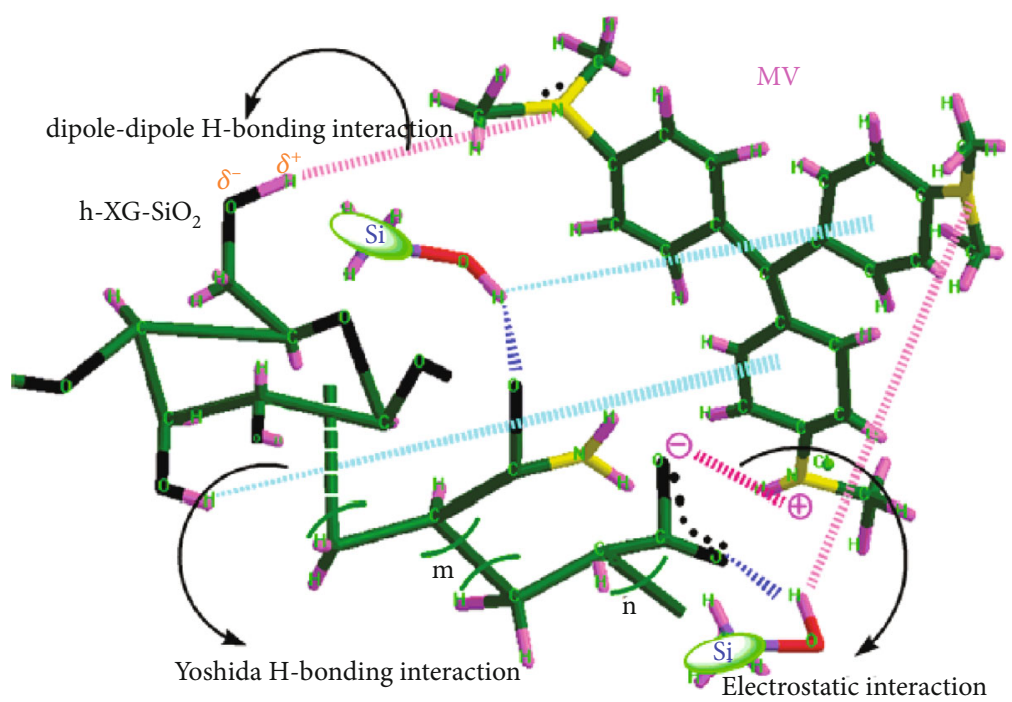

(b)

Figure 42: Mechanism of sorption of (a) MB and (b) MV [74].

To determine the mechanism of $\mathrm{CR}$ sorption to the BNCs, the FTIR spectra of the NCs before and after CR sorption were explored in this study. Hydrogen bonding was observed to exist as hydroxyl, carboxyl, imine, and amine functional groups of the NCs and CR dye functional groups. It was also noticed that the FTIR peaks of real polyaniline (PAN) marginally shifted in the composite, indicative of the effect of $\mathrm{TiO}_{2}$ and carboxymethyl CLL (CMC). Peaks at wavenumbers of 1471 and $1543 \mathrm{~cm}^{-1}$ attributed to $\mathrm{C}=\mathrm{C}$ benzenoid and $\mathrm{C}=\mathrm{C}$ quinonoid bonds were noticed to shift in the composite to 1485 and $1570 \mathrm{~cm}^{-1}$ after sorption of molecules of dyes with PAN. Also, it was observed that the FTIR peaks at wavenumbers of $1647 \mathrm{~cm}^{-1}$ in CMC shift to $1658 \mathrm{~cm}^{-1}$ indicative of dye bonding with this group. There was also a minor shift in the peak due to the hydroxyl group relating to water in the sample and $\mathrm{CMC}$ indicative of bonding of dye molecules with the $\mathrm{OH}$ group of CMCs. The FTIR spectrum of the sorbent in Figure 37 after sorption shows evidence of the presence of the sorbate in the struc- ture of the sorbent. Therefore, molecules of dye made a sturdy bond with the sorbent in chemical sorption, and at low $\mathrm{pH}$, the molecules of dye sorbed onto the surface of the sorbent owing to the electrostatic force between negatively charged pigment and positively charged sorbent surface. Figure 38 depicts the mechanism of CR sorption onto NCs [75].

In this study, the major mechanism of sorption of $\mathrm{MB}$ was attributed to the electrostatic interaction according to the $\mathrm{pH}$ studies. At lower $\mathrm{pH}$, there were more protons available, and the amorphous carbon's surface became $\mathrm{C}-\mathrm{OH}_{2}{ }^{+}$. As a result, there was ionic repulsion between the positively charged surface and positively charged $\mathrm{MB}$ molecules, reducing the sorption ability. The surface $\mathrm{C}-\mathrm{OH}_{2}{ }^{+}$was converted to $\mathrm{C}-\mathrm{OH}$ as the $\mathrm{pH}$ intensified, and the sorption ability improved without ionic repulsion. When the $\mathrm{pH}$ rises over 8 , the surface $\mathrm{C}-\mathrm{OH}$ bonds turn to $\mathrm{C}^{-} \mathrm{O}^{-}$, and the electrostatic interaction between positively charged dye ions and negatively charged sorption sites causes an enhanced $\mathrm{MB}$ 
dye sorption. This result showed that, while multipores were prominent in the sorption of $\mathrm{MB}$ to sorbent, the sorption ability could be increased by inducing the formation of micropores. The mechanism of MB sorption to the bionanosorbent is depicted in Figure 39 [70].

In this study, it was reported that extra active sites were provided by the CS-clay NCs for the confiscation of MI comprising of the cation exchange sites and extra surface area. The functional groups in CS were observed to coordinate with $\mathrm{Cu}$ (II) ion, with the MI acting as a Lewis acid receiving electron sets from the hydroxyl and amino groups of CS (Lewis base). As noticed in Figure 40, some of the $\mathrm{Cu}$ (II) ions also usurp clay's interlayer cations and this cooperative effect significantly improves the sorption performance of the CS-clay sorbent [71].

In the sorption of R-6G to the BNC hydrogel, the cationic dye was swiftly sorbed to the negative charge BNC surface due to van der Waals forces, hydrogen bonding, and electrostatic interactions. From the FTIR result, the characteristic peaks of the dye-loaded BNC hydrogel were broadened and shifted marginally when compared to the pure BNCs. The $-\mathrm{OH} /-\mathrm{NH}$ stretching vibration, $\mathrm{COO}^{-}$stretching vibration, amide stretching vibration, $\mathrm{COO}^{-}$asymmetric stretching vibration, -NH in-plane bending vibration, and amide -C-N stretching vibration were observed to shift marginally from 3349 to 3362,1710 to 1716,1658 to 1651,1565 to 1590 , 1455 to 1456 , and 1232 to $1218 \mathrm{~cm}^{-1}$. A new peak was noticed at $1153 \mathrm{~cm}^{-1}$ after sorption which was attributed to -COC- of $\mathrm{R}-6 \mathrm{G}$ and indicative of the bonding of dye molecules to the BNC hydrogel. These changes observed signify electrostatic and hydrogen bonding interaction between the functional groups of the sorbate and sorbent as shown in Figure 41 [87].

The mechanism of sorption of dye molecules to the BNCs from FTIR result was due to specific electrostatic and $\mathrm{H}-$ bonding interactions between the cationic dye active sites and the silanol- $\mathrm{OH}$ and polysaccharide- $\mathrm{OH}$ groups, amide carbonyl groups, and COO groups of the BNCs as depicted in Figure 42. The sorption mechanism can also be elucidated by the successive process of dye diffusion consisting of bulk diffusion, intraparticle diffusion, and surface sorption [74].

In this study, surface complexation between the surface functional groups $\left(-\mathrm{NH}_{2},-\mathrm{OH}\right.$, and $\left.-\mathrm{OH}_{2}\right)$ of the CSGO and the $\mathrm{H}_{3} \mathrm{AsO}_{3}{ }^{0}$ was reported to be the dominant mechanism of sorption of As (III) to CSGO NCs from the impact of $\mathrm{pH}$, $\mathrm{pH}_{\text {PZC }}$, and FTIR study. A characteristic example of outersphere complex structure between $\mathrm{H}_{3} \mathrm{AsO}_{3}{ }^{0}$ and $\mathrm{OH}$ group at the surface of CSGO and a characteristic monodentate bond mechanism is symbolized by equations (9) and (10) [114].

$$
\begin{aligned}
& \mathrm{OH}+\mathrm{H}_{3} \mathrm{AsO}_{3}{ }^{0} \longrightarrow \mathrm{O}-\mathrm{H}-\mathrm{O}-\mathrm{As}<{ }_{\mathrm{OH}}^{\mathrm{OH}} \\
& \mathrm{OH}+\mathrm{H}_{3} \mathrm{AsO}_{3}{ }^{0} \longrightarrow \mathrm{O}-\mathrm{As}<{ }_{\mathrm{OH}}^{\mathrm{OH}}+\mathrm{H}_{2} \mathrm{O}
\end{aligned}
$$

\section{Conclusion and Future Potential}

The production of environmentally friendly sorbents which are considered as one of the promising techniques in water remediation has been made possible by BNC trends. Reportedly, various BP NCs with sorption capacities comparable to or greater than viable sorbents have been created over the last decades. This review paves the way for the novel bionanosorbents developed for the sequestration of environmental contaminants. The sorption of most contaminants was noticed to be dependent on the $\mathrm{pH}$, sorbent dosage, and initial contaminant concentration, with most contaminants' sorption, noticed within the $\mathrm{pH}$ range of 2-10. The sorption process of HMs and dyes to various BNCs was superlatively depicted utilizing the LNR and FL as well as the PSO models, suggestive of the sorption process of a monolayer and multilayer as well as the chemisorption process and the ratelimiting stage in surface sorption. The use of these NCs as sorbents in industrial and domestic environments is currently under investigation, and the majority of studies carried out are with synthetically polluted water achieved by the dissolution of contaminants in deionized water. To conduct full-scale researches, the structural stability of BNCs and their ecological noxiousness should be understood to show their useful functionality. Since there is presently limited fiscal information on the long-term use of BNCs for remediation of wastewater, financial assessments in this regard would aid in giving more understanding on the practicability and durability of these sorbents for contaminated water. Conclusively, it is suggested and recommended that more studies on BNC sorbents that would exhibit more excellent applicability, isolation, and efficiency as well as fast analysis for the trace determination, sorption, and elimination of inorganic and toxic substances in water samples should be the direction for future prospective for the treatment and remediation of contaminated water vis-à-vis water purification technology.

\section{Abbreviations}

BP: Biopolymer

CNT: Carbon nanotube

CS: Chitosan

FL: Freundlich

HM: Heavy metal

HMI: Heavy metal ion

KNT: Kinetic

LNR: Langmuir

MB: Methyl blue

MCL: Maximum allowed level

NM: Nanomaterial

NC: Nanocomposite

NP: Nanoparticle

NT: Nanotube

PFO: Pseudo-first-order

PSO: Pseudo-second-order

IST: Isotherm

TMD: Thermodynamic.

\section{Conflicts of Interest}

The authors wish to state that they have no personal relations or competing for financial interests that could otherwise have seemed to influence the review work reported here. 


\section{Acknowledgments}

The authors appreciate their respective institutions and authors of publications used for this review study.

\section{References}

[1] P. Dhiman, T. Mehta, A. Kumar et al., " $\mathrm{Mg}_{0.5} \mathrm{Ni}_{\mathrm{x}} \mathrm{Zn}_{0.5-\mathrm{x}} \mathrm{Fe}_{2} \mathrm{O}_{4}$ spinel as a sustainable magnetic nano-photocatalyst with dopant driven band shifting and reduced recombination for visible and solar degradation of reactive blue-19," Advanced Powder Technology, vol. 31, no. 12, pp. 4585-4597, 2020.

[2] H. Beyene and T. Ambaye, "Application of sustainable nanocomposites for water purification process," in Sustainable Polymer Composites and Nanocomposites, pp. 387-412, Springer, Cham, 2019.

[3] D. Sudarni, U. Aigbe, K. Ukhurebor et al., "Malachite green removal by activated potassium hydroxide clove leaves agro-waste biosorbent: characterization, kinetics, isotherms and thermodynamics studies," Adsorption Science \& Technology, vol. 2021, article 1145312, 15 pages, 2021.

[4] S. Homaeigohar, "The nanosized dye adsorbents for water treatment," Nanomaterials, vol. 10, no. 2, p. 295, 2020.

[5] R. Sangeetha Piriya, R. Jayabalakrishnan, M. Maheswari, K. Boomiraj, and S. Oumabady, "Coconut shell derived $\mathrm{ZnCl} 2$ activated carbon for malachite green dye removal," Water Science and Technology, vol. 83, no. 5, pp. 11671182, 2021.

[6] J. Yang, B. Hou, J. Wang et al., "Nanomaterials for the removal of heavy metals from wastewater," Nanomaterials, vol. 9, no. 3, 2019.

[7] S. Lee, Y. Eom, J. Park, J. Lee, and S. Kim, "Micro-hydrogel particles consisting of hyperbranched polyamidoamine for the removal of heavy metal ions from water," Scientific Reports, vol. 7, no. 1, pp. 1-9, 2017.

[8] P. Dhiman, G. Rana, A. Kumar et al., "Nanostructured magnetic inverse spinel Ni-Zn ferrite as environmental friendly visible light driven photo-degradation of levofloxacin," Chemical Engineering Research and Design, vol. 175, pp. 85-101, 2021.

[9] K. Ukhurebor, H. Athar, C. Adetunji, U. Aigbe, R. Onyancha, and O. Abifarin, "Environmental implications of petroleum spillages in the Niger Delta region of Nigeria: a review," Journal of Environmental Management, vol. 293, no. 112872, 2021.

[10] M. A. Gabris, B. Hadi Jume, I. Sadegh Amiri, R. Khanam, H. Rashidi Nodeh, and S. Shahabuddin, "Magnetic graphene oxide nanocomposite functionalized with glucamine for the trace extraction of arsenic (III) from aqueous media," International Journal of Environmental Science and Technology, vol. 18, no. 5, pp. 1109-1118, 2021.

[11] M. Barakat, "New trends in removing heavy metals from industrial wastewater," Arabian Journal of Chemistry, vol. 4, no. 4, pp. 361-377, 2011.

[12] I. Ali, C. Peng, T. Ye, and I. Naz, "Sorption of cationic malachite green dye on phytogenic magnetic nanoparticles functionalized by 3-marcaptopropanic acid," RSC Advances, vol. 8, no. 16, pp. 8878-8897, 2018.

[13] E. Femila, R. Srimathi, and C. Deivasigamani, "Removal of malachite green using silver nanoparticles via adsorption and catalytic degradation," International Journal of Pharmacy and Pharmaceutical Sciences, vol. 6, pp. 579-583, 2014.
[14] U. Aigbe and O. Osibote, "Carbon derived nanomaterials for the sorption of heavy metals from aqueous solution: a review," Environmental Nanotechnology, Monitoring \& Management, vol. 16, p. 100578, 2021.

[15] G. Sharma, A. Kumar, S. Sharma et al., " $\mathrm{Fe}_{3} \mathrm{O}_{4} / \mathrm{ZnO} / \mathrm{Si}_{3} \mathrm{~N}_{4}$ nanocomposite based photocatalyst for the degradation of dyes from aqueous solution," Materials Letters, vol. 278, no. 128359,2020 .

[16] P. Srivatsav, B. Bhargav, V. Shanmugasundaram, J. Arun, K. Gopinath, and A. Bhatnagar, "Biochar as an eco-friendly and economical adsorbent for the removal of colorants (dyes) from aqueous environment: a review," Water, vol. 12, no. 12, 2020.

[17] H. Anwer, A. Mahmood, J. Lee, K. Kim, J. Park, and A. Yip, "Photocatalysts for degradation of dyes in industrial effluents: opportunities and challenges," Nano Research, vol. 12, no. 5, pp. 955-972, 2019.

[18] B. Lellis, C. Fávaro-Polonio, J. Pamphile, and J. Polonio, "Effects of textile dyes on health and the environment and bioremediation potential of living organisms," Biotechnology Research and Innovation, vol. 3, no. 2, pp. 275-290, 2019.

[19] O. Agboola, O. Fayomi, A. Ayodeji et al., "A Review on Polymer Nanocomposites and Their Effective Applications in Membranes and Adsorbents for Water Treatment and Gas Separation," Membranes, vol. 11, no. 2, p. 139, 2021.

[20] O. Bello, I. Bello, and K. Adegoke, "Adsorption of dyes using different types of sand: a review," South African Journal of Chemistry, vol. 66, pp. 117-129, 2013.

[21] S. Aqdam, D. Otzen, and D. Morshedi, "Adsorption of azo dyes by a novel bio-nanocomposite based on whey protein nanofibrils and nano-clay: equilibrium isotherm and kinetic modeling," Journal of Colloid and Interface Science, vol. 602, pp. 490-503, 2021.

[22] O. Makarchuk, T. Dontsova, and I. Astrelin, "Magnetic nanocomposites as efficient sorption materials for removing dyes from aqueous solutions," Nanoscale Research Letters, vol. 11, no. 1, pp. 161-167, 2016.

[23] U. O. Aigbe, M. K. Khenfouch, W. H. Ho, A. Maity, V. J. Vallabhapurapu, and N. M. Hemmaragala, "Congo red dye removal under the influence of rotating magnetic field by polypyrrole magnetic nanocomposite," Desalination and Water Treatment, vol. 131, pp. 328-342, 2018.

[24] O. Ama, A. Wilson, and S. Ray, "Photoelectrochemical degradation of methylene blue dye under visible light irradiation using EG/Ag- $\mathrm{ZrO}_{2}$ nanocomposite electrodes," International Journal of Electrochemical Science, vol. 1, pp. 9982-10001, 2019.

[25] U. Aigbe, R. Das, W. Ho, V. Srinivasu, and A. Maity, "A novel method for removal of $\mathrm{Cr}(\mathrm{VI})$ using polypyrrole magnetic nanocomposite in the presence of unsteady magnetic fields," Separation and Purification Technology, vol. 194, pp. 377387, 2018.

[26] U. Aigbe and O. Osibote, "A review of hexavalent chromium removal from aqueous solutions by sorption technique using nanomaterials," Journal of Environmental Chemical Engineering, vol. 8, no. 6, article 104503, 2020.

[27] N. Mohanan, Z. Montazer, P. Sharma, and D. Levin, "Microbial and enzymatic degradation of synthetic plastics," Frontiers in Microbiology, vol. 11, 2020.

[28] U. Aigbe, R. Onyancha, K. Ukhurebor, and K. Obodo, "Removal of fluoride ions using a polypyrrole magnetic 
nanocomposite influenced by a rotating magnetic field," RSC Advances, vol. 10, no. 1, pp. 595-609, 2020.

[29] R. B. Onyancha, U. O. Aigbe, K. E. Ukhurebor, and P. W. Muchiri, "Facile synthesis and applications of carbon nanotubes in heavy-metal remediation and biomedical fields: a comprehensive review," Journal of Molecular Structure, vol. 1238, article 130462, 2021.

[30] K. Ukhurebor, U. Aigbe, R. Onyancha et al., "Effect of hexavalent chromium on the environment and removal techniques: a review," Journal of Environmental Management, vol. 280, article 111809, 2021.

[31] U. Aigbe, K. Ukhurebor, R. Onyancha, O. Osibote, H. Darmokoesoemo, and H. Kusuma, "Fly ash-based adsorbent for adsorption of heavy metals and dyes from aqueous solution: a review," Journal of Materials Research and Technology, vol. 14, pp. 2751-2774, 2021.

[32] T. Sethy and P. Sahoo, "Highly toxic Cr (VI) adsorption by (chitosan-g-PMMA)/silica bionanocomposite prepared via emulsifier-free emulsion polymerisation," International Journal of Biological Macromolecules, vol. 122, pp. 1184-1190, 2019.

[33] J. Oboh, J. Okafor, A. Kovo, and A. Abdulrahman, "Investigation of eco-friendly cellulosic nanoparticles potential as reinforcement agent in the production of natural rubber composites," Nigerian Journal of Technology, vol. 36, no. 4, pp. 1078-1087, 2017.

[34] T. Motaung and L. Linganiso, "Critical review on agrowaste cellulose applications for biopolymers," International Journal of Plastics Technology, vol. 22, no. 2, pp. 185-216, 2018.

[35] M. Bhattacharya, "Polymer nanocomposites-a comparison between carbon nanotubes, graphene, and clay as nanofillers," Materials, vol. 9, no. 4, p. 262, 2016.

[36] R. Zafar, K. Zia, S. Tabasum, F. Jabeen, A. Noreen, and M. Zuber, "Polysaccharide based bionanocomposites, properties and applications: a review," International Journal of Biological Macromolecules, vol. 92, pp. 1012-1024, 2016.

[37] R. Saini, A. Bajpai, and E. Jain, "Fundamentals of bionanocomposites," in Biodegradable and Biocompatible Polymer Composites: Processing, Properties and Applications, pp. 351-377, Woodhead Publishing, Oxford, UK, 2018.

[38] S. Sarkar, N. Ponce, A. Banerjee, R. Bandopadhyay, S. Rajendran, and E. Lichtfouse, "Green polymeric nanomaterials for the photocatalytic degradation of dyes: a review," Environmental Chemistry Letters, vol. 18, no. 5, pp. 15691580, 2020.

[39] J. W. Rhim, H. M. Park, and C. S. Ha, "Bio-nanocomposites for food packaging applications," Progress in Polymer Science, vol. 38, no. 10-11, pp. 1629-1652, 2013.

[40] M. del Mar Orta, J. Martín, J. Santos, I. Aparicio, S. MedinaCarrasco, and E. Alonso, "Biopolymer-clay nanocomposites as novel and ecofriendly adsorbents for environmental remediation," Applied Clay Science, vol. 198, article 105838, 2020.

[41] V. Pande and V. Sanklecha, "Bionanocomposite: a review," Austin Journal of Nanomedicine \& Nanotechnology, vol. 5, no. 1, p. 104, 2017.

[42] O. Oyewo, E. Elemike, D. Onwudiwe, and M. Onyango, "Metal oxide-cellulose nanocomposites for the removal of toxic metals and dyes from wastewater," International Journal of Biological Macromolecules, vol. 164, pp. 2477-2496, 2020.

[43] C. Song, S. Wu, M. Cheng, P. Tao, M. Shao, and G. Gao, "Adsorption studies of coconut shell carbons prepared by
$\mathrm{KOH}$ activation for removal of lead (II) from aqueous solutions," Sustainability, vol. 6, no. 1, pp. 86-98, 2014.

[44] T. R. Sethy, A. K. Pradhan, and P. K. Sahoo, "Simultaneous studies on kinetics, bio-adsorption behaviour of chitosan grafted thin film nanohydrogel for removal of hazardous metal ion from water," Environmental Nanotechnology, Monitoring \& Management, vol. 12, article 100262, 2019.

[45] R. Ahmad and A. Mirza, "Synthesis of guar gum/bentonite a novel bionanocomposite: isotherms, kinetics and thermodynamic studies for the removal of $\mathrm{Pb}$ (II) and crystal violet dye," Journal of Molecular Liquids, vol. 249, pp. 805-814, 2018.

[46] S. Anush and B. Vishalakshi, "Modified chitosan gel incorporated with magnetic nanoparticle for removal of $\mathrm{Cu}(\mathrm{II})$ and $\mathrm{Cr}(\mathrm{VI})$ from aqueous solution," International Journal of Biological Macromolecules, vol. 133, pp. 1051-1062, 2019.

[47] K. Seema, B. Mamba, J. Njuguna, R. Bakhtizin, and A. Mishra, "Removal of lead (II) from aqeouos waste using (CD-PCL- $\mathrm{TiO}_{2}$ ) bio-nanocomposites," International Journal of Biological Macromolecules, vol. 109, pp. 136-142, 2018.

[48] N. Kumar, H. Mittal, S. M. Alhassan, and S. S. Ray, "Bionanocomposite hydrogel for the adsorption of dye and reusability of generated waste for the photodegradation of ciprofloxacin: a demonstration of the circularity concept for water purification," ACS Sustainable Chemistry \& Engineering, vol. 6, no. 12, pp. 17011-17025, 2018.

[49] N. Subedi, A. Lähde, E. Abu-Danso, J. Iqbal, and A. Bhatnagar, "A comparative study of magnetic chitosan (Chi@ Fe3O4) and graphene oxide modified magnetic chitosan (Chi@ Fe3O4GO) nanocomposites for efficient removal of $\mathrm{Cr}(\mathrm{VI})$ from water," International Journal of Biological Macromolecules, vol. 137, pp. 948-959, 2019.

[50] A. Mirza and R. Ahmad, "Novel recyclable (xanthan gum/ montmorillonite) bionanocomposite for the removal of $\mathrm{Pb}$ (II) from synthetic and industrial wastewater," Environmental Technology \& Innovation, vol. 11, pp. 241-252, 2018.

[51] G. Mahdavinia and A. Mosallanezhad, "Facile and green rout to prepare magnetic and chitosan-crosslinked $\kappa$-carrageenan bionanocomposites for removal of methylene blue," Journal of Water Process Engineering, vol. 10, pp. 143-155, 2016.

[52] R. Gomes, A. de Azevedo, A. Pereira, E. Muniz, A. Fajardo, and F. Rodrigues, "Fast dye removal from water by starchbased nanocomposites," Journal of Colloid and Interface Science, vol. 454, pp. 200-209, 2015.

[53] Á. García-Padilla, K. Moreno-Sader, Á. Realpe, M. AcevedoMorantes, and J. Soares, "Evaluation of adsorption capacities of nanocomposites prepared from bean starch and montmorillonite," Sustainable Chemistry and Pharmacy, vol. 17, p. 100292, 2020.

[54] E. S. Abdel-Halim, "Preparation of starch/poly(N,N-diethylaminoethyl methacrylate) hydrogel and its use in dye removal from aqueous solutions," Reactive and Functional Polymers, vol. 73, no. 11, pp. 1531-1536, 2013.

[55] L. Li, J. Iqbal, Y. Zhu et al., "Chitosan/Ag-hydroxyapatite nanocomposite beads as a potential adsorbent for the efficient removal of toxic aquatic pollutants," International Journal of Biological Macromolecules, vol. 120, no. Part B, pp. 17521759, 2018.

[56] R. Eivazzadeh-Keihan, F. Radinekiyan, S. Asgharnasl, A. Maleki, and H. Bahreinizad, "A natural and eco-friendly magnetic nanobiocomposite based on activated chitosan for heavy metals adsorption and the in-vitro hyperthermia of 
cancer therapy," Journal of Materials Research and Technology, vol. 9, no. 6, pp. 12244-12259, 2020.

[57] M. Peralta, R. Nisticò, F. Franzoso et al., "Highly efficient removal of heavy metals from waters by magnetic chitosanbased composite," Adsorption, vol. 25, no. 7, pp. 1337-1347, 2019.

[58] C. Duan, T. Ma, J. Wang, and Y. Zhou, "Removal of heavy metals from aqueous solution using carbon-based adsorbents: a review," Journal of Water Process Engineering, vol. 37, article 101339, 2020.

[59] R. Ahmad and A. Mirza, "Application of xanthan gum/nacetyl cysteine modified mica bionanocomposite as an adsorbent for the removal of toxic heavy metals," Groundwater for Sustainable Development, vol. 7, pp. 101-108, 2018.

[60] J. Kazemi and V. Javanbakht, "Alginate beads impregnated with magnetic Chitosan@ Zeolite nanocomposite for cationic methylene blue dye removal from aqueous solution," International Journal of Biological Macromolecules, vol. 154, pp. 1426-1437, 2020.

[61] Y. Wu, H. Pang, Y. Liu et al., "Environmental remediation of heavy metal ions by novel-nanomaterials: a review," Environmental Pollution, vol. 246, pp. 608-620, 2019.

[62] L. Pandey, "Surface engineering of nano-sorbents for the removal of heavy metals: interfacial aspects," Journal of Environmental Chemical Engineering, vol. 9, no. 1, article 104586, 2021.

[63] E. Igberase, P. Osifo, and A. Ofomaja, "The adsorption of Pb, $\mathrm{Zn}, \mathrm{Cu}, \mathrm{Ni}$, and $\mathrm{Cd}$ by modified ligand in a single component aqueous solution: equilibrium, kinetic, thermodynamic, and desorption studies," International Journal of Analytical Chemistry, vol. 2017, Article ID 6150209, 15 pages, 2017.

[64] H. Yan, H. Li, H. Yang, A. Li, and R. Cheng, "Removal of various cationic dyes from aqueous solutions using a kind of fully biodegradable magnetic composite microsphere," Chemical Engineering Journal, vol. 223, pp. 402-411, 2013.

[65] R. Ahmad and A. Mirza, "Adsorptive removal of heavy metals and anionic dye from aqueous solution using novel xanthan gum-glutathione/ zeolite bionanocomposite," Groundwater for Sustainable Development, vol. 7, pp. 305312, 2018.

[66] M. Salam, M. Makki, and M. Abdelaal, "Preparation and characterization of multi-walled carbon nanotubes/chitosan nanocomposite and its application for the removal of heavy metals from aqueous solution," Journal of Alloys and Compounds, vol. 509, no. 5, pp. 2582-2587, 2011.

[67] G. Yu, X. Wang, J. Liu et al., "Applications of nanomaterials for heavy metal removal from water and soil: a review," Sustainability, vol. 13, no. 2, 2021.

[68] N. Gupta, A. Kushwaha, and M. Chattopadhyaya, "Adsorptive removal of $\mathrm{Pb}^{2+}, \mathrm{Co}^{2+}$ and $\mathrm{Ni}^{2+}$ by hydroxyapatite/chitosan composite from aqueous solution," Journal of the Taiwan Institute of Chemical Engineers, vol. 43, no. 1, pp. 125-131, 2012.

[69] R. Ahmad and I. Hasan, "L-Methionine montmorillonite encapsulated guar gum-g-polyacrylonitrile copolymer hybrid nanocomposite for removal of heavy metals," Groundwater for Sustainable Development, vol. 5, pp. 75-84, 2017.

[70] D. Tong, C. Wu, M. Adebajo et al., "Adsorption of methylene blue from aqueous solution onto porous cellulose- derived carbon/montmorillonite nanocomposites," Applied Clay Science, vol. 161, pp. 256-264, 2018.
[71] E. Azzam, G. Eshaq, A. Rabie et al., "Preparation and characterization of chitosan-clay nanocomposites for the removal of $\mathrm{Cu}(\mathrm{II})$ from aqueous solution," International Journal of Biological Macromolecules, vol. 89, pp. 507-517, 2016.

[72] N. Gerard, R. S. Krishnan, S. K. Ponnusamy, H. Cabana, and V. K. Vaidyanathan, "Adsorptive potential of dispersible chitosan coated iron-oxide nanocomposites toward the elimination of arsenic from aqueous solution," Process Safety and Environmental Protection, vol. 104, pp. 185-195, 2016.

[73] A. Shahzad, W. Miran, K. Rasool et al., "Heavy metals removal by EDTA-functionalized chitosan graphene oxide nanocomposites," RSC Advances, vol. 7, no. 16, pp. 97649771, 2017.

[74] S. Ghorai, A. Sarkar, M. Raoufi, A. Panda, H. Schönherr, and S. Pal, "Enhanced removal of methylene blue and methyl violet dyes from aqueous solution using a nanocomposite of hydrolyzed polyacrylamide grafted xanthan gum and incorporated nanosilica," ACS Applied Materials \& Interfaces, vol. 6, no. 7, pp. 4766-4777, 2014.

[75] M. Tanzifi, M. T. Yaraki, M. Karami et al., "Modelling of dye adsorption from aqueous solution on polyaniline/carboxymethyl cellulose $/ \mathrm{TiO}_{2}$ nanocomposites," Journal of Colloid and Interface Science, vol. 519, pp. 154-173, 2018.

[76] N. Soliman and A. F. Moustafa, "Industrial solid waste for heavy metals adsorption features and challenges; a review," Journal of Materials Research and Technology, vol. 9, no. 5, pp. 10235-10253, 2020.

[77] T. Altun and H. Ecevit, "Cr(VI) removal using $\mathrm{Fe}_{2} \mathrm{O}_{3}$-chitosan-cherry kernel shell pyrolytic charcoal composite beads," Environmental Engineering Research, vol. 25, no. 3, pp. 426-438, 2020.

[78] S. Wang, C. Zhang, and Q. Chang, "Synthesis of magnetic crosslinked starch-graft-poly(acrylamide)-co-sodium xanthate and its application in removing heavy metal ions," Journal of Experimental Nanoscience, vol. 12, no. 1, pp. 270-284, 2017.

[79] M. Alam, M. Aslam, and S. Rais, "Adsorption of zinc (II) and nickel (II) from aqueous solution using Syzygium aromaticum (cloves): kinetic and isotherm studies," Rasayan Journal of Chemistry, vol. 4, no. 2, pp. 791-806, 2009.

[80] E. Jang, S. Pack, I. Kim, and S. Chung, "A systematic study of hexavalent chromium adsorption and removal from aqueous environments using chemically functionalized amorphous and mesoporous silica nanoparticles," Scientific Reports, vol. 10, no. 1, p. 5558, 2020.

[81] K. Abuthahir, C. Pragathiswaran, P. Govindhan, B. Abbubakkar, and V. Sridevi, "Adsorption of methylene blue dye using activated carbon from the natural plant stem," International Journal of Research in Pharmacy and Chemistry, vol. 7, no. 1, pp. 120-125, 2017.

[82] S. Rahpeima, V. Javanbakht, and J. Esmaili, "Synthesis and characterization of activated carbon/maghemite/starch magnetic bionanocomposite and its application for permanganate removal from aqueous solution," Journal of Inorganic and Organometallic Polymers and Materials, vol. 28, no. 1, pp. 195-211, 2018.

[83] F. Boudrahem, F. Aissani-Benissad, and A. Soualah, "Adsorption of lead(II) from aqueous solution by using leaves of date trees as an adsorbent," Journal of Chemical \& Engineering Data, vol. 56, no. 5, pp. 1804-1812, 2011.

[84] T. Masilompane, N. Chaukura, S. Mishra, and A. Mishra, "Chitosan-lignin-titania nanocomposites for the removal of 
brilliant black dye from aqueous solution," International Journal of Biological Macromolecules, vol. 120, no. Part B, pp. 1659-1666, 2018.

[85] M. Dinari and R. Tabatabaeian, "Ultra-fast and highly efficient removal of cadmium ions by magnetic layered double hydroxide/guargum bionanocomposites," Carbohydrate Polymers, vol. 192, pp. 317-326, 2018.

[86] R. Chen, Y. Zhang, L. Shen et al., "Lead(II) and methylene blue removal using a fully biodegradable hydrogel based on starch immobilized humic acid," Chemical Engineering Journal, vol. 268, pp. 348-355, 2015.

[87] N. Kumar, H. Mittal, V. Parashar, S. Ray, and J. Ngila, "Efficient removal of rhodamine $6 \mathrm{G}$ dye from aqueous solution using nickel sulphide incorporated polyacrylamide grafted gum karaya bionanocomposite hydrogel," RSC Advances, vol. 6, no. 26, pp. 21929-21939, 2016.

[88] I. Minisy, N. Salahuddin, and M. Ayad, "Adsorption of methylene blue onto chitosan-montmorillonite/polyaniline nanocomposite,” Applied Clay Science, vol. 203, p. 105993, 2021.

[89] F. Abreu, N. Silva, M. Sipauba et al., "Chitosan and gum arabic nanoparticles for heavy metal adsorption," Polímeros, vol. 28, no. 3, pp. 231-238, 2018.

[90] M. Gandhi, N. Viswanathan, and S. Meenakshi, "Preparation and application of alumina/chitosan biocomposite," International Journal of Biological Macromolecules, vol. 47, no. 2, pp. 146-154, 2010.

[91] H. Shi, W. Li, L. Zhong, and C. Xu, "Methylene blue adsorption from aqueous solution by magnetic cellulose/graphene oxide composite: equilibrium, kinetics, and thermodynamics," Industrial \& Engineering Chemistry Research, vol. 53, no. 3, pp. 1108-1118, 2014.

[92] A. Al-Sherbini, H. Ghannam, G. El-Ghanam, A. El-Ella, and A. Youssef, "Utilization of chitosan/Ag bionanocomposites as eco-friendly photocatalytic reactor for bactericidal effect and heavy metals removal," Heliyon, vol. 5, no. 6, 2019.

[93] M. Mahmoodi and V. Javanbakht, "Fabrication of Zn-based magnetic zeolitic imidazolate framework bionanocomposite using basil seed mucilage for removal of azo cationic and anionic dyes from aqueous solution," International Journal of Biological Macromolecules, vol. 167, pp. 1076-1090, 2021.

[94] C. Zhou, Q. Wu, T. Lei, and I. Negulescu, "Adsorption kinetic and equilibrium studies for methylene blue dye by partially hydrolyzed polyacrylamide/cellulose nanocrystal nanocomposite hydrogels," Chemical Engineering Journal, vol. 251, pp. 17-24, 2014.

[95] C. Li, H. Ma, S. Venkateswaran, and B. Hsiao, "Highly efficient and sustainable carboxylated cellulose filters for removal of cationic dyes/heavy metals ions," Chemical Engineering Journal, vol. 389, article 123458, 2020.

[96] V. Alamillo-López, V. Sánchez-Mendieta, O. Olea-Mejía, M. González-Pedroza, and R. Morales-Luckie, "Efficient removal of heavy metals from aqueous solutions using a bionanocomposite of eggshell/Ag-Fe," Catalysts, vol. 10, no. 7, 2020.

[97] Z. Chen, Z. Li, G. Chen, J. Zhu, Q. Liu, and T. Feng, "In situ formation of AgNPs on S. cerevisiae surface as bionanocomposites for bacteria killing and heavy metal removal," International journal of Environmental Science and Technology, vol. 14, no. 8, pp. 1635-1642, 2017.

[98] H. Kono, K. Ogasawara, R. Kusumoto, K. Oshima, H. Hashimoto, and Y. Shimizu, "Cationic cellulose hydrogels cross-linked by poly(ethylene glycol): preparation, molecular dynamics, and adsorption of anionic dyes," Carbohydrate Polymers, vol. 152, pp. 170-180, 2016.

[99] U. Malayoglu, "Removal of heavy metals by biopolymer (chitosan)/nanoclay composites," Separation Science and Technology, vol. 53, no. 17, pp. 2741-2749, 2018.

[100] N. Kochkina, O. Skobeleva, and Y. Khokhlova, "Investigation of cationic starch/Na-montmorillonite bionanocomposite adsorbent prepared by vibration milling for acid dye removal," Particulate Science and Technology, vol. 35, no. 3, pp. 259-264, 2017.

[101] E. Fosso-Kankeu, H. Mittal, S. Mishra, and A. Mishra, "Gum ghatti and acrylic acid based biodegradable hydrogels for the effective adsorption of cationic dyes," Journal of Industrial and Engineering Chemistry, vol. 22, pp. 171-178, 2015.

[102] W. Boulaiche, B. Hamdi, and M. Trari, "Removal of heavy metals by chitin: equilibrium, kinetic and thermodynamic studies," Applied Water Science, vol. 9, no. 2, pp. 1-10, 2019.

[103] M. Maghsoudi, M. Abbasian, and K. Farhadi, "Design and synthesis of novel chitosan-based nanocomposite containing mesoporous nanosilica MCM-41: effective absorbent for the elimination of $\mathrm{Pb}$ (II) from aqueous solution," Journal of Elastomers \& Plastics, vol. 53, no. 5, pp. 469-488, 2021.

[104] M. Dinari, M. Shirani, M. Maleki, and R. Tabatabaeian, "Green cross-linked bionanocomposite of magnetic layered double hydroxide/guar gum polymer as an efficient adsorbent of $\mathrm{Cr}(\mathrm{VI})$ from aqueous solution," Carbohydrate Polymers, vol. 236, article 116070, 2020.

[105] F. Lyu, H. Yu, T. Hou, L. Yan, X. Zhang, and B. Du, "Efficient and fast removal of $\mathrm{Pb}^{2+}$ and $\mathrm{Cd}^{2+}$ from an aqueous solution using a chitosan $/ \mathrm{Mg}$-Al-layered double hydroxide nanocomposite," Journal of Colloid and Interface Science, vol. 539, pp. 184-193, 2019.

[106] S. Razani and A. Tehrani, "Development of new organicinorganic, hybrid bionanocomposite from cellulose nanowhisker and Mg/Al-CO3-LDHfor enhanced dye removal," International Journal of Biological Macromolecules, vol. 133, pp. 892-901, 2019.

[107] A. Kausar, R. Shahzad, J. Iqbal, N. Muhammad, S. Ibrahim, and M. Iqbal, "Development of new organic-inorganic, hybrid bionanocomposite from cellulose and clay for enhanced removal of Drimarine yellow HF-3GL dye," International Journal of Biological Macromolecules, vol. 149, pp. 1059-1071, 2020.

[108] F. Zarei, A. Marjani, and R. Soltani, "Novel and green nanocomposite-based adsorbents from functionalised mesoporous KCC-1 and chitosan-oleic acid for adsorption of $\mathrm{Pb}(\mathrm{II})$," European Polymer Journal, vol. 119, pp. 400-409, 2019.

[109] J. Yee, C. Arida, C. Futalan, M. de Luna, and M. Wan, "Treatment of contaminated groundwater via arsenate removal using chitosan-coated bentonite," Molecules, vol. 24, no. 13, 2019.

[110] G. Güçlü, E. Al, S. Emik, T. İyim, S. Özgümüş, and M. Özyürek, "Removal of $\mathrm{Cu}^{2+}$ and $\mathrm{Pb}^{2+}$ ions from aqueous solutions by starch-graft-acrylic acid/montmorillonite superabsorbent nanocomposite hydrogels," Polymer Bulletin, vol. 65, no. 4, pp. 333-346, 2010.

[111] K. Kalantari and A. Afifi, "Novel chitosan/polyvinyl alcohol/ talc composite for adsorption of heavy metals and dyes from aqueous solution," Separation Science and Technology, vol. 53, no. 16, 2018. 
[112] M. Samuel, S. Shah, J. Bhattacharya, K. Subramaniam, and N. Singh, "Adsorption of $\mathrm{Pb}(\mathrm{II})$ from aqueous solution using a magnetic chitosan/graphene oxide composite and its toxicity studies," International Journal of Biological Macromolecules, vol. 115, pp. 1142-1150, 2018.

[113] H. Shan, S. Peng, C. Zhao, H. Zhan, and C. Zeng, "Highly efficient removal of As(III) from aqueous solutions using goethite/graphene oxide/chitosan nanocomposite," International Journal of Biological Macromolecules, vol. 164, pp. 13-26, 2020.

[114] A. Sherlala, A. Raman, M. Bello, and A. Buthiyappan, "Adsorption of arsenic using chitosan magnetic graphene oxide nanocomposite," Journal of Environmental Management, vol. 246, pp. 547-556, 2019.

[115] Q. Zhou, Z. Zheng, J. Xiao, and H. Fan, "Sensitive determination of As (III) and As (V) by magnetic solid phase extraction with Fe@polyethyleneimine in combination with hydride generation atomic fluorescence spectrometry," Talanta, vol. 156-157, pp. 196-203, 2016.

[116] L. Min, L. Yang, R. Wu, L. Zhong, Z. Yuan, and Y. Zheng, "Enhanced adsorption of arsenite from aqueous solution by an iron-doped electrospun chitosan nanofiber mat: preparation, characterization and performance," Journal of Colloid and Interface Science, vol. 535, pp. 255-264, 2019.

[117] G. Kyzas and K. Matis, "Nanoadsorbents for pollutants removal: a review," Journal of Molecular Liquids, vol. 203, pp. 159-168, 2015. 